الجمعية المصرية للقر اعة و المعرفة عضو الجمعية الدولية للمعرفة المية

\title{
تطوير إدارة الأزمات وصنع القرار بوزارة التعليم بالمملكة العربية السعودية في ضوء خبرات بعض الأر الدول
}

\author{
إعداد \\ دكتور/علي فهران محمد القحطاني
}




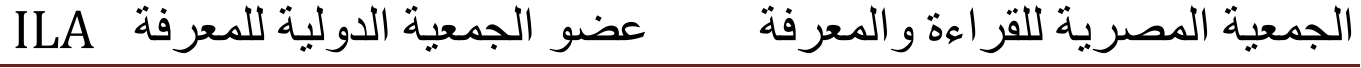


يشـهـه العصـر الحسالي العديد من التحديات والتغيرات السريعة ، كـان من أبرزهـا التحديات

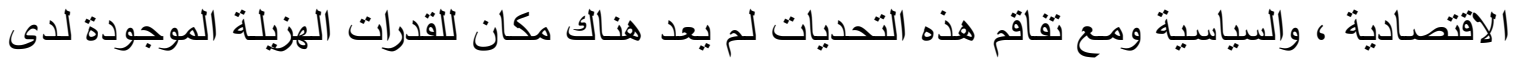

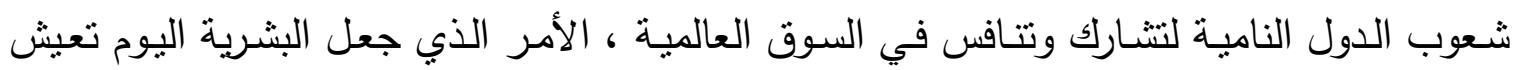

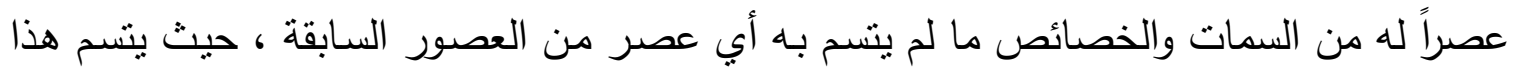
العصر بمتغيرات مذهلة ومتلاحقة في شتى المجالات المختلفة بصفة عامـة والمجالات التعليمية بصفة خاصة والتي فرضت العديد من التحديات والأزمات التعليمية .

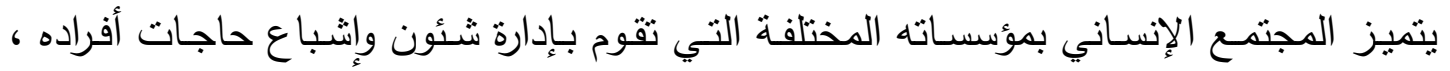

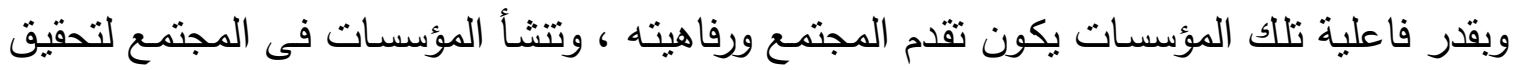
أهداف محددة ، ولذلك فهي تمارس مجموعة من الأنشطة التي ترتبط بهذه الأهداف ، وتستغل فى ولى

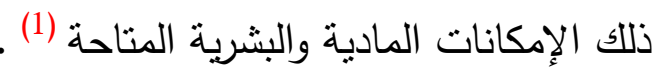
ويمثل النظام التعليمي في أي مجتمع أحد الأنظمة الاجتماعية الفرعية للنظام الاجتماعي العام ، كما انه يمكن القول إنه نظام تعليمي مفتوح تتحدد فلسفته انطلاقا من عقيدة المجتمع ، وثقافته من

خلال تراكم رصيد الخبرات تجمعت بمراحل التاريخ الاجتماعي (2). وفى هذا الصدد يتضح أن التعليم في الآونة الأخيرة يواجه مشكلات ومطالب متعددة في كثثر من

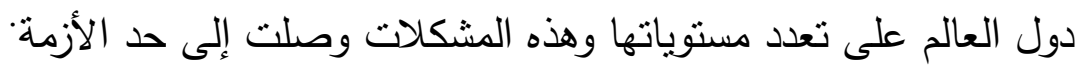

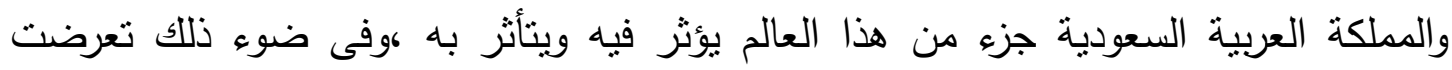

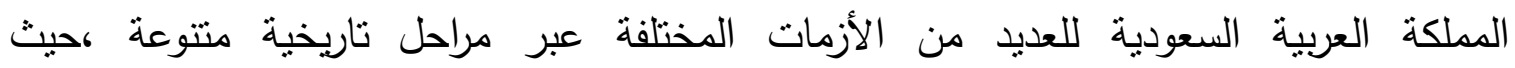
تعتبر المملكة العربية السعودية من الدول العربية المحورية التي تلعب دورا هاما في الإحداث والمنطقة فى ظل الأزمات المختلفة التى تعصف بالمنطقة فى شتى المجالات المختلفة بصفة عامة ، والمجالات التعليمية بصفة خاصة ، والتي تحتاج الى إلى حكمة فى صنع القرار لمعالجة العديد

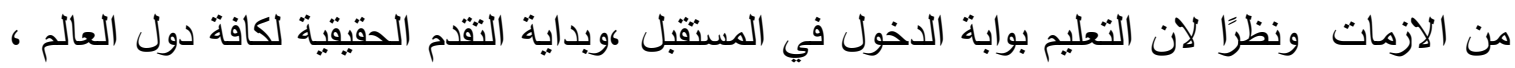

(1) عبد العزيز السنبل وآخرون : نظام التعليم فى الملكة العربية السعودية ، الرياض ، ط 6 ، دار الخريجى للطبع والتوزيع ،هـ1417، ص 11

(2) حمدان أحمد الغامدي : نزر الدين عبد الجواد تطور نظام التعليم بالمملكة العربية السعودية ، مكتبة الملك غهر

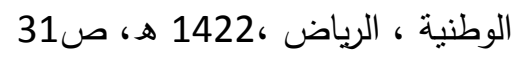


وفى هذا السباق تولي المملكة العربية السعودية اهتماماً كبيراً بالتعليم في خططها التتموية، وأن تخصص للتعليم نصيبا وافرا في ميزانياتها السنوية.

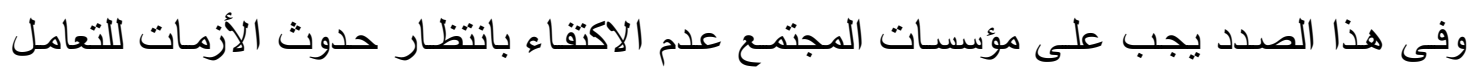

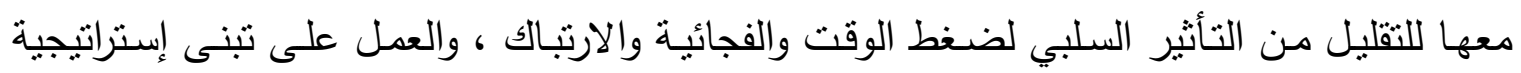
لإدارة الأزمات والسعي بتتبؤ الأزمات المحتملة ووضع الخطط ورسم السيناريوهات المستقبلية ورصد

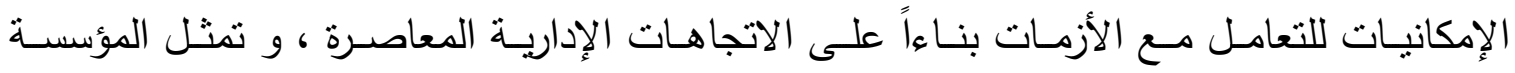

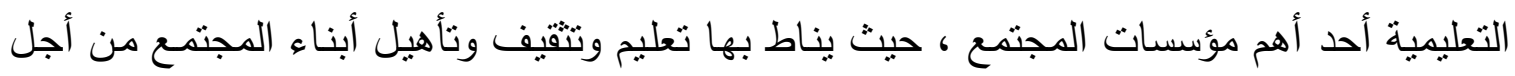

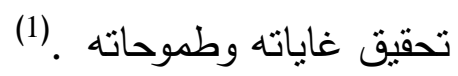

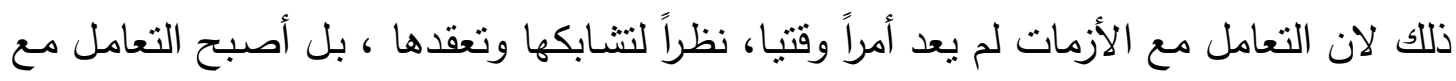

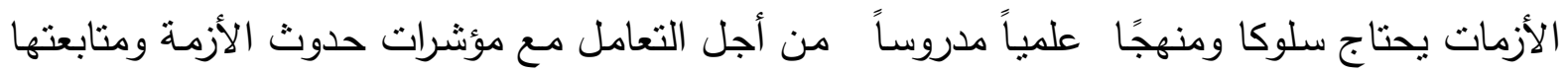

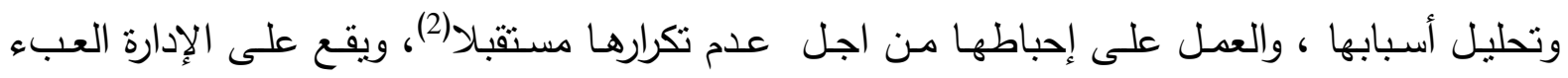

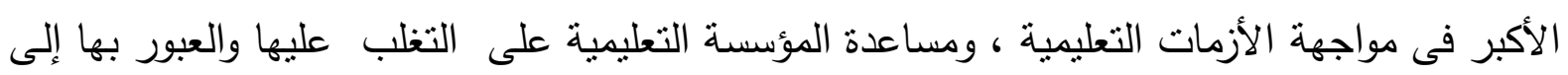

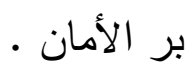

في ضـوء ذلك تمثل إدارة الأزمـة بصفة عامـة المفتاح الأساسي لضمان الأمسان في الممارسـات داخل غرف النظم التعليمية والصناعية ، من أجل تحقيق التعاون البناء بين جميع العاملين لتجاوز

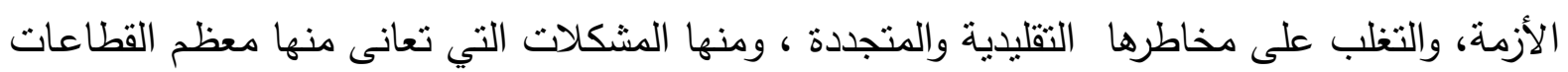

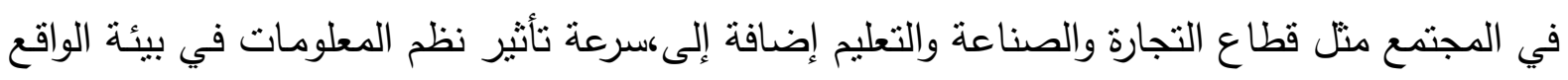
الافتراضي التي تؤدى إلى مشكلات جذرية وسرعة المعلومات تؤثر بشكل فعال في البنية التحتية والمادية للتعليم وحدوث بعض أزمات التعليم( ().

، (1010) حسن محد حسان ومحمد حسين العجمي: الإدارة التريوية ،الأردن: عمان، دار السسيرة للنشر والتوزيع ، ط 25 .35 2010، (2) رجب عبدا لحميد : إستراتيجية التعامل مع الأزمات والكوارث:دراسة نظرية تطبيقية،مصر :القاهرةدار أبو الدجد

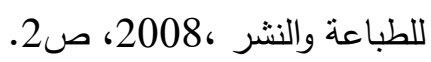
$\left(^{3}\right)$ Bharat Sharma, Sylvain Boet, Dylan Bould, and others : Kirkpatrick evaluation of interprofessional simulation-based education for preoperative crisis resource management, Journal of the American College of Surgeons, Vol. 213, Issue 3, Supplement, 2011, Page S129. 


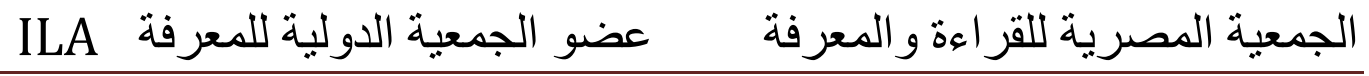

حيث أن إدارة الأزمات في مجال التعليم لا تقتصر على الإدارة فقط ، بل تلعب كل الأطراف في

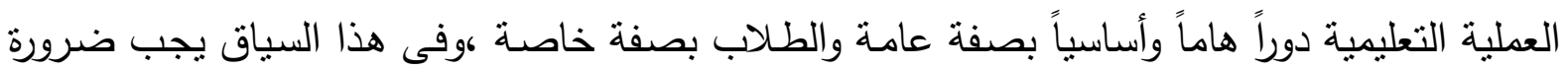

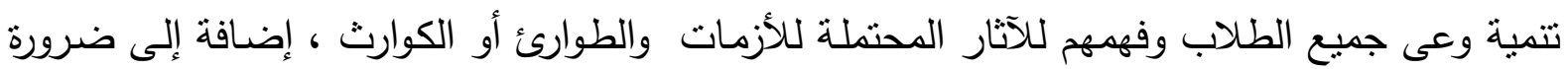
ومعرفة نداخلات الأزمات ، وإدارتها فضلاً عن طبيعة محتوى الإعداد والأنشطة المختلفة يعكس الأزمة الحقيقية التي تواجه إدارة الأزمة وخطورتها (1 ). وفى هذا السياق يمنل صنع القرارات أحد أهم أسباب النجاح في إدارة الأزمات إجادة واتخاذها في الوقت المناسب في أي جانب من جوانب الحياة المختلفة بصفة عامة والتعليمية بصفة خاصة، وكثثر الهير من الناس يعملون، ويجتهدون ثم في لحظة حاسمة من مراحل عملهم أو بحثهم يحتاجون لقرار صائب

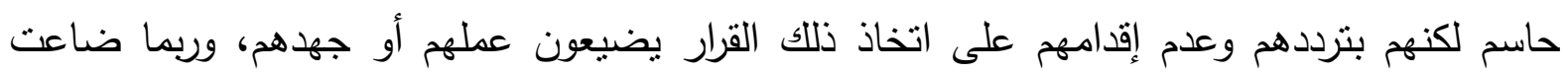
منهم فرص لن تتكرر لهم مرة أخرى. (2) وتجدر الإثـارة إلى أن وزارة التعليم في المملكة العربيـة السعودية، تجد مـن الدعم مـا بمكنها من مواكبة التقدم العلمي والتقني في مجال التعليم بصفة عامـة( قبل الجامعي والجامعي)، كما أن اهتمام

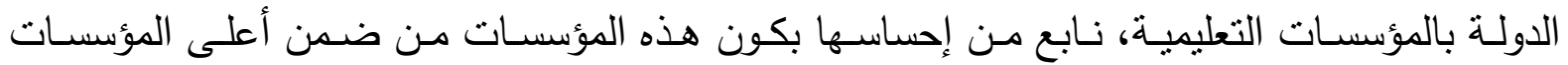
الأخرى الضاغطة في المجتمع السعودي، وبذللك فهي معرضة بدرجة كبيرة للازمات، والأحداث الطارئة

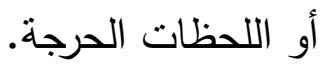
• خ الاراسات السابقة ذات الصلة بالبحث .

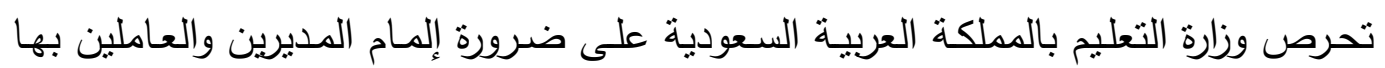
ببعض مهارات إدارة الأزمة من أساسيات وقواعد وأساليب للتعامل معها.

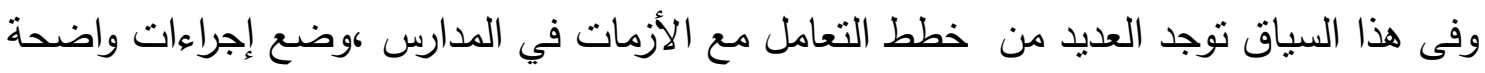

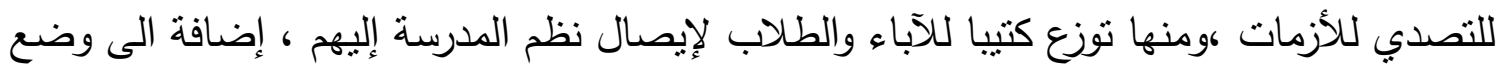

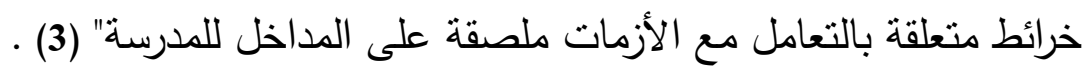

( $\left.{ }^{1}\right)$ Minton, C. : The Status of Crisis Preparation in Counselor Education: A National Study and Content Analysis. Journal Of Professional Counseling: Practice, Theory \& Research, 38(2), 2010,pp 5-17 .

$\left({ }^{2}\right)$ Schoemaker, A F.:The Relationship between Decision-Making Style and Negative Affect in College Students. Master of Science, Drexel University. 2010.p.26

$\left(^{3}\right)$ Coleman, M.: A Study of Crisis response plans in suburban secondary Schools in New Jersey " .PH.D. , university of widener, U.S A, 2002. 
وفى هذا الثأن أشثار اشرف عبده الألفي2003 (1) إلى أن العديد من أزمات التعليم التي واجهت

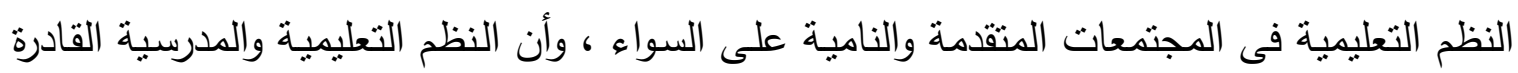
على وضع توقعات للأزمات والإعداد لمواجهتها تكون أكثر قدرة من غيرها على تجاوزها بسرعة .

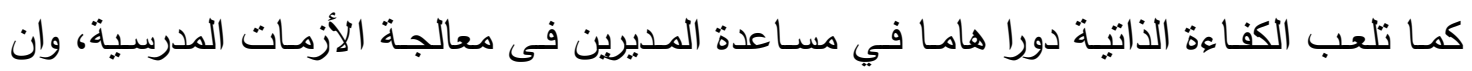
التصرف الفعال يعتمد ليس فقط على مهارات المدرسين ومعرفتهم ولكن على درجة كفاءتهم في استخدام المهارات في ظروف الأزمات وهذا ما أكدته دراسة( جارفيلين

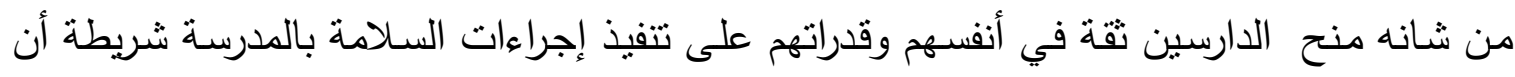
يكون لديهم إثارات وتدريب مسبق تعرفهم بمسؤولياتهم تجاه كل موقف حرج حيث أنهم لم يتلقوا أي تدريب في إدارة الأزمات. إلا أن هناك من يرى ضرورة العمل إنشاء مدارس جاهزة لمواجهة الأزمات"مثل (باربارا جانى 2004: Gainey, Barbara

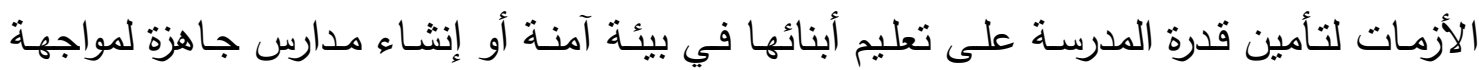

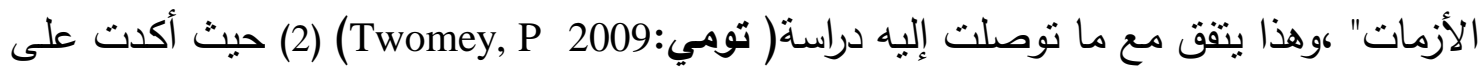

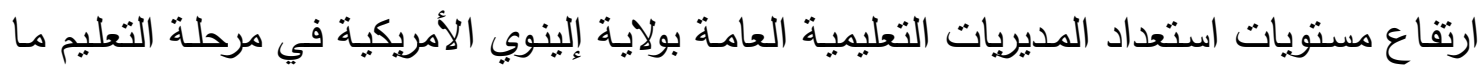

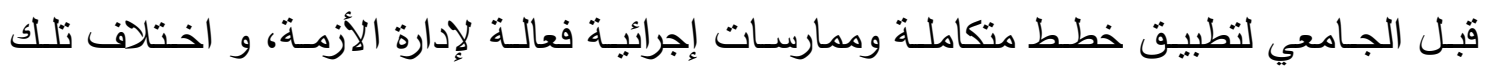
المستويات في ضوء تباين حجم تلك المديريات التعليمية بحيث تتزايد مستويات استعدادها لإدارة الأزمة (فيما يتعلق بالتخفيف من حدة/منع، والاستعداد، والاستجابة للأزمات ومواجتهاتها) كلما زاد

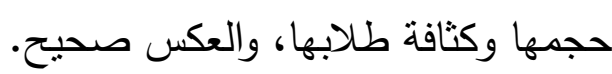
وقد اكدت ناهد الموسى:2006 أن مديرو ومديرات التعليم العام يهتمون بإدارة الأزمات المدرسية وهات من حيث وجود طفايات حريق في أماكن مناسبة بالمدرسة وسهولة الاتصال بالجهات الأمنية في

1) اشرف عبده الألفي : "إدارة أزمات التعليم فى مصر دراسة تحليلية دستقلية" ، رسالة دكتوراه غبر منشورة ، كلية

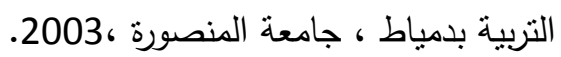

$\left.{ }^{1}\right)$ Graveline, M: "Teacher self - efficacy a managing of a school crisis ". Ph.D. dissertation, university Harford, London. 2003.

$\left({ }^{2}\right)$ Gainey, Barbara:Creating Crisis-ready school districts. P.H.D

Undistributed,University of South Carolina, U S.A,2004.

(2) Twomey, P.: Analysis of crisis management planning in Illinois public schools. Ed.D. dissertation, Western Illinois University, United States, Illinois. Retrieved December 7, 2009. 
حالة وجود أزمات بالمدرسة مع الاحتفاظ بالبيانات الخاصة بالمدرسة في مكان آمن.، أضافة الى وجود خطة إخلاء واضحة لدى جميع منسوبات المدرسة للإخلاء الفوري(2).

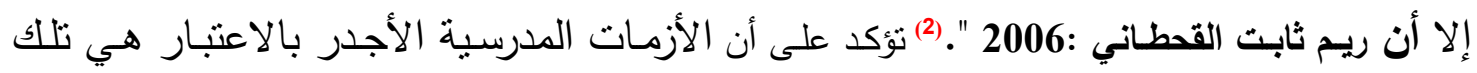

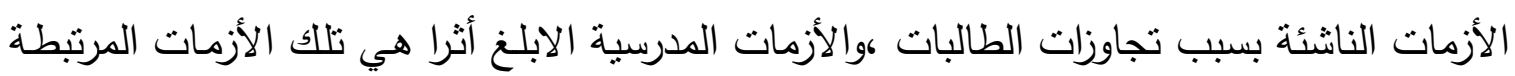

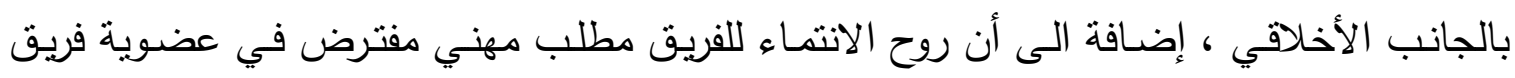

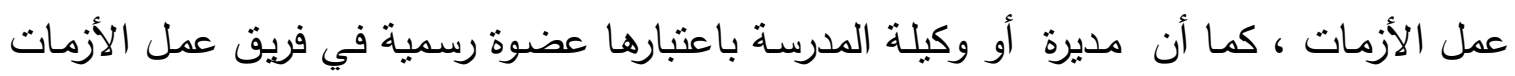

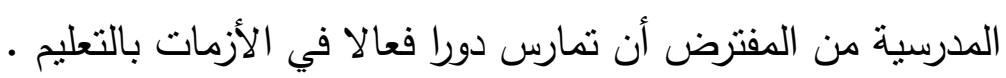

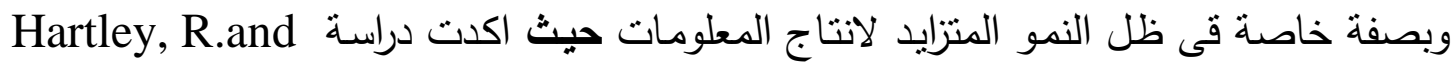
2007. : Almuhaidib S.M.Y

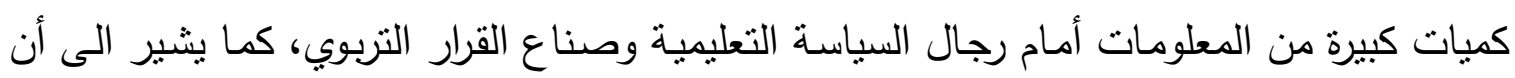

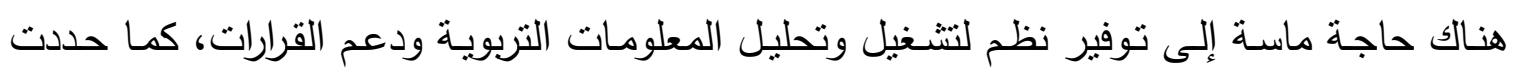
الدراسة أهم العوامل الأساسية والمتغيرات الثرطية التي يجب أن تؤخذ في الاعتبار عند نطوير نظم

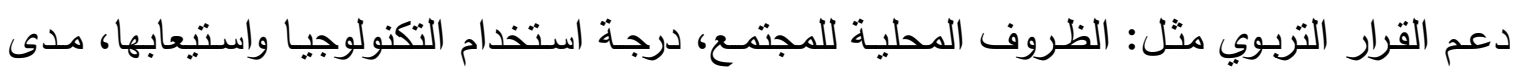

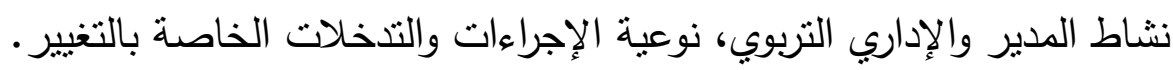
وهذا ينطلب الاستفادة من بعض الخبرات فى صنع القرار والازمات وفى هذا الثأن أثنارت هبه محمد عبد المحسن: 2009 (2). الى ضرورة إتاحة الفرص الكافية للقائمين على العملية التعليمية بإبداء آرائهم ومشاركة خبرائهم مع صانعي القرار التعليمي، وكذلك المتأثرون بالقرارات مثل أولياء

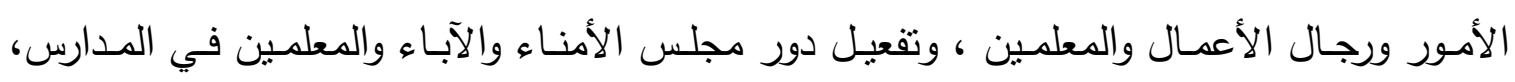

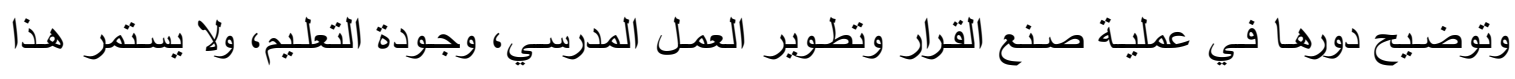

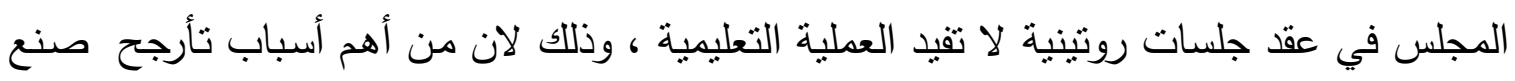

(2) ناهد الموسى : إدارة الأزمات في مدارس التعليم العام بمدينة الرياض "تموذج مقترح"، رسالة دكتوراه غير

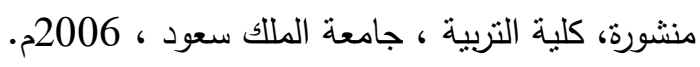

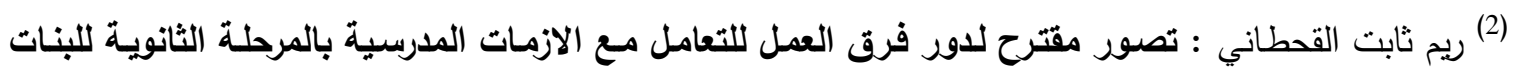

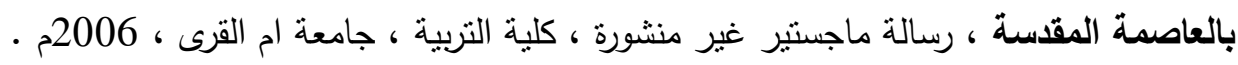

( $\left.{ }^{1}\right)$ Hartley, R.and Almuhaidib S.M.Y.,"User Oriented Techniques to Support Interaction and Decision Making with Large Educational Databases", Computers and Education, V.48, N.2, feb2007, PP:268-284.

(2) هبه محمد عبد المحسن: صنع القرار التعليمي في جمهورية مصر العربية وكندا واستراليا " دراسة مقارنة"، رسالة ماجستير ، كلية التزبية، جامعة سوهاج، 2009. 
القرار التعليمي بالمملكة قى المعوقات التنظيمية حيث تعتبر أبرز معوقات صنع القرار الإداري

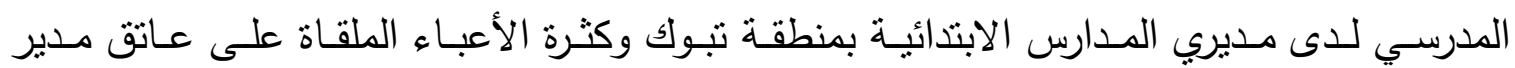

المدرسة، ونقص خبرة المشاركين في صنع القرار (1)

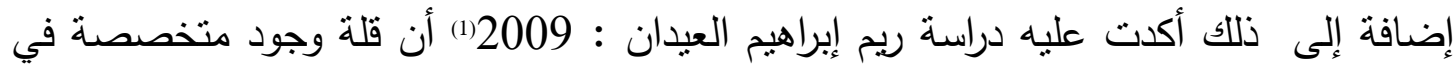

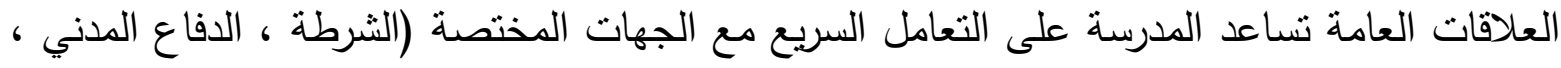
الإسعاف ، الإدارة) عند وقوع الأزمات ، إضافة قلة توافر البيانات الفورية والتى تشمل معلومات وبيانات الثهات كافية عن الطالبات وهيئة العاملين يمكن استخدامها في حالة حدوث أزمة داخدة داخل المدرسة .

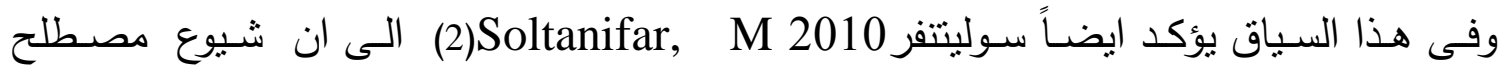

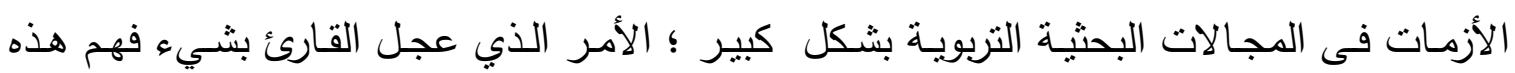
المصطلحات إضـافة إلى وجود بعض المفاهيم الخاطئة عن العلاقة بين النظم التربويـة والأزمات

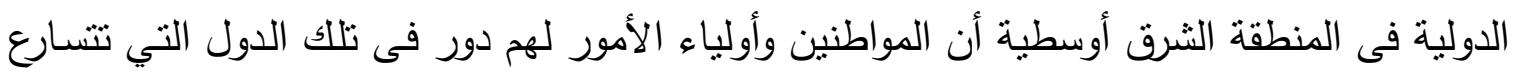

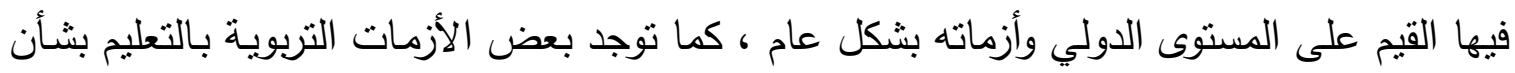

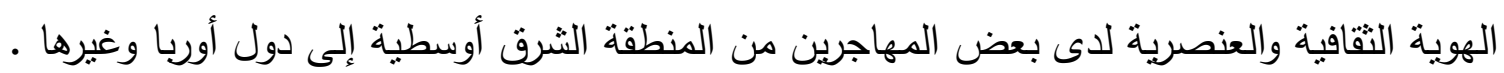
كمـا اكد زيد الدلمانى: 2010(3) ـ على انه تواجه العاملين بالمدارس معوقات كثيرة فى تقديم

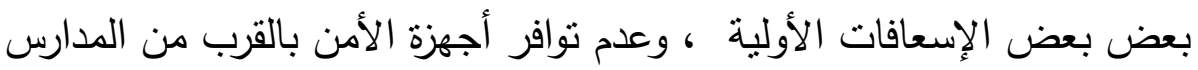

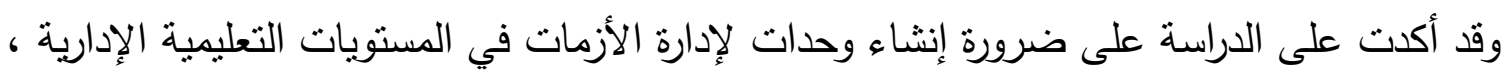
ويتفق معه فى هذا الثأن داليا ابو بكر أحمد عبده :2011 (1) جيث أكلت على وجود العديد من الأزمات المختلفة التي تواجهه التعليم الثانوي، إضافة إلى وجود العديد من جوانب القصور في إدارتها.

(1) نايف نفاع نويفع الحربي: أبرز معوقات صنع القرار الإداري المدرسي لدى مديري المدارس الابتدائية بمنطقة

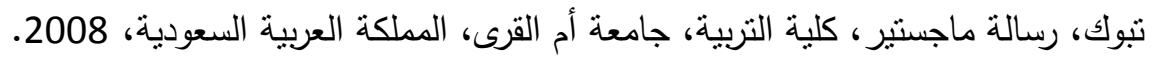

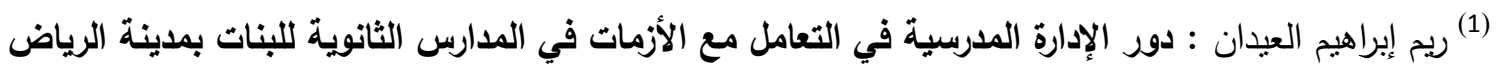

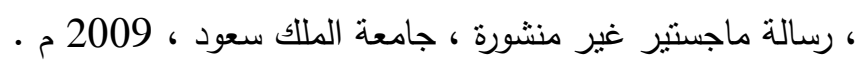

${ }^{(2)}$ Soltanifar, M. : The Role of Educational Systems in International Crises: A Reappraisal of Middle East Countries. European Journal Of Social Science, 13(2), 2010,pp 201-210 .

3) زيد عصويد الدلمانى: "إدارة الأزمات المدرسية فى مدارس التعليم العام بدولة وزارة التعليم بالمملكة العربية

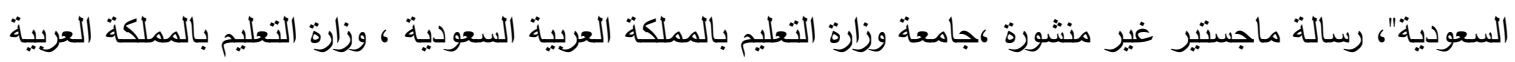

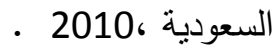


وفى ضوء العرض السابق يتضح ان هذا البحث يختلف عن الأبحاث والدراسات السابقة فى تتاوله

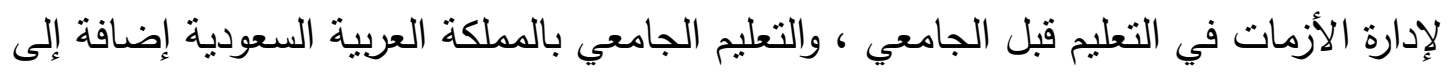

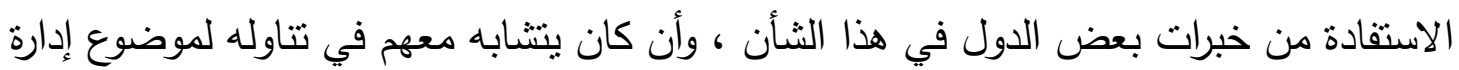

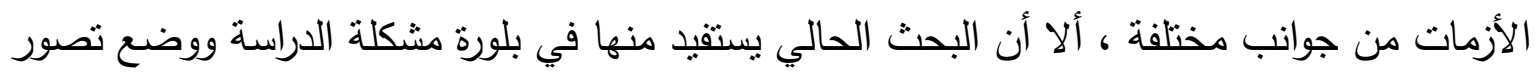

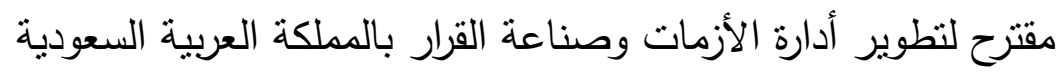

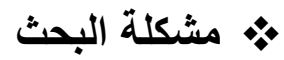

فى ضوء ما توصلت إليه نتائج الدراسات السابقة ذات الصلة بالبحث والتي أوصت نتائج بعضها ؛ بأنه نظراً للتغيرات السريعة والمتلاحقة على الساحة التعليمية ، والتي أدت بدورها إلى ظهور أسباب مختلفة للازمات تختلف باختلاف مستوياتها وشدة تأثيرها ، إضافة إلى ضعف في في نواحي التئي التظيم والتخطيط لجوانب إدارة الأزمات، ووجود العديد من جوانب القصور والضعف في الجوانب الإدارية لإدارة الأزمات

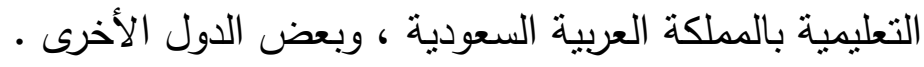
وفى ضوء ذللك تبلور مشكلة البحث الحالي في التساؤل الرئيسي التالي :

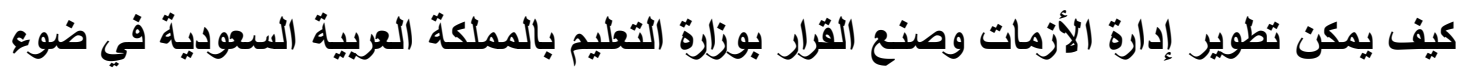

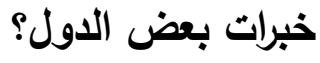

والإجابة على هذا التساؤل الرئيسي تتطلب على التساؤلات الفرعية التالية :

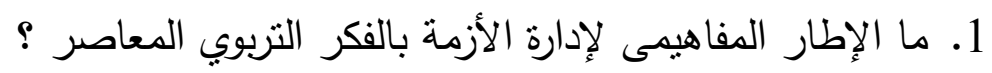

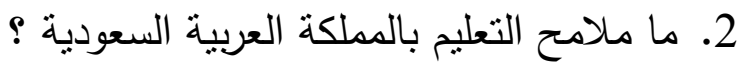
3. ما الإطار المفاهيمى لصنع القرار وملاهحه بوزارة التعليم بالمملكة العربية السعودية؟

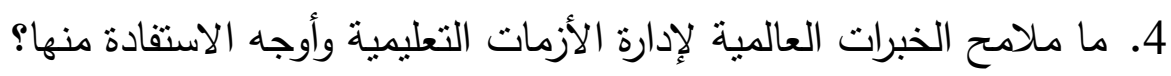

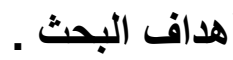

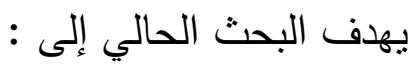
1. تعرف طبيعة إدارة الأزمات التعليمية في الفكر الإداري المعاصر. 2. دراسة وتحليل بعض ملامح التعليم بالمملكة العربية السعودية. 3. تعرف ماهية وأنواع وطرق صنع القرار بوزارة التعليم بالمملكة العربية السعودية. 4. تعرف سلطات صنع القرار بوزارة التعليم بالمملكة العربية السعودية.

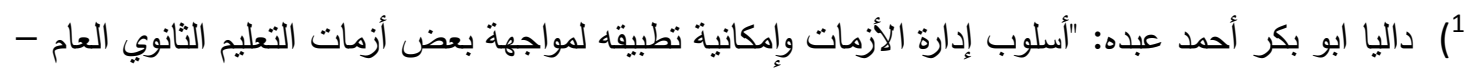
دراسة ميدانية "، ماجستير غير منشوره ، كلية التربية ، جامعة المنصورة، 2011 . 
5. دراسة وتحليل بعض الخبرات العالمية فى إدارة الأزمات التعليمية .

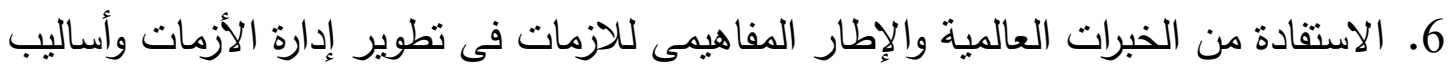
صنع القرار بوزارة التعليم فى ضوء هذه الخبرات .

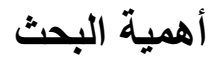
تنتلور أهمية البحث الحالي فى :

1. دراسة بعض الخبرات العالمية لبعض الدول فى إدارة الأزمات التعليمية.

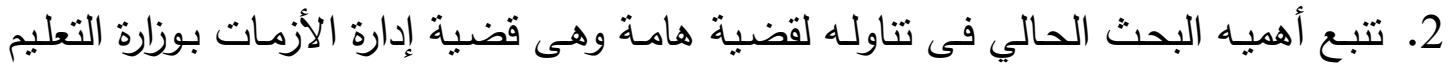

$$
\text { بالمملكة العربية السعودية }
$$

3. تبصير السـادة المسئولين عن التعليم بالمملكة العربية السعودية، ومن بعده السلطة اتخاذ

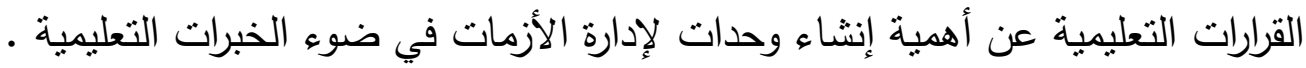

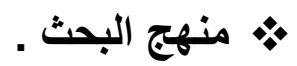

نظرًا لأن طبيعة الدراسات الإنسانية يتحدد من خلالها نمط المنهج الذي تستخدمه الدراسة

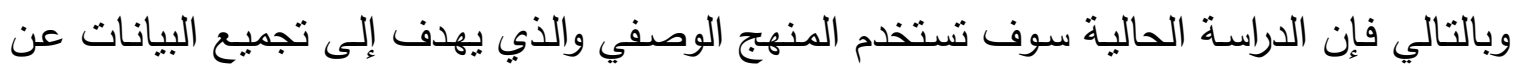
الظاهرة موضع الدراسة وتوصيفها وتحليلها ودراسة ما بينها من علاقات (1)، أضافة الى الدنهج الدقارن. حيث يتم دراسـة وتحليل العديد من المفاهيم، والأبعاد المختلفة المرتبطة بإدارة الأزمـة بوزارة التربيـة بدولـة وزارة التعليم بالمملكـة العربيـة السعودية، إضـافة إلى تجميع العديد من البيانات عن

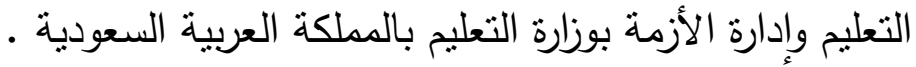

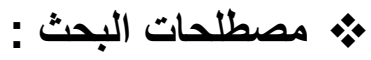
يتبني البحث المصطلحات التالية . الأزمـة :- (الأزمة : السنة المجدبة ، وأزم عليهم العام والدهر : اشتـ قحطه وقيل اشتـ وقل

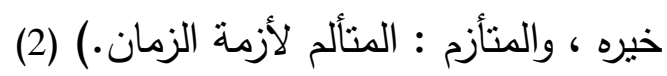

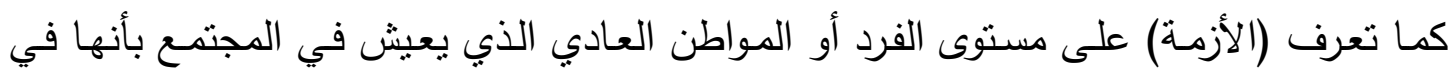

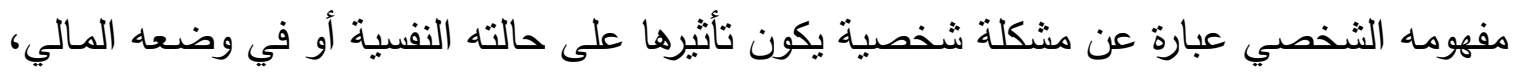
أو حالته الصحية أو مشاكل تحدث في حياته الزوجية أو صعوبات في بيئة العمل الوظيفي (1).

(1) فؤاد أبو حطب وآمال صادق، مناهج البحث وطرق التحليل الإحصائي في العلوم النفسية والتربوية والاجتماعية،

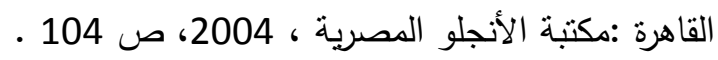

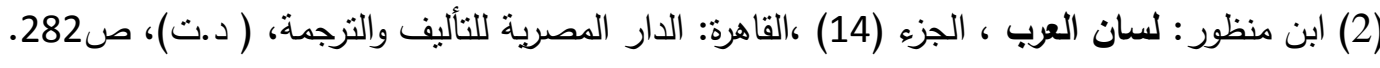


هو اتجاه سائد فى مجال السياسة والاقتصاد ، يقصد به تدريب العاملين على كيفية مواجهة الأزمات والمشكلات وحلها عن طريق الأسلوب العلمى ، والتوصل إلى حلول وبدائل لكل مشكلة أو أزمـة ،

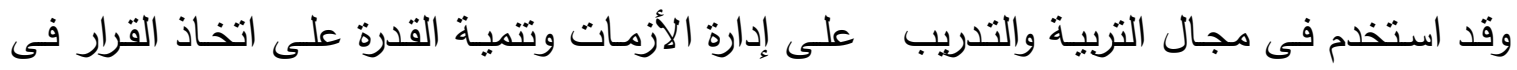

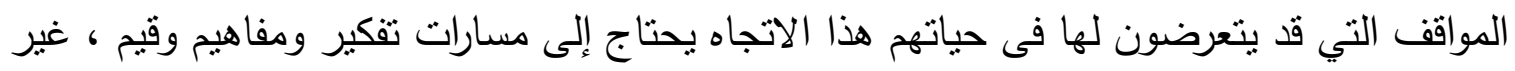

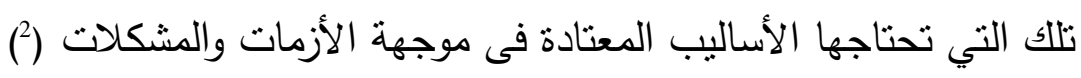
• • الإطار المفاهيمي لإدارة الأزمات

يشار إلى الأزمة على انها حالة مرضية ونقطة تحول للمؤسسة نحو الأمات الأسوأ أو نحو الأفضل وتتميز بدرجة عالية من الخطورة، فهي كالمرض تمر بأربع مراحل هي: مرحلة الأعراض، والمهار المرحلة

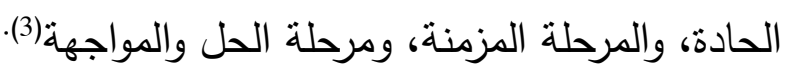
الأزمة والمفاهيم المختلطة والعالقة بها:

يوجد خلط كثبر بين مفهوم الأزمة والمفاهيم العالقة والمرتبطة بها ويتضح ذلك من خلد

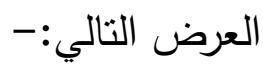
الأزمة: من خلال استعراض الأدبيات وجد أن للأزمة العديد من التعاريف نتيجة لاختلاف وجهات

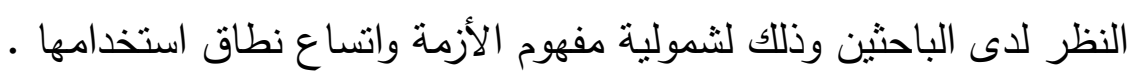

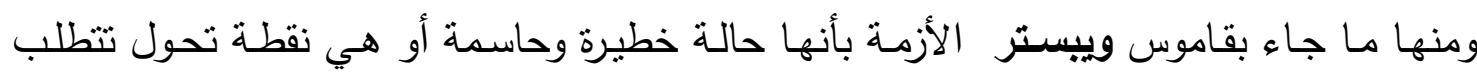

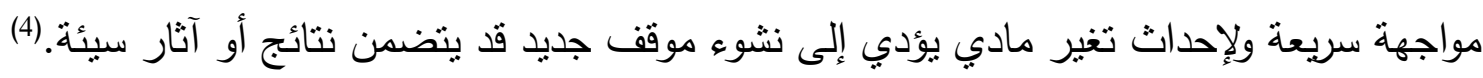

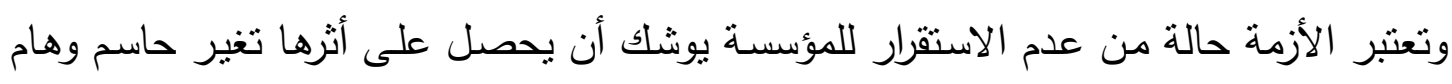

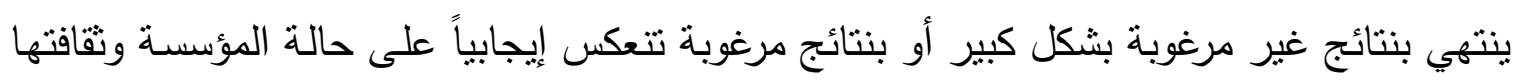
وأدائها.

(1) السيد عليوة: إدارة الأزمات والكوارث مخاطر العولمة والإرهاب الدولي، سلسلة دليل صنع القرار (2). القاهرة: دار

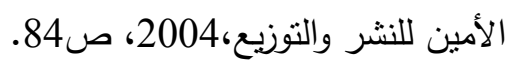

2) احمد حسين اللقانى، على أحمد الجمل: معجم المصطلحات التربوية المعرفة فى المناهج وطرق التدريس ،

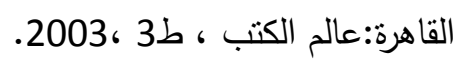

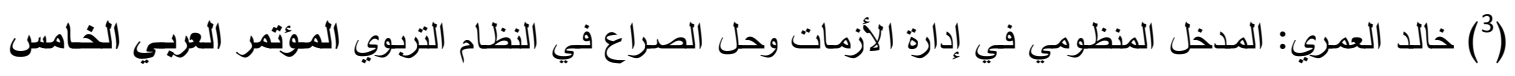

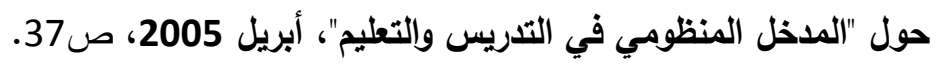

4- Webster New Twentieth Century: Dictionary of the English Language, new York, Collins world publishing .co inc .,p.32 
ولـلإدارة دور حيوي بل محوري فى معالجـة الأزمات ، كمـا أن نظريات وفلسفة إدارة الأزمات

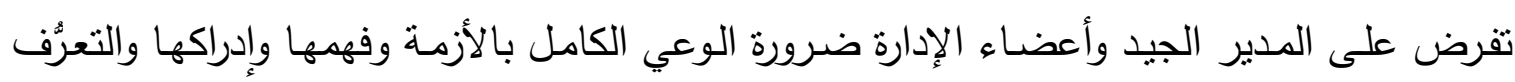

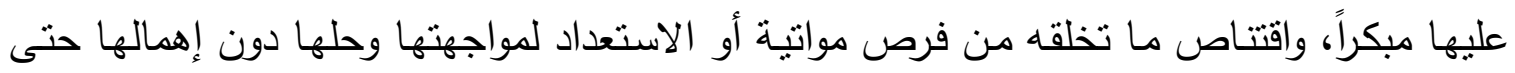
تثفاقم الأوضاع.

المفاهيم المختلطة والعالقة بالأزمة: تتعدد المفاهيم المختلطة والعالقة بالأزمة شأنها في ذلك شأن

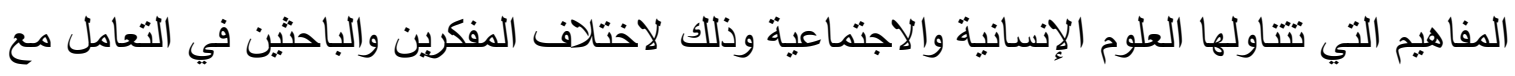
ظاهرة الأزمات والمنظور الفكري الذي ينظرون به للأزمة.

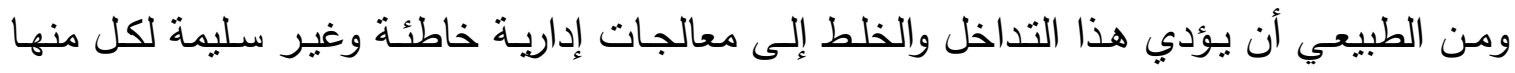

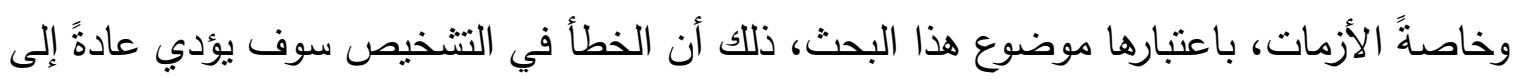
أخطاء في المعالجات، وغالباً ما يؤدي إلى أخطاء في الحلول والقرارات التي تتخذها الإدارة للخروج من الأزمة.

\section{مفهوم الكارثة . من الارمه}

يعتبر مفهوم الكارثة أكثر ارتباطاً في الفهم العام، بمفهوم الأزمـة وذلك على الرغم من التباين الكبير والواضح بين المفهومين على المستويين النظري والعملي، فالكارثة تتميز عادةً بثلاثة عناصر لاصر رئيسية هي: 1- أن الكارثة هي حالـة مدمرة حدثت فعـلاً بفعل الطبيعـة في حين أن الأزمـات قد تكون بفعل الطبيعة أو بفعل الإنسان من خلال ما يقوم به من تصرفات أو يتخذه من قرارات غير رشيدة.

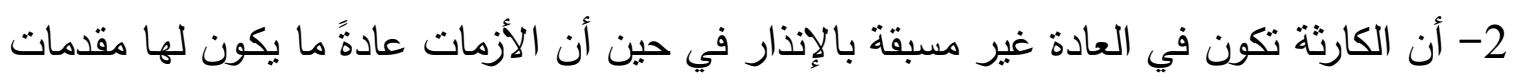

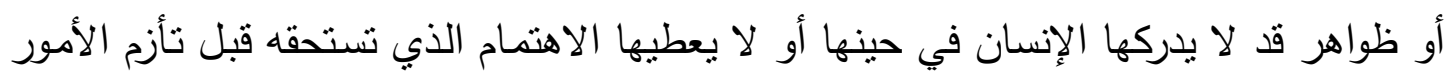
وتفاقمها.

3- أن الكارثة عـادةً مـا تكون مصـحوبة بخسـائر وأضـرار جسيمة ومؤلمـة تطـال المـوارد والثروات

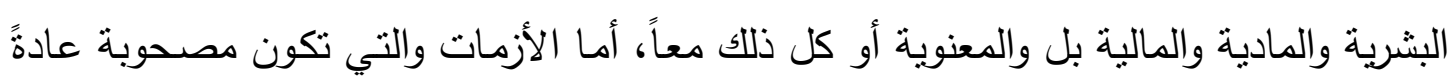

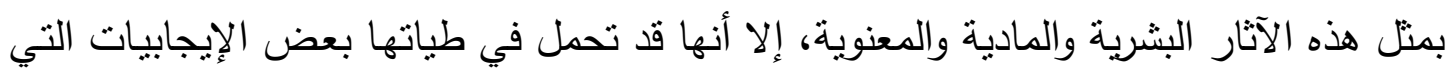
يمكن الاستفادة منها والتخفيف من آثارها السلبية. يقى أن نشير إلى أن الكوارث على الرغم من ارتباطها الغالب والمباشر بالطبيعة، إلا أنها

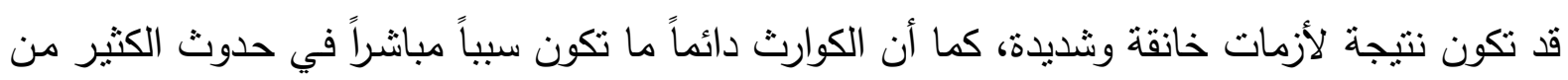


الجمعية المصرية للقر اعة و المعرفة عضو الجمعية الدولية للمعرفة

الأزمات، وهذا الارتباط المزدوج بين الكوارث والأزمات هو السبب الرئيسي في الارتباط الوثيق بين

الدفهومين.

المشكلة :

تعرف المشكلة بأنها عائق أو مانع يحول بين الفرد والهدف - الذي يسعى إلى تحقيقه ـ (1)

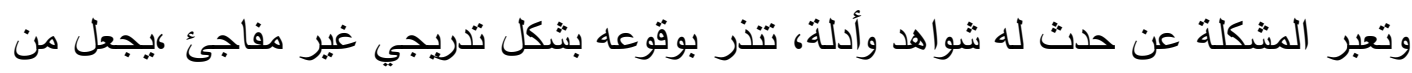

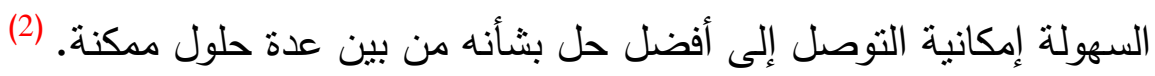

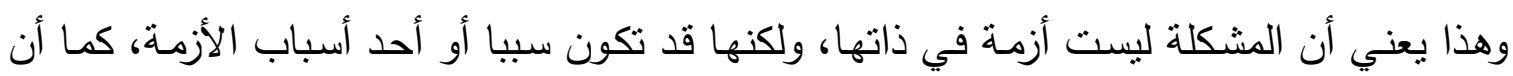

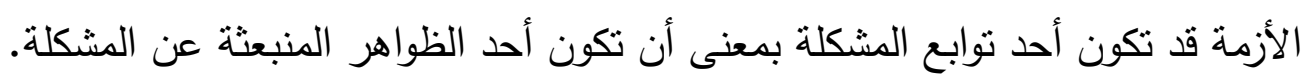

التأزم

التأزم ما هو إلا إفرازات ونتائج لعوامل وبواعث لأسباب الأزمة، ومن ثم فإن معالجة حالة التأزم

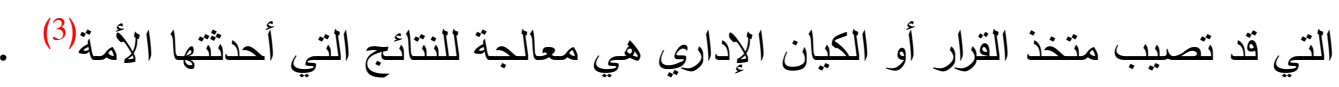

الصراع.

يشير الصراع إلى نزاع بين طرفين أو إدارتين، وتعارض وتضاد مصالحهما وأهدافهما، مما

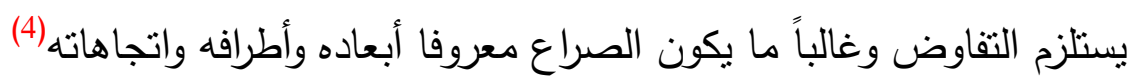

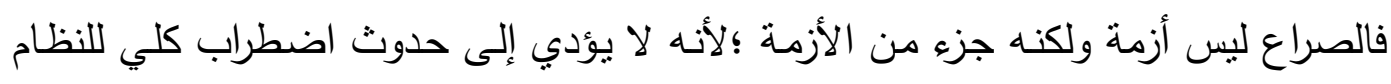

أو المنظومة، كما أن الصراع قد لا يكون بالغ الحدة والتنمير كما هو في الأزمة.

الحادث.

في الاصطلاح يعبر الحادث عن شيء مفاجئ غير منوقع تم بشكل سريع وانقضى أثزه فور

تمامه، ولا تكون له صفة الاستمرار.

(1)فاروق السيد عثمان: سيكولوجية التفاوض وإدارة الأزمات، الإسكندرية: منشأة المعارف، 2000م، ص106

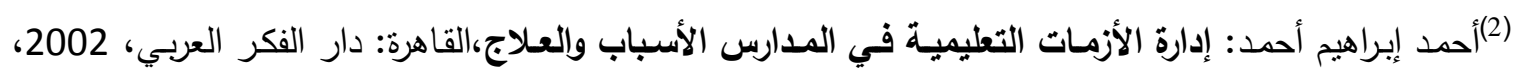
ص24

(3)(مسن أحمد الخضيري: إدارة الأزمات الإدارية،القاهرة، شركة الخبرات الدولية المتكاملة، 2000،ص 13.

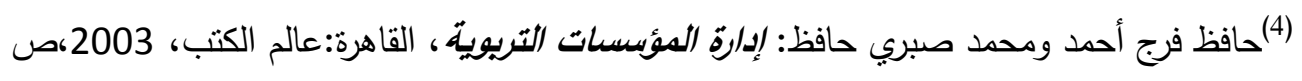
، ص 226. 
ويتضح الفارق بين مفهومي الأزمة والحادث، في أن الأزمة قد تتجم عن الحادث بيد أنها لا

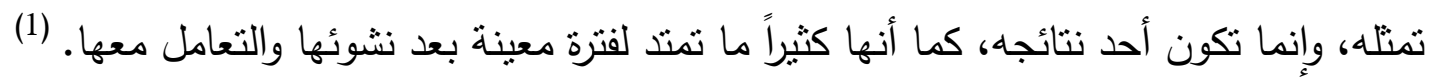
وهي بذلك عكس الحادث الذي يتلاشى بعد حدوثه فورا. تصنيف الأزمات ومناهج تشخيصها. إن الخطوة الأولى للإدارة السليمة للأزمة هي تحديد طبيعة أو نوع الأزمة، لكن تحديد نوع الأزمة ليس عملية سهلة ،لأن الأزمة - أبي أزمة- بحكم طبيعتها تتطوي على عدة جوانب منتـابكة إدارية

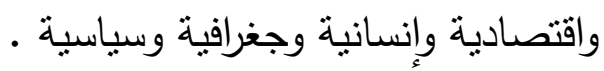

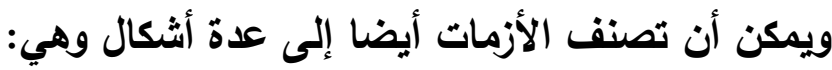

1- أزمة شخصية أو جماعية ذات طابع معنوي تمس الجانب الإنساني أو الاجتماعي مثل الطلاق، المرض الثديد، الطرد من العمل، وفاة أحد الوالدين. r- أزمة اجتماعية تهز المجتمع بأسر منل الزلزال، الفيضانات - البراكين - الحرب.

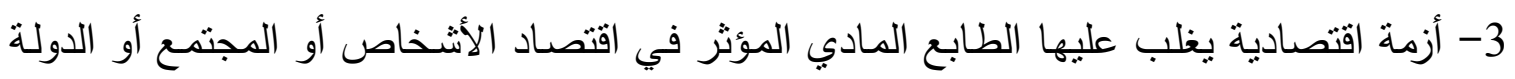
كضرب العملة وتدهورها، الإفلاس، تكدس المنتجات وعدم القدرة على تصريفها.

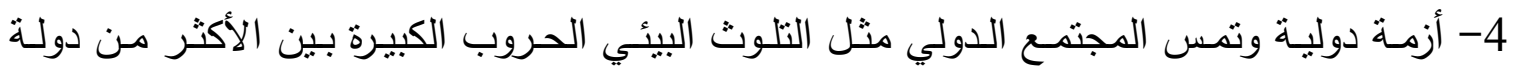

$$
\text { والتسرب الإشعاعي. }
$$

5- أزمة إدارية وهي التي تتعلق بالمنظمة كاحتراق ملفات المنظمة أو إضراب الموظفين عن العمل،

نقص المواد الخام، العجز المالي، الخلافات الحادة بين الإدارة العليا(2).

تصنيف حسب المستوى إلى (3):

أ- أزمـات دوليـة:ويقصد بها الأزمات التي تتشأ عن العلاقات الدولية بين دولة وأخرى بسبب ألبات

$$
\text { تضارب وتعارض المصالح. }
$$

ب-أزمات إقليمية: ويقصد بها الأزمات التي تحدث بين مجموعة دول تعيش في إقليم واحد أو

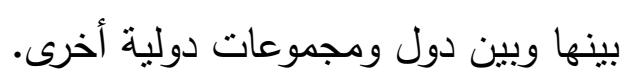

(1)مركز القرار للاستشارات: إدارة الوقت والأزمات والإدارة بالأزمات،القاهرة: دار الأمين،2003 ، ص80

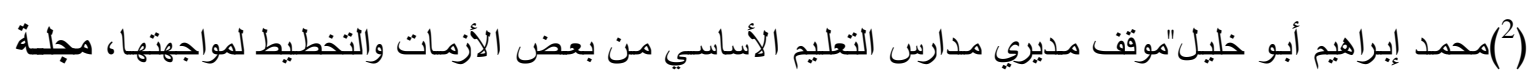

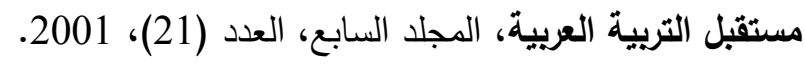

(1) عبد الله عبد الرحمن البريدي : الإبداع يخلق الأزمات، رؤية جديدة في إدارة الأزمات، المملكة العربية السعودية

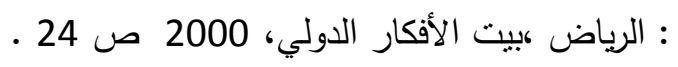


الجمعية المصرية للقر اءة و المعرفة عضو الجمعية الدولية للمعرفة المية

ج- أزمات محلية أو وطنية: ويقصد بها الأزمات التي تحدث وتتثأ داخل دولة واحدة أو أحد مؤسساتها.

\section{تصنيف الأزمات على أساس طبيعة سبب حدوثها: إلى:}

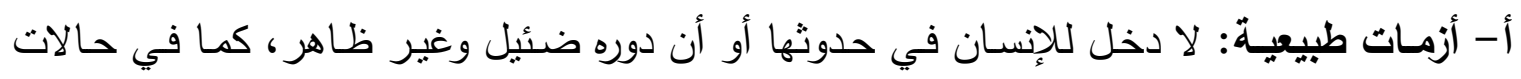

الزلازل والبراكين والأعاصبر والفيضانات والتغيرات المناخية والجوية.

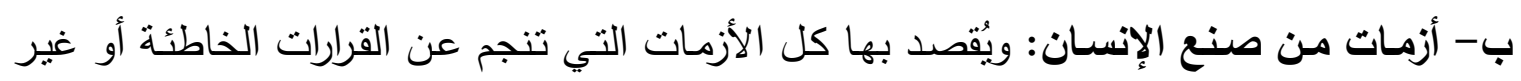

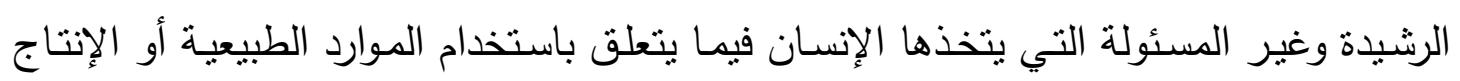

والاستهلاك وصياغة حياته الاجتماعية والثقافية والسياسية.... إلخ.

خطوات واستراتيجيات مواجهة الأزمات.

الخطوات التي يجب اتباعها عند حدوث الأزمات:

هناك عدة خطوات يجب اتباعها وقت الأزمات:

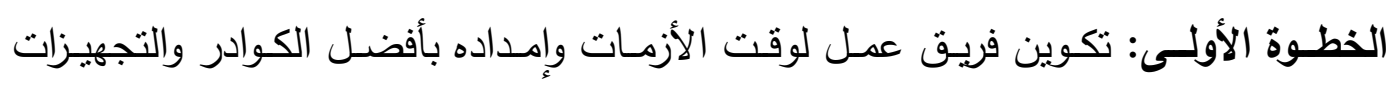
والأدوات.

هالخطوة الثانيـة: تخطيط الوقت أثناء الأزمات، والاستفادة من كل دقيقة في تخفيف أثر الأزمات.

الخطوة الثالثة: الارتفاع بالمعنويات وقت الأزمات للعاملين حوللك فيما يشعل لديهم الحماس

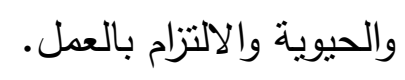

•الخطوة الرابعة: الإبداع والتجديد في المواقف العصبية، وإثنعال نور الإبداع لدى العاملين

$$
\text { لتقديم حلول وآراء غبر مسبوقة. }
$$

الخطوة الخامسةة: حل المشكلات وقت الأزمات بتحديد المشكلة وإجراء المشورة، ومن ثم

$$
\text { اختيار الحل الأنسب من الحلول المتاحة. }
$$

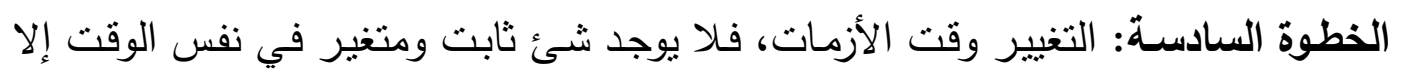

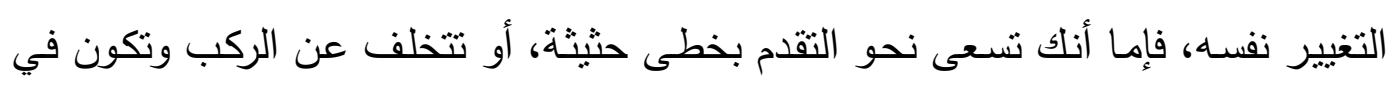

عالم النسيان (1).

استراتيجيات المواجهة مع الأزمة التربوية :

(1) عبد الله بن عبد العزيز آل الثيخ: لمحات عن التعليم ويداياته في المملكة العربية السعودية، الرياض ، مكتبة

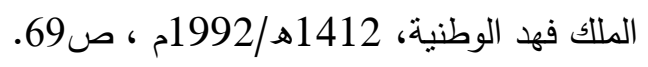




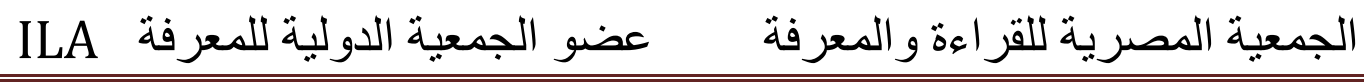

هناك مجموعة من الاستراتيجيات المختلفة التي يمكن استخدامها في التعامل مـع الأزمات التربوية، وينوقف استخدامها على القدرات الثخصية والظروف الموضوعية والإمكانات المتاحة.

$$
\text { (2): وهذه الاستراتيجيات هي }
$$

أولاً : إستراتيجية العنف في التعامل مع الأزمة التريوية :

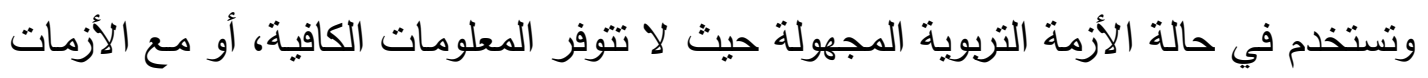
المتعلقة بالمبادئ والقيم التربوية، أو عند الانتشار السرطاني للازمة التربوية في عدة اتجاهات. ثنانيًا : إستراتيجية وقف النمو :

وتستخدم هذه الإستراتيجية في الحالات التالية : المواجهة مع قوى ذات حجم كبير ومتشعبة.

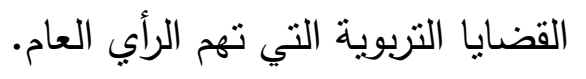

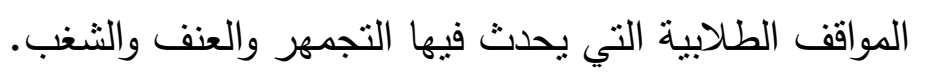

ثالثًا: إستراتيجية التجزئة :

تعتمد هذه الإستراتيجية إلى الدراسة والتحليل الكافي والدقيق للعوامل المكونة والقوة المؤثرة

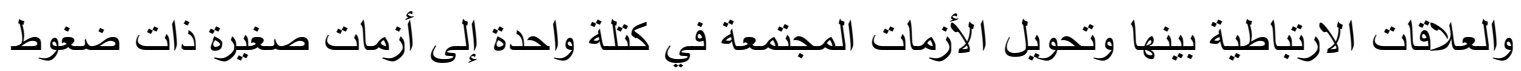
اقل قوة مما يسهل التعامل معها. وتركز هذه الإستراتيجية على : ضرب الروابط المجعة للازمة لتجزئتها. تحويل العناصر المتحدة إلى عناصر متعارضة.

رابعًا : إستراتيجية إجهاض الفكر الصانع للازمة التربوية : يمنل الفكر الذي يقف وراء الأزمة التربوية في صورة قيم واتجاهات معينة تأثثرا شديدا على إنى

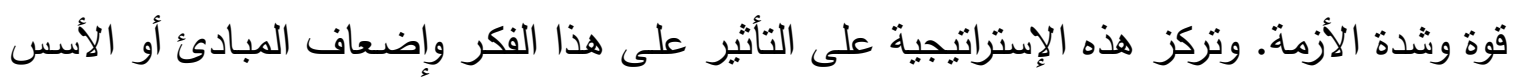
التي يقوم عليها بحيث تتصرف عنه بعض القوى المؤيدة ولإضعاف الضغوط الدافعة لظهور الأزمة. خامسًا : إستراتيجية دفع الأزمة التريوية للأمام : وتهدف إلى الإسـراع بدفع القوى المشـاركة في صناعة الأزمـة إلى مرحلـة منقدمـة لنظهر

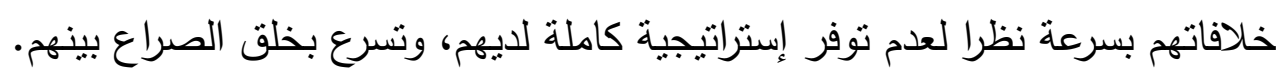

(2) محمد عبدالغني حسن هلا : مهارات إدارة الأزمات التربوية : الأزمة الناتجة عن الثورة المعلوماتية

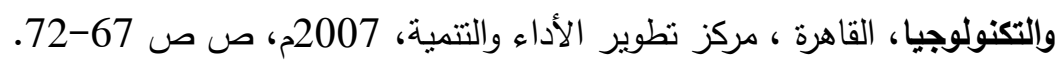


سادسًا: إستراتيجية تغيير المسار: تهدف هذه الإستراتيجية إلى التعامل مع الأزمات التربوية الجارفة

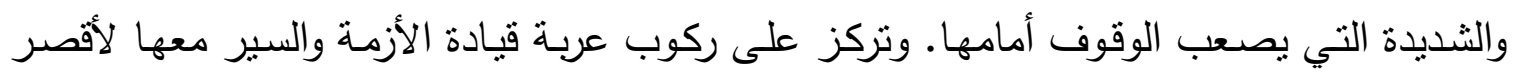
مسافة مدكنة ثم تغيير مسارها وتحويلها إلى مسارات بعيدة عن اتجاه قمة الأزمة التربوية. مواجهة الأزمات في التعليم:

يتوقف النجاح في مواجهة الأزمات التعليمية والقضاء عليها على ما يلي:

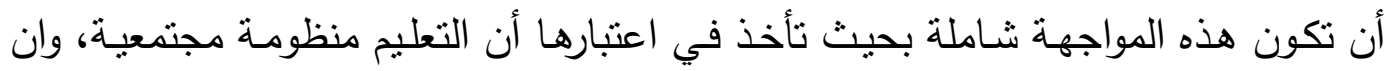
هناك منظومات فرعية له بينها اعتماد وتأثثر وتبادل واستخدام أساليب بينها اتساق وتتاغم

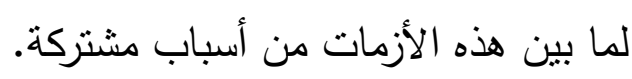
أن تكون المواجهة قائمة وفقا لبرنامج علمي للأولويات. المرونة: وتعني التخطيط والإعداد لمواجهة المواقف في ضونه كافة الاحتمالات والإمكانيات

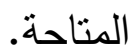

الدقة: وتعني التصور الدقيق لموقف الأزمة أو الكارثة واحتمالاتها. أن تكون كذلك قائمة على أساس من الكفاءة العالية في الأداء والمتابعة.

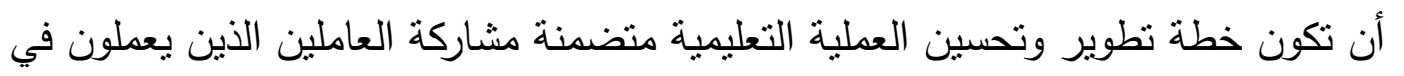

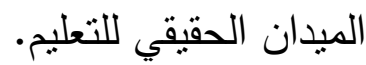
يجب أن تكون المواجهة قائمة على إدارة المخرجات، وهي طريقة لتعظيم نواتج المدرسة من خلال تعظيم إسهامات أفرادها. تحديد الواجبـات الخاصـة والعامـة للجهات والأجهزة المختلفة التي يمكنها أن تشـارك في في

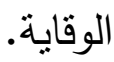
ضرورة إدخال علم إدارة الأزمات بكليات التربية والمدارس.

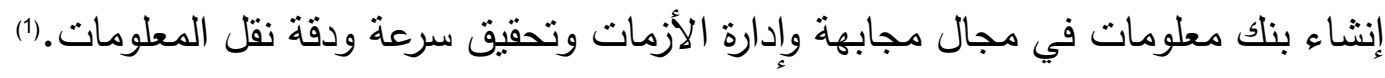
عوامل النجاح في إدارة الأزمات :

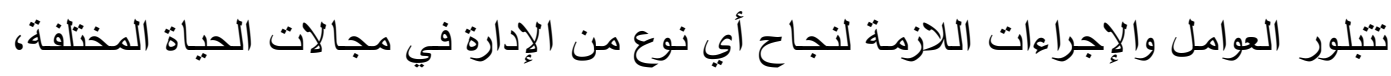

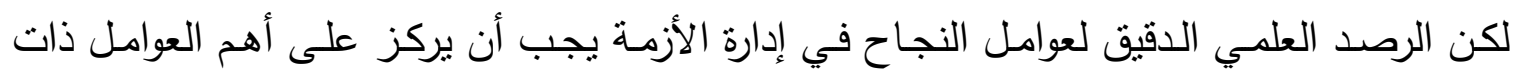

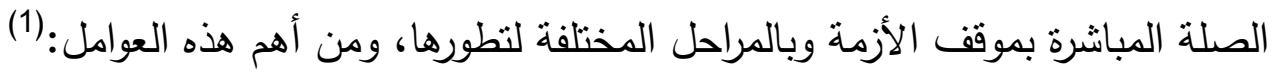

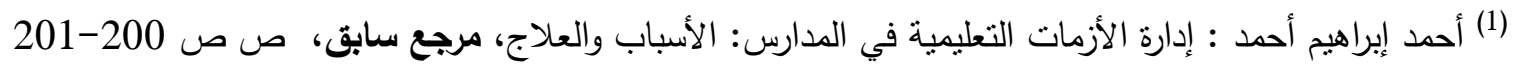

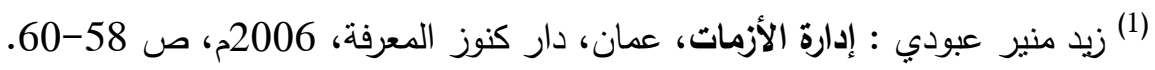


هار ادارك أهمية الوقت : ويعتبر عنصر الوقت احد أهم المتغيرات الحاكمة في إدارة الأزمات، فهو

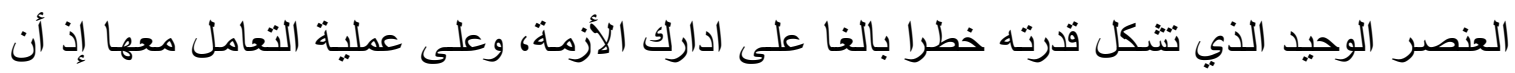
السرعة مطلوب لاستيعاب الأزمة والتفكير في البدائل واتخاذ القرارات المناسبة، والسرعة في تحريك الكي فريق إدارة الأزمات والقيام بالعمليات الواجبة لاحتواء الأضرار أو الحد منها واستعادة نشاط المنظمة.

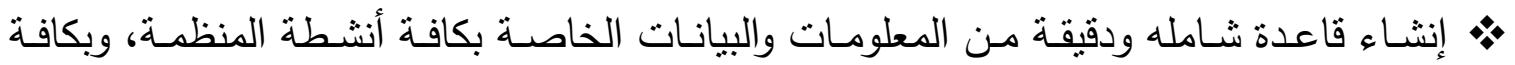
الأزمات والمخاطر التي قد تتعرض لها، وآثار وتداعيات ذلك على مجمل أنشطتها ومواقف للأطراف

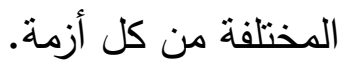
• أجهزة اتصـال منطورة وحديثة فقد أثنتت دراسـات وبحوث الأزمـة والدروس المستفادة من إدارة

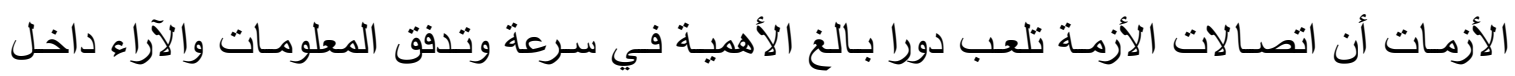

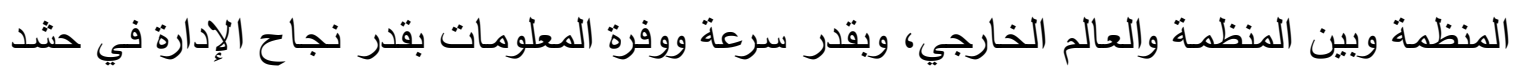

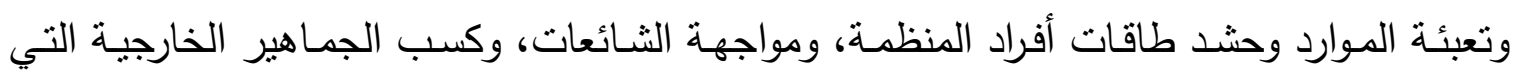
تتعامل مع المنظمة، بالإضافة إلى كسب الرأي العام أو على الأقل تحييدها.

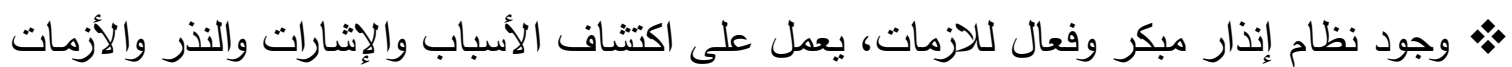

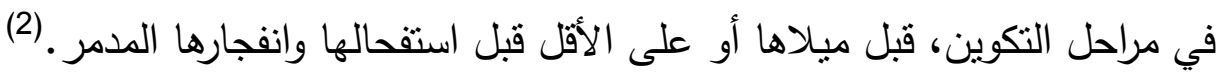
• وجود فرضيات وسيناريوهات يتم التدريب عليها باستمرار ، تغطي طيف الأزمات المحتملة ودرجة احتمالها مبنية على أسس تستفيد من تجارب الماضي ومعطيات الواقع، لتستقرئ المستقبل وأزماته المحتملة.

وجود نظام تقويم ومراجعة مستمرة للأداء وللنظم ولإجراءات ولمدى كفاءة وفعالية واكتمال الموارد

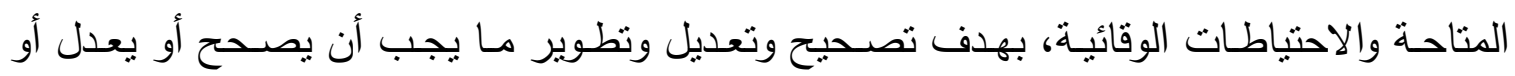
يطور، مع الاهتمام بتحديد المهام والوجبات الوقائية والتأكد من تكاملها. لونها. الإطار المفاهيمي لصنع القرار:-

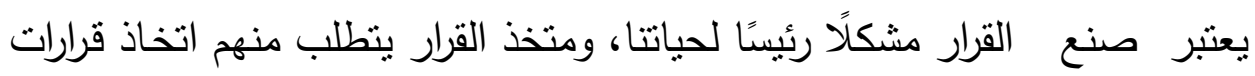

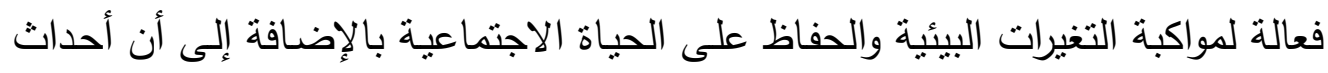

(2) سعد علي الثهراني : إدارة عمليات الأزمات الأمنية، مجلة الأمن والحياة، الرياض ، أكاديمية نايف العربية للعلوم الأمنية ، العدد 279، السنة الرابعة والعشرون، 2005م، ص الفرات 68 
الحياة اليومينة تؤثر في صنع واتخاذ القرارات، وبالتالي يتتوع الأفراد في طريقة اتخاذ

\section{ماهية صنع القزار}

من أهم أسباب النجاح في الحياة إجادة صنع القرارات واتخاذها في الوقت المناسب في أي جانب من جوانب الحياة المختلفة، وكثير من الناس يعملون، ويجتهدون ثم في لحظة حاسمة من الن الهن

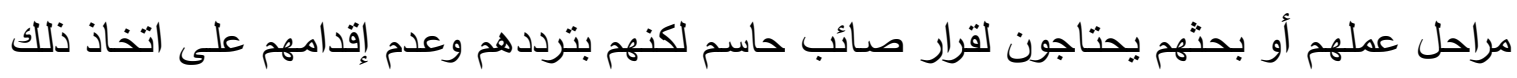
القرار يضيعون عمهم أو جهذهم، وربما ضاعت منهم فرص لن تتكرر لهم مرة أخرى(1).

\section{مفهوم القرار:}

القرار في اللغة العربية كما تذكر المعاجم اللغوية: هو المستقر من الأرض، والقرار في أي

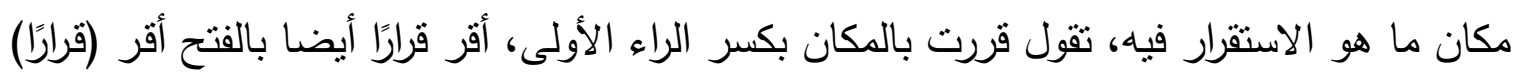

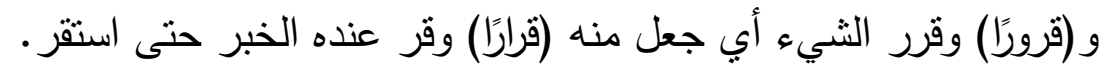

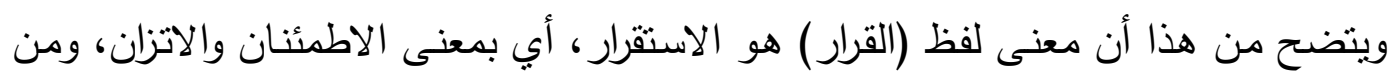

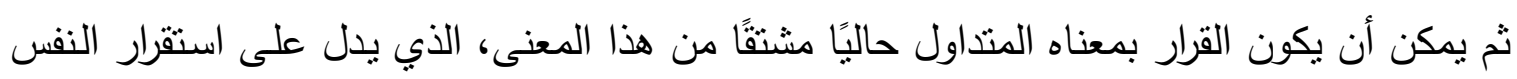

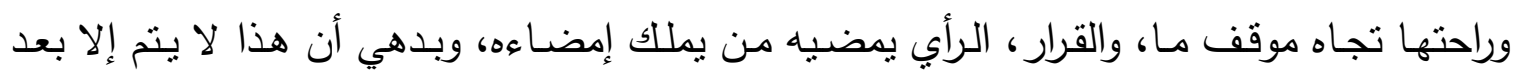

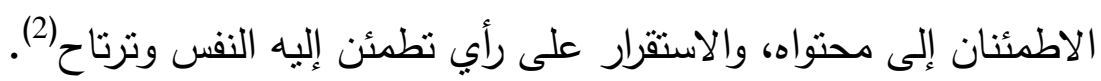

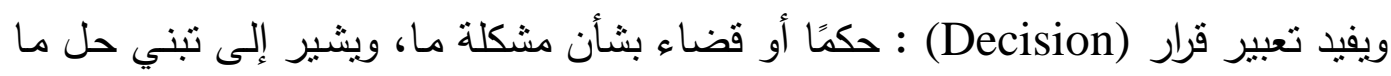

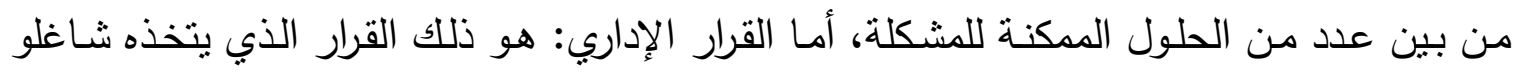

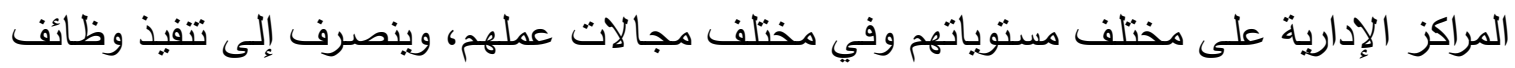

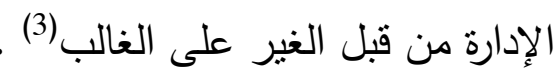
كما تعددت مفاهيم القرار بتعدد الكتاب والمستقفيدين ومدارسهم الفكريـة فعلى سبيل المثنال: يعرفهـ

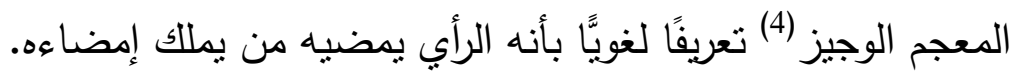

(1) Schoemaker, A. F. :.The Relationship between Decision-Making Style and Negative Affect in College Students. Master of Science, Drexel University, 2010.P.3.

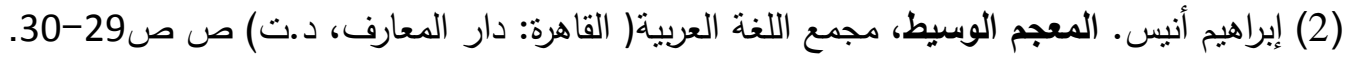

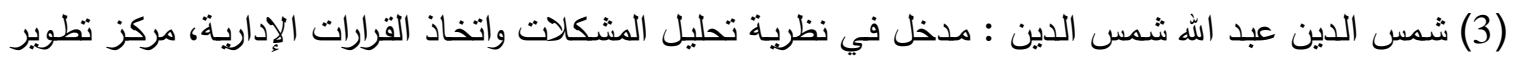

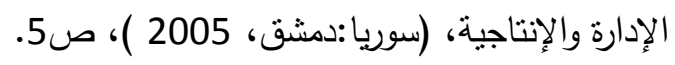

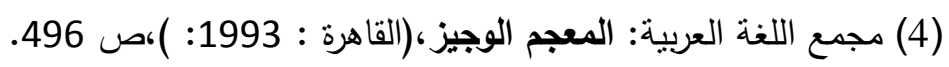




\section{مفهوم صناعة القرار.}

ينظر البعض إلى صناعة القرار على أنها إصدار حكم معين عما يجب أن يفعله الفرد في

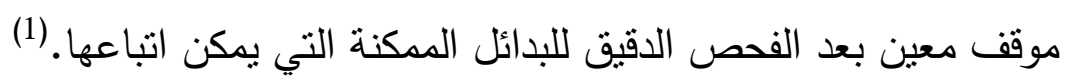

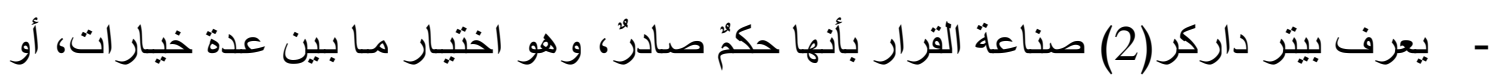
اختيار بين الصواب أو الخطأ، والخطأ المحتمل، إلا أنه غالبًا ما يكون هو الاختيار بين عملين

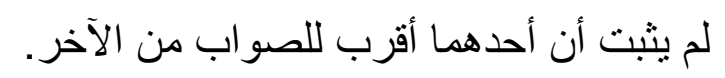

- يرى ستيف وليم(3) أن عملية صنع القرار مر ادفة للعملية الإداريـة برمتها، فهي تبدأ بنشـاط

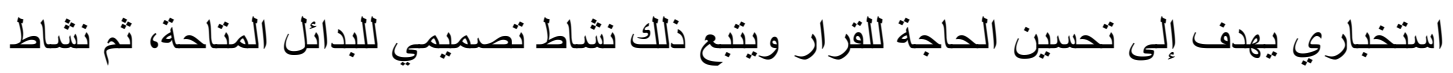
يهدف للوصول إلى اختيار سليم من بين هذه البدائل. • ثنيف القرارات التعليمية وأنواعها. فيما يلي عرض لأهم تصنيفات القرار ات التعليمية:1 وتتقسم القرارات في هذا التصنيف إلى ثلاثة أنواع: أ - القرارات الإستراتيجية

تشمل القرارات الإستراتيجية المبادرة بتقديم منتج أو خدمة جديدة (أو إدخال نظام جديد للامتحانات)، فهي تتطلب معرفة قادة Leaders' Knowledge، ويتضح ذللك من خلاد نظريـة

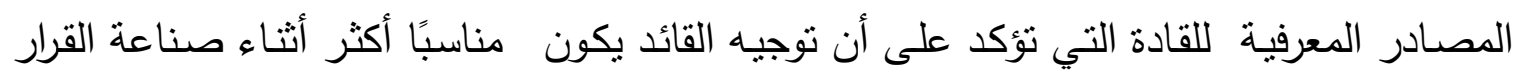
الاستراتيجي. ب - القرارات التكتيكية . هي تلك القرارات التي تتعامل مع طرق العمل أو التعيينات (تقديم طرق تدريس جديدة)،

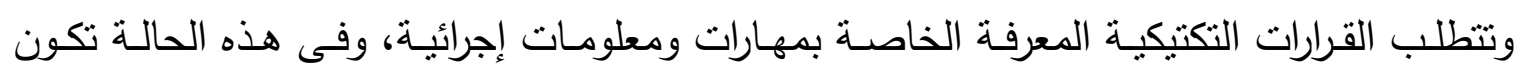

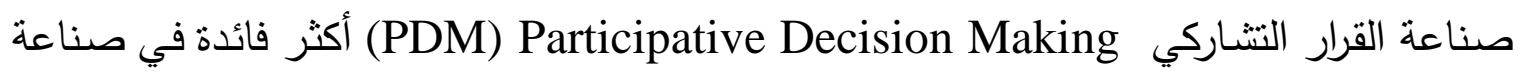

(1) نبيل سعد خليل: "واقع عملية اتخاذ القرارات التزبوية على مستوى المدرسة:دراسة تحليلية"، مجلة التربية، المجلد

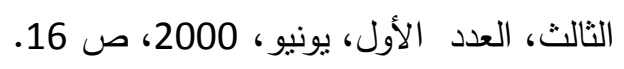

(2) بيثر داركر : الإدارة: المهام - المسئوليات - التطبيقات، ترجمة اللونة اللواء محمد الكريم، ( القاهرة: الدار الدولية

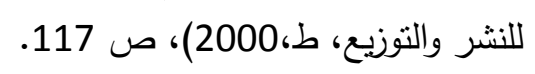

(3)Steve, W. Williams , Making Better Business Decision ; Understanding and Improving Critical Thinking and Problem Solving Skills, NewDelhi: Sage Publications, Inc. , 2002 , PP.20-21. 
القرارات التكتيكية(1)

للذلك فهذا النوع مـن القرارات، سـواء التكتيكيـة أو الإسـتراتيجية، بهتم بمسـتقبل المؤسســة

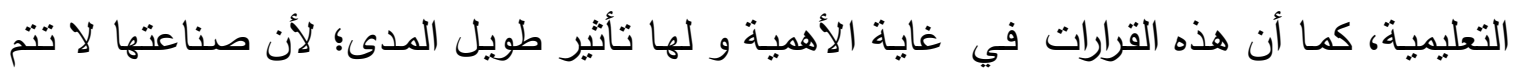

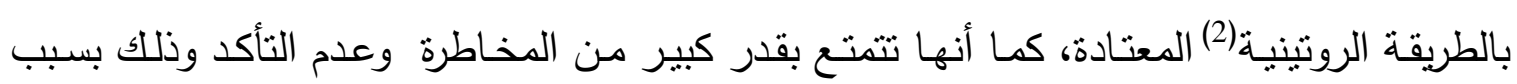
معدل التغيرات التي تحدث في البيئة المحيطة بالمؤسسة التعليمية.

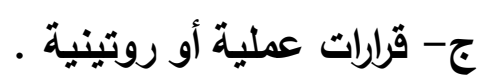

تعرف بأنها أسلوب روتيني عادة يحتوي على بدائل قليلة، ويتطلب هذا النوع من القرارات

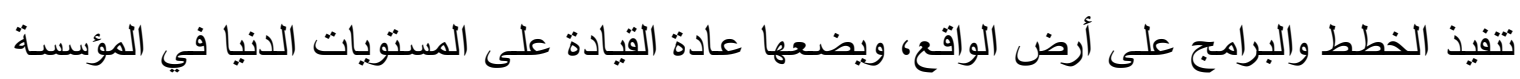

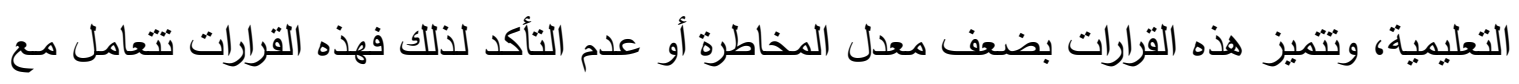
الوسائل (3)؛ لذا فهي لا تحتاج التفكير ، فغالبا مـا تتعلق هذه القرارات بمشاكل العمل اليومي كمنح الإجازات للمدرسين أو توزيع الطلاب على الفصول (4).

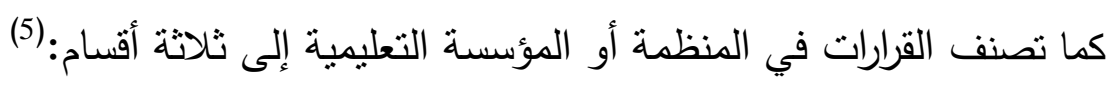

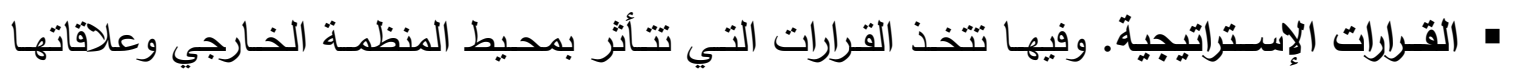

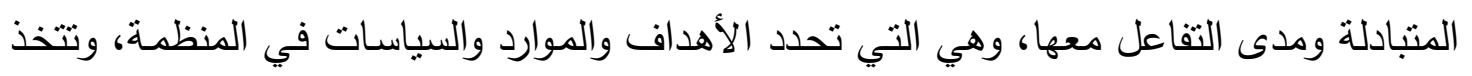

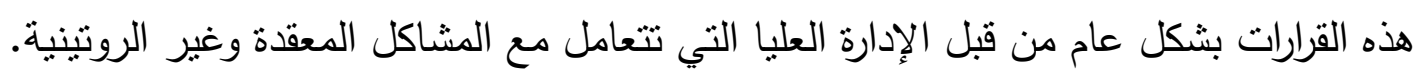

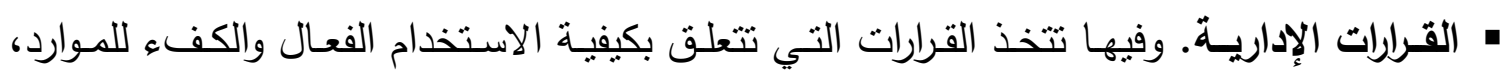
وينطلب اتخاذها تفاعلًا كبيرًا مع أولئك الذين ينفذون المهام في المنظمة.

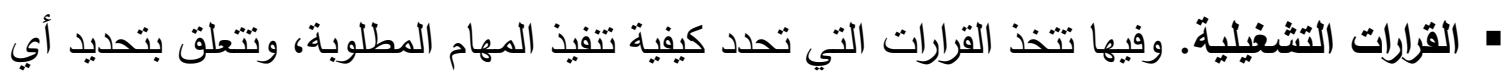

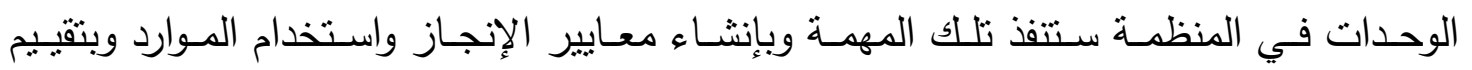

$$
\text { وقد أضيف لاحقًا نوع آخر من القرارات وهي: }
$$

(1) Abraham, Sagie. And Meni Koslowsky: Participation and Empowerment in Organizations'; Modeling Effectiveness and Applications , London: Sage Publication , Ins , 2004, PP. 65-66.

(2) Robert C. Appleby: Modern Business Administration, (Singapore: NP, 2000). PP.111

(3) Cooke Steve and Nigel Sleck: Making Management Decisions, New York: Prentic Hall, 2006, PP. 22-23

(4) Robert C. Appleby: Modern Business Administration, Op. cit, PP.112

(5)Kenneth C. Laudon \& Jane P. Laudon. Management Information Systems. New Jersey: Prentice Hall International Inc, 2006 
• القرارات المعرفيـة. وهي التي تتعلق بتقيميم الأفكار الجديدة للسـلع والخدمات، وتتعلق بطرق الوصول إلى معرفة جديدة وبطرق نوزيع المعلومات عبر المنظمة.

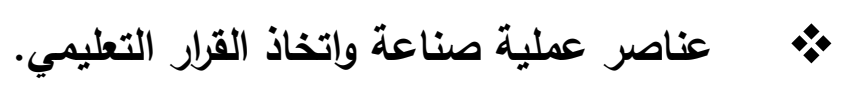

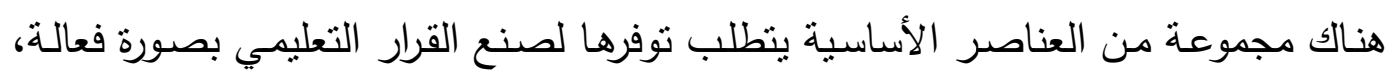

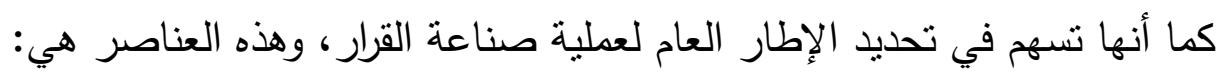

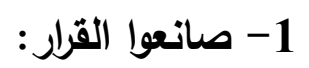

وهم الأفراد والمجموعات التي تقوم بالاختيار الفعلي بين البدائل، وقد صُنِفَ صانعوا القرارات

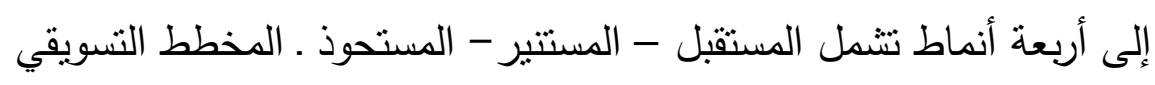
2- 2 - مشكلة القرار:

ويقصد هنا بمشكلة القرار وجود حالة أو صعوبة نستلزم صناعة القرار ، وقد تكون المشكلة حقيقة أو اصطناعية، ينطلب حلها إعمال الفكر أو بمعنى أشمل أي موقف يتطلب قرارًا من أجل تسيير العملية الإدارية تسييرًا منتظمًا ودوريًا. 3- - 3 بائل القرار:

إن صناعة أي قرار تتطلب وجود عدد من البدائل المتاحة، بحيث بمكن لأي منها أن بسهم

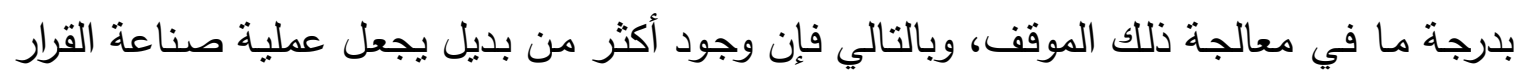

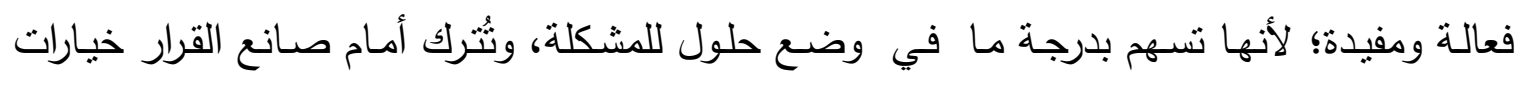
متعددة تساعده على اختيار البديل المناسب.(1)

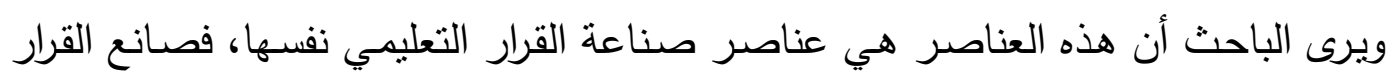

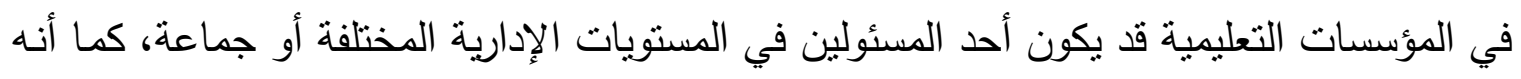

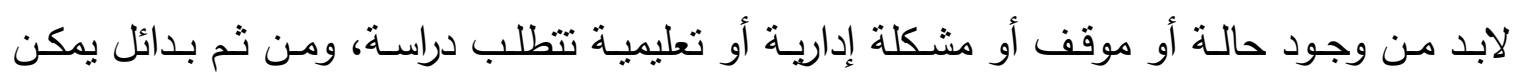
الاختيار منها بما يتتاسب والوضع الطارئ.

ويرى شاكر محمد فتحي عملية صنع القرار التعليمي تنكون من عناصر عدة عدة لها تأثنير

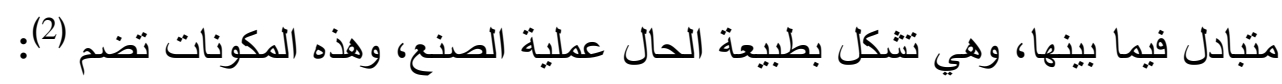

$$
\text { 2- 1 الأهداف والغايات أو محركات ودوافع السلوك. }
$$

(1) هليقا دومنير ، اتخاذ القرارات الفعالة، ترجمة مصطفى دراسي،( القاهرة:دار المعارف، 2002م )، ص صاكئ 4.

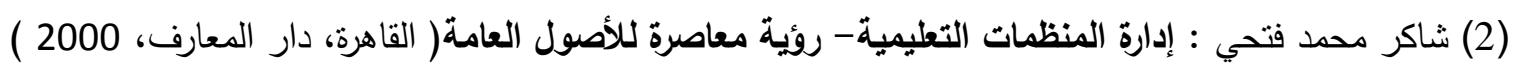




$$
\text { 4- 4- توافر البدائل. }
$$

5- الموارد البشرية والمادية المتوافرة للمنظمات التعليمية.

6- البيئة الداخلية للمنظمات التعليمية.

7- البيئة الخارجية للمنظمات التعليمية بما تحويـه من متغيرات سياسية واقتصادية واجتماعية

$$
\text { وتكنولوجية وغيرها. }
$$

\section{• خ أساليب صنع واتخاذ القزارات التعليمية.}

تتعدد الأساليب والطرق المستخدمة في عملية صنع القرار داخل الإدارات التعليمية والمدارس، ومن

$$
\text { أبرز هذه الأساليب: }
$$

أ) الأساليب التقليدية في صنع القرار: وتثثمل:

- أسلـوب الخبرة: يمر صـانع القرار بالعديد من التجارب أثناء أدائه لمهامها الإدارية يخرج منها بدروس مستفادة من النجاح أو الفنل، وهذه الدروس المستفادة من التجارب الماضية غالبا ما تكسب صانع القرار مزيدًا من الخبرة الني تساعده في الوصول إلى صنع قرارات سليمة. ويمكنه الاستفادة من خبرات الآخرين وتجاربهم في حل الشكلات الإدارية، ويستخدم أسلوب الخبرة في

$$
\text { القرارات المتكررة والبسيطة(1). }
$$

- - أسلوب التفويض: التفويض هو تللك العملية التتظيمية التي تتنقل بموجبها السلطة من الرئيس

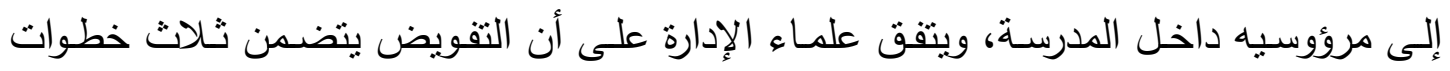
رئيسة، هي: تحديد المسئولية، وتفويض السلطة، والمساءلة. ويعتبر أسلوب تفويض السلطة من إنس أكثر أسـاليب صنع القرار شيوعًا لها له من مزايا عديدة تتمثل في تخفيف أعباء ومسئوليات

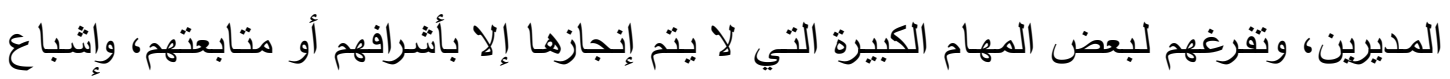

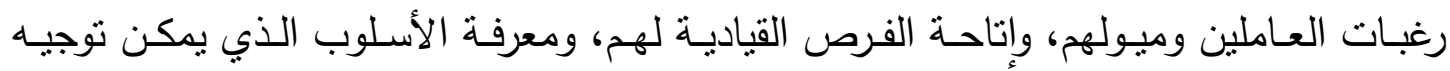
العاملين به لتتفيذ القرارات المطلوبة من أجل تحقيق الأهداف العامة (2). أسلوب الاستشارة: ويعتمد هذا الأسلوب على استعانة المدير بآراء بعض معاونيه ومشورتهم للتوصل إلى القرار الأنسب، ويساعد هذا الأسلوب في رفع الروح المعنويـة لدى معظم العاملين

(1) Davis K: " Human Behavior at Work", Organizational Behavior, New York, McGrawHill, 2001, P.221.

(2) Kinaki A.\& Kreitner A: Organizational Behavior Key Concepts Skills Best Practices, McGraw Hill, New York, 2003, P.332. 
المشاركين في صنع وتتفيذ القرار، مما يؤدي إلى فعاليته ونجاحه، ولقد ظهر اتجاه متزايد لاستخدام

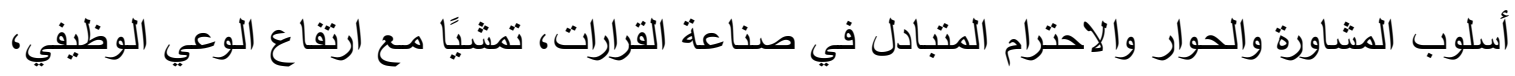
وتحسن المستويات التعليمية بالمدارس (1) ب) الأساليب الحديثة في عملية صنع القرار: نتيجة التقدم المـذهل في العلـوم الإحصـائية والرياضسية وانتنـار الحاسـب الآلكي والبـرامج المتصلة بها، فقد ظهرت الحاجة للجوء إلى تلك الأساليب في معالجة البيانات الرقمية وصنع قرارات فعالة بشأنها نظرا لسهولة التعرف على المشكلة وتحديدها بصورة كمية، وأيضا سهولة التعبير عن التهاته العلاقات بين العوامل المرتبطة بتلك المشكلة والتعبير عنها بصورة كمية، ومن أبرز هذه الأساليب:

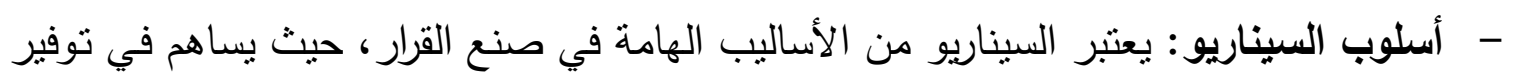
العديد من البدائل والممارسات في عملية صنع القرار، كما يساهم في تحقيق عدد من النتائج والفوائد الإيجابية على روح العمل داخل المدرسة. وهي عملية تهدف إلى تصميم سيناريوهات

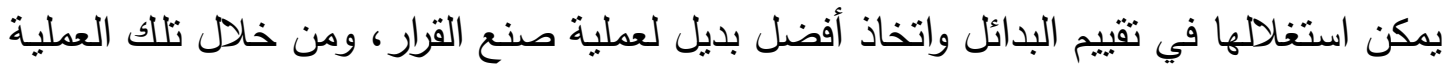
يتم قياس وتقييم القرارات الإستراتيجية التي تؤثر بشكل أو بآخر على الوضع المستقبلي للمدرسة،

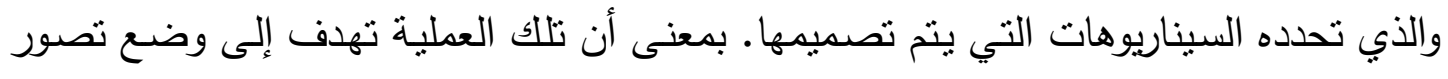

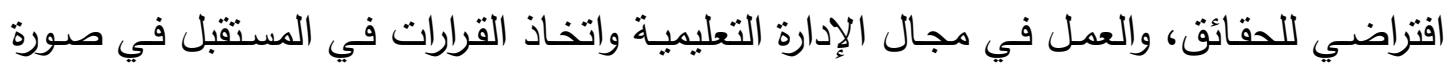
سيناريوهات ومحاولة استخدام تلك السيناريوهات في ضبط وتحريك عملية صنع القرار (2).

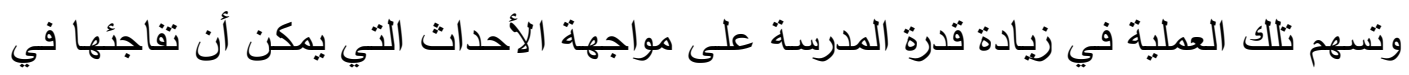
المستقبل. - أسـلوب فريق العمل: يعد أسلوب فرق العمل من أهم الأسـاليب التي تهيئ مناخ عمل أكثر

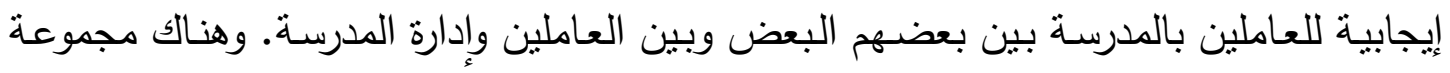

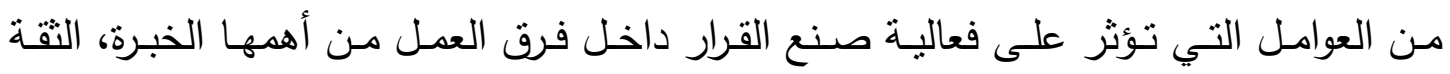

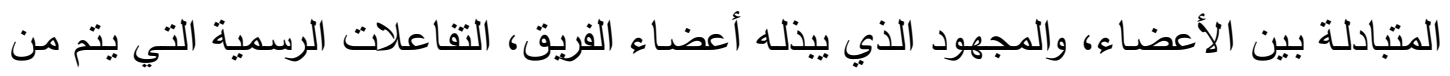

(1) عبد الرحمن توفيق: تحليـل المشـكلات واتخــاذ القـرارات،(القـاهرة: مركز الخبرات المهنـــة لـلإدارة (بيمكل)،

. 2001

(2) Mc Burney P.\& Parsons S.: Ensemble Theory Arguing Across and Within Scenarios, A paper Presented at the An Conference at the University of Strathclyde Graduate School of Business in Glasgow, Uk Probing the Future Developing Organizational Foresight in the Knowledge Economy, 2002, P.6. 
خلالهـا تبـادل المعلومـات، والتفاعلات غير الرسـية مثل المناقثـات والحسوار الذي يتم ببين الأعضاء خارج الاجتماعات الرسمية للفريق (1). - - أسلوب نظرية شجرة القرار: يعتبر أسلوب نظرية شجرة القرار واحدًا من الأساليب العلمية التي

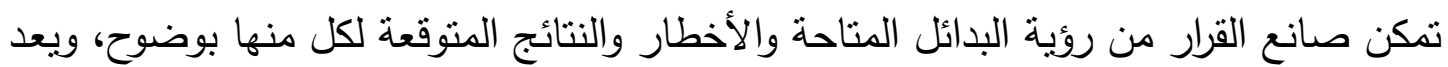
أسلوب نظرية شجرة القرار أداة أو نموذجا بيانيا يستخدم لتوضيح العلاقة بين ولين القرارات وعوامل الاحتمال، وتستخدم عادة في القرارات المالية للمدرسة من حيث اختيار وتفضيل مشروع دون

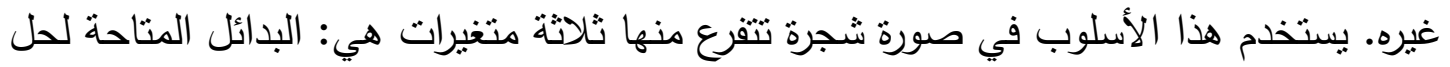
المشكلة، والاحتمالات التي تمثل الكسب المتوقع أو الفتشل، والقيم التي تمثل إجمالي العوائد

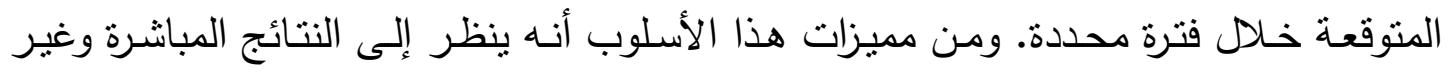

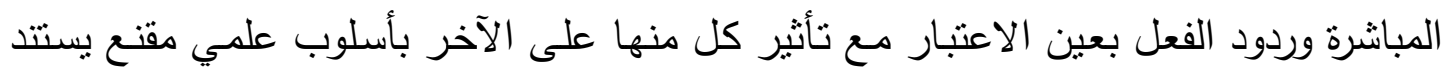

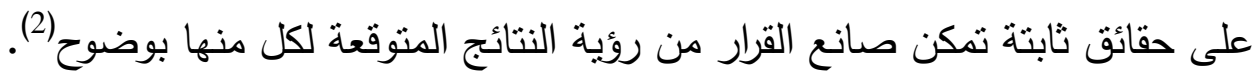

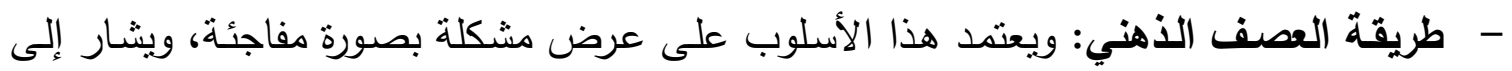
هذه الطريقة باسم الزوبعـة العقلية وتعد هذه الطريقة من أكثر الطرق المستخدمة في الإدارة

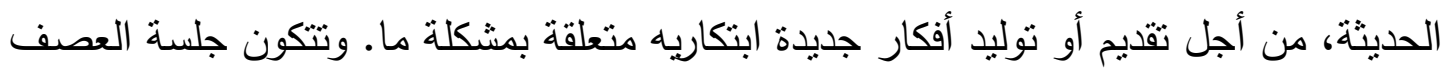

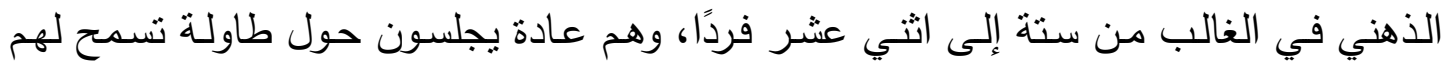

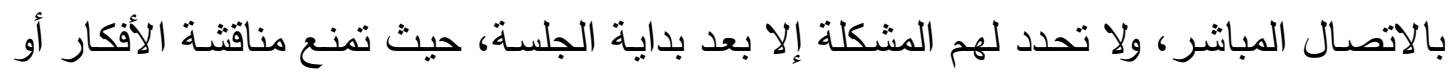

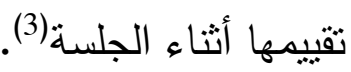
ويعتمد أسلوب العصف الذهني في صناعة القرار على ثلاث قواعد هي: - التركيز على كمية الأفكار أكثر من جودتها. - - يتم توجيه الأعضاء لتقديم أفكارهم دون حدود أو قيود. - إرجاء الأحكام فلا ينبغي النقد أثناء المرحلة الأولى لتوليد الأفكار .

(1) Flowers N.: The Impact of Teaming: Five Research -Based Outcomes of Teaming, Middle School Journal, 2000, London, Vol.31, No.2, p.64.

(2) Mann L.: "Flinders Decision - Making Ouestionnaire I and II", Unpublished Ouestionnaires, School of Social Sciences, Flinders University of South Australia, 2008, p82.

(3) Owens R.: Organizational Behavior, Adaptive Leadership and School Reform, 8th Ed, Prentice Hell, Boston, 2004, p.241. 
ويؤدى صنّع واتخاذ القرار باستخدام أسلوب العصف الذهني إلى إنتاج قرارات ذات نوعية جيدة

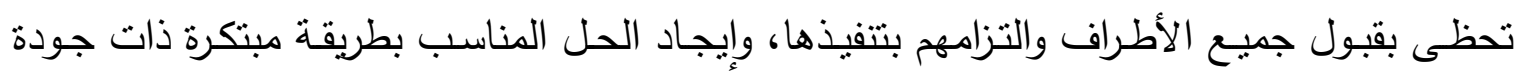
عالية. (1)

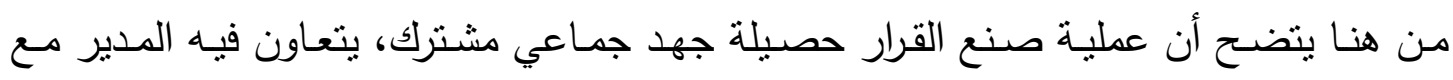
المرؤوسين، مما يتطلب جمع المعلومات والبيانات، وتحليلها، وتقديم الآراء والأفكار الممكنة، وتحقيق هيته الاتصالات الفردية والجماعية لضمان نجاح خط سير القرار. وهكذا تتتوع الأساليب التي يمكن استخدامها في عملية صنع القرارات المدرسية، ويتوقف استخدام

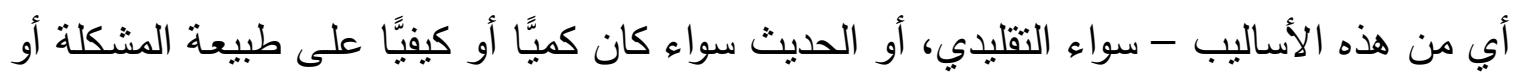
موضوع القرار، كما يمكن استخدام أكثر من أسلوب لحل المشكلة.

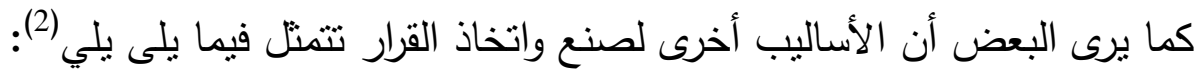

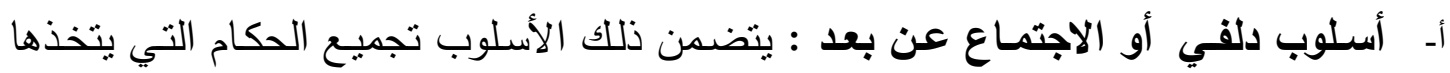
الخبراء ممن يستجييون بشكل مستقل على الاستبيانات، ولذلك يتم تلخيص النتائج وتعود إلى ه المشاركين من أجل إضـافة الملاحظات، وبالتالي يقوم جميع المشاركين بالتصويت بشكل مستقل على الحلول أو القرارات المتعددة، وعلى الرغم من أن أسلوب دلفي يبدو أنه يطور من عملية صنع القرارات، إلا أن العقبة الأساسية هي أنه لا يتضمن أي تفاعل بين أعضاء الفريق، مما يؤدي إلى تقليل من قبول قرار الفريق والالنزام به.

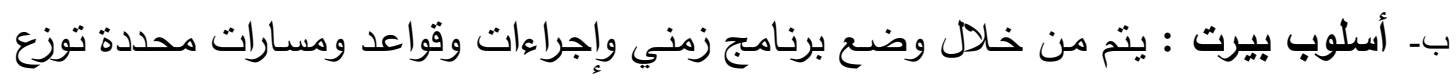
على فريق المهام الأزموية، توضح لكل فرد من أفراد الفريق الدور المتعين القيام به، ونترح لهم أهمية أن يتم تتفيذ مهنته بدقة كاملة سواء في التوقيت المحدد أو في النتائج المطلوبة، ويعتبر أسـلوب بيرت أحد الأسـاليب التي تستخدم في عمليات التخطيط والرقابـة، بحيث تنتكن الإدارة مـن خلالـه تقليـل الحـ الأدنى مـن التوقعـات والتأخير، ويتم التعامـل بهذا الأسلوب في ظروف عدم التأكد.

(1)محمد بن عبد اله البرعى، محمد بن إبراهيم التو يجرى: الأسلوب القويم في صنع القرار السليم،(الرياض: مكتبة

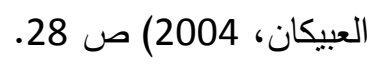

(2) Richard W. Sears, et al : Consultation Skills for Mental Health Professionals John Wiley \& Sons, INC, Canada, 2006, P.246. 
ج- أسلوب نظرية المباريات : يتضمن نموذجًا رياضيًّا كميًّا يرتبط بالصراع الأزموي الذي يقوم

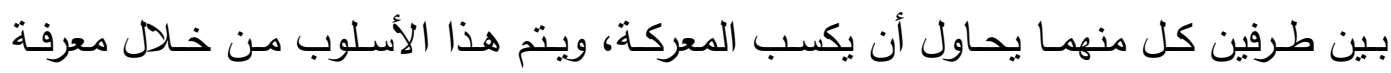

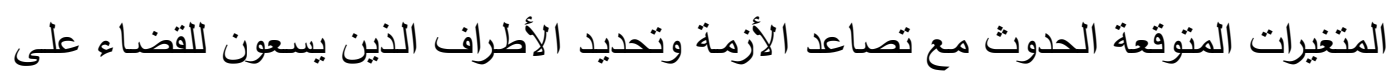

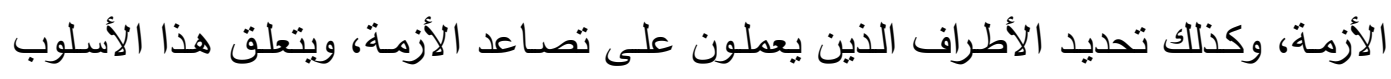

$$
\text { بصنع القرارات في مواقف وظروف المنافية }
$$

الملامح الرئيسة للتعليم واتخاذ القرار بوزارة التعليم التعافيم بالمملكة العربية السعودية

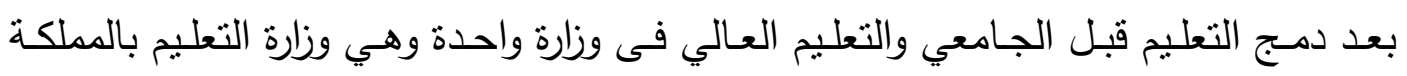
العربية السعودية التى اصبحت تهدف إلى إعداد جيل مؤمن قوي متزن عامل نافع لنفسه ووطنه

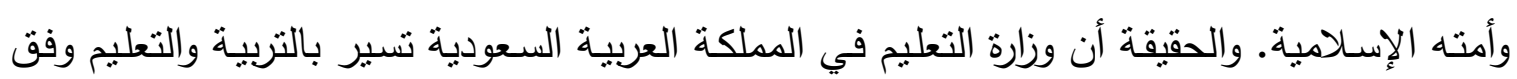
هذه الأسس ، وتتخذها مرجعاً دائماً لها.

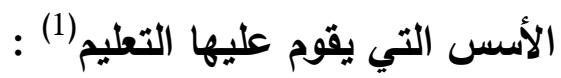

(1) الإيمان باله رباً ، وبالإسلام ديناً ، وبمحد صلى الهيله اله عليه وسلم نبياً ورسولاً .

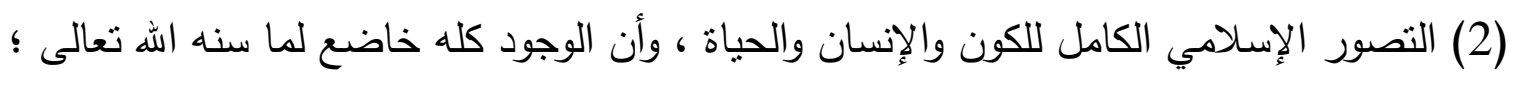
ليقوم كل مخلوق بوظيفته دون خلل أو اضطراب. (3) الحياة الدنيا مرحلة إنتاج وعمل، يستثمر فيها المسلم طاقاته عن إيمان وهدى للحياة الأبدية الخالدة في الدار الآخرة ، فاليوم عمل ولا حساب ، وغداً حساب ولا عمل. (4) الرسالة المحمدية هي المنهج الأقوم للحياة الفاضلة، التي تحقق السعادة لبني الإنسان ، وتتقذ وعال

$$
\text { البثرية مما نزرد فيه من فساد وشقاء . البهاء }
$$

(5) المثل العليا التي جاء بها الإسلام لقيام حضارة إنسانية رشيدة بناءة تهتدي برسالة محمد صلى الله عليه وسلم لتحقيق العزة في الدنيا ، والسعادة في الدار الآخرة. (6) الإيمان بالكرامة الإنسانية التي قررها القرآن الكريم ، وأناط بها القيام بأمانة الله في الأرض، قال الهال

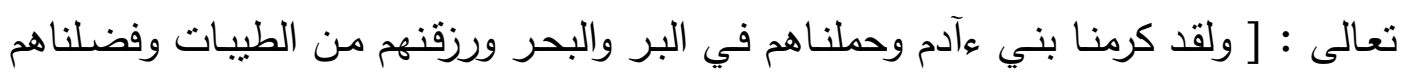
على كثير ممن خلقنا تفضيلاً ]. (7) فرص النمو مهيأة أمام الطالب للمساهمة في تتمية المجتمع الذي يعيش فيه، ومن ثم الإفادة من هذه التتمية التي شارك فيها. 


\section{الجمعية المصرية للقر اعة و المعرفة عضو الجمعية الدولية للمعرفة}

(8) تقرير حق الفتاة في التعليم بما يلائم فطرتها ، ويعدها لمهمتها في الحياة ، على أن يتم هذا بحشمة ووقار ، وفي ضوء شريعة الإسلام؛ فإن النساء شقائق الرجال.

(9) طلب العلم فرض على كل فرد بحكم الإسلام ، ونشره وتيسيره في المراحل المختلفة واجب على الدولة بقدر وسعها وإمكانياتها .

(10) العلوم الدينية أساسية في جميع سنوات التعليم الابتدائي والمتوسط والثانوي بفروعه، والثقافة الإسلامية مادة أساسية في جميع سنوات التعليم العالي.

(11) توجيه العلوم بمختلف أنواعها وموادها - منهجاً وتأليفاً وتدريساً - وجهة إسلامية في معالجة قضاياها والحكم على نظرياتها وطرق استثمارها ، حتى تكون منبنقة من الإسـام، متتاسقة

$$
\text { مع التفكير الإسلامي السديد. }
$$

(12) الاستفادة من جميع أنواع المعارف الإنسانية النافعة على ضوء الإسـلام ، للنهوض بالأمسة

ورفع مستوى حياتها ، فالحكمة ضالة المؤمن أنى وجدها ، فهو أولى الناس بها.

(13) التناسق المنسجم مـع العلم والمنهجيـة التطبيقيـة ( التقنية) باعتبارهما من أهم وسائل التنميـة الثقافية والاجتماعية والاقتصادية والصحية ؛ لرفع مستوى أمتتا وبلادنا ، والقيام بدورنا في التقدم الثقافي العالمي.

(14) ربط التربية والتعليم في جميع المراحل بخطة التتمية العامة للدولة.

التفاعل الواعي مع التطورات الحضارية العالمية في ميادين العلوم والثقافة والآداب ، بتتبعها لتهريا والمشاركة فيها، وتوجيهـا بما يعود على المجتمع والإنسانية بالخير والتقدم.

اولاً: الأهداف العامة للتعليم قبل الجامعي بالمملكة العربية السعودية (1): تتمية روح الولاء لشريعة الإسـام ، وذلك بالبراءة من كل نظام أو مبدأ يخالف هذه الثريعة

واستقامة الأعمال والتصرفات وفق أحكامها العامة الثاملة. تزويد الفرد بالأفكار والمشاعر والقدرات اللازمة لحمل رسالة الإسلام .

تحقيق الخلق القرآني في المسلم ، والتأكيد على الضوابط الخلقية لاستعمال المعرفة 》إنما بُعثت

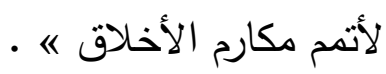




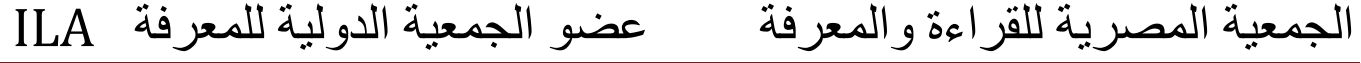

تربيـة المواطن المؤمن ليكون لبنـة صـالحة في بنـاء أُمتـه ، ويشـعر بمسؤوليته لخدمة بـلاده

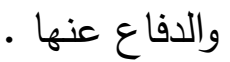

تزويد الطالب بالقدر المناسب من المعلومـات الثقافية ، والخبرات المختلفة التي تجعل منـه

• عضواً عاملاً في المجتمع

تتميـة إحسـاس الطـلاب بمشكلات المجتمع الثقافيـة والاقتصـادية والاجتماعيـة ، وإعدادهم

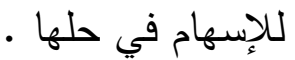

تأكيد كرامة الفرد وتوفير الفرص المناسبة لتتمية قدراته ؛ حتى يستطيع المساهمة في نهضـة

الأمة . - الم

دراسة ما في هذا الكون الفسيح من عظيم الخلق، وعجيب الصنع، واكتشـاف ما ينطوي عليه من أسرار قدرة الخالق للاستفادة منها وتسخيرها لرفع كيان الإسلام وإعزاز أمته. بيـان الانسـام التام بين العلم والدين في شـريعة الإسـلام، فإن الإسـلام ديـن ودنيا، والفكر الإسلامي يفي بمطالب الحياة البشرية في أرقى صورها في كل عصر •

تكوين الفكر الإسلامي المنهي لدى الأفراد ، ليصدروا عن تصور إسلامي موحد فيما يتعلق بالكون والإنسان والحياة ، وما يتفرع عنها من تفصيلات.

(11)تتجيع وتتمية روح البحث والتفكير العلميين ، وتقوية القدرة على المشاهدة والتأمل ، وتبصير

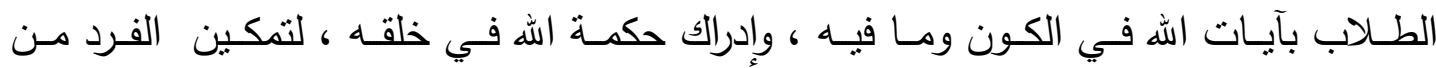
الاضطلاع بدوره الفعال في بناء الحياة الاجتماعية وتوجيهـا توجيهاً سليماً . (12) الاهتمام بالإنجازات العالمية في ميادين العلوم والآداب والفنون المباحة ، وإظهار أن تقدم العلوم ثمرة لجهود الإنسانية عامة ، وإبراز ما أسهم به أعلام الإسلام في هذا المجال، وتعريف الناشئة برجالات الفكر الإسـلامي ، وتبيان نواحي الابتكار في آرائهم وأعمالهم في مختلف الميادين

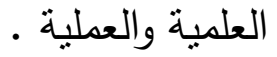

(13)تتمية الفكر الرياضي والمهارات الحسابية ، والتدريب على استعمال لغة الأرقام والإفادة منها في

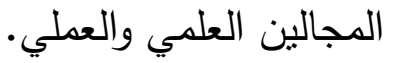
(14)تتمية مهارات القراءة ، وعادة المطالعة سعياً وراء زيادة المعارف. (15) اكتساب القدرة على التعبير الصحيح في التخاطب والتحدث والكتابة بلغة سليمة وتفكير منظم . 
(16) تتميـة القدرة اللغويـة بشتى الوسـائل التي تغذي اللغـة العربيـة ، وتنساعد على تذوقها وإدراك نواحي الجمال فيها أسلوباً وفكرة .

(17) تدريس التاريخ دراسـة منهجيـة مـع استخلاص العبرة منـهـ ، وبيـان وجهة نظـر الإسـلام فيما يتعـارض معـه ، وإبراز المواقف الخالدة في تـاريخ الإسـام وحضـارة أمتـه، حتى تكون قدوة لأجيالنا المسلمة ، تولا لايها الثقة والإيجابية .

تبصير الطلاب بما لوطنهم من أمجاد إسلامية تليدة ، وحضارة عالمية إنسانية عريقة ، ومزايا جغرافية وطبيعية واقتصادية ، وبما لمكانته من أهمية بين أمم الدنيا. (19) فهم البيئة بأنواعها المختلفة ، وتوسيع آفاق الطلاب بالتعرف على مختلف أقطار العالم، وما

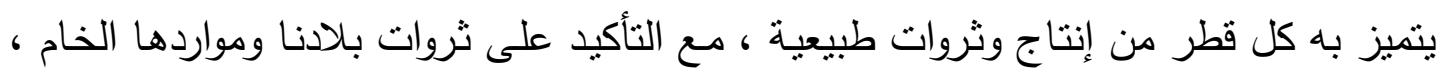
ومركزها الجغرافي ، والاقتصادي ، ودورها السياسي القيادي في الحفاظ على الإسلام ، والقيام بواجب دعوته ، وإظهار مكانة العالم الإسلامي ، والعمل على ترابط أمته.

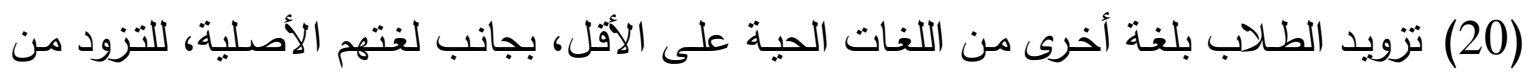
العلوم والمعارف والفنون والابتكارات النافعة ، والعمل على نقل علومنا ومعارفنا إلى المجتمعات الأخرى إسهاماً في نشر الإسلام وخدمة الإنسانية .

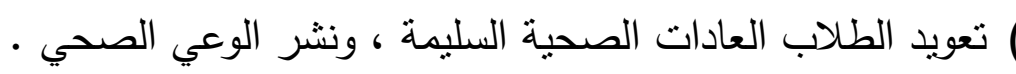

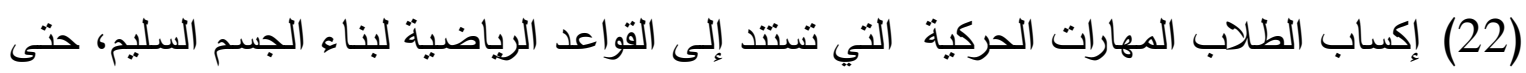

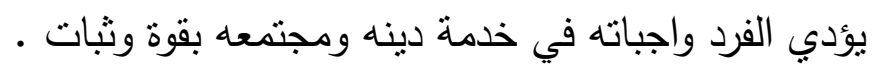

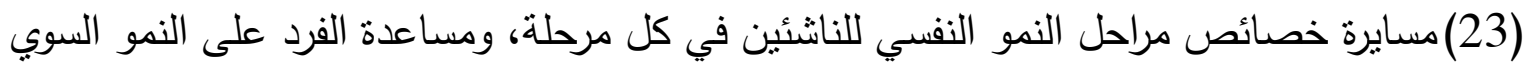

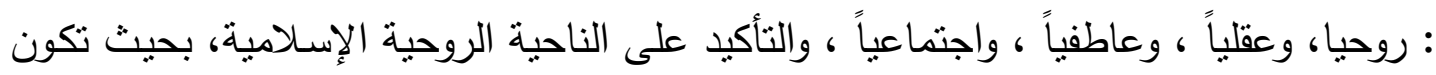

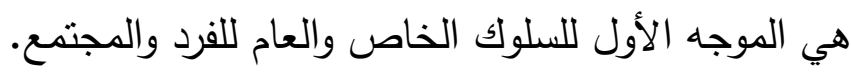
(24) التعرف على الفروق الفردية بين الطلاب توطئة لحسن توجيهـه ، ومساعدتهم على النمو وفق قدراتهم واستعداداتهم وميولهم • (25) العناية بالمتأخرين دراسياً ، والعمل على إنى إزالة ما يمكن إزالته من أسباب هذا التأخر، ووضع

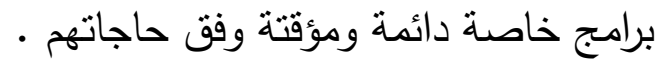

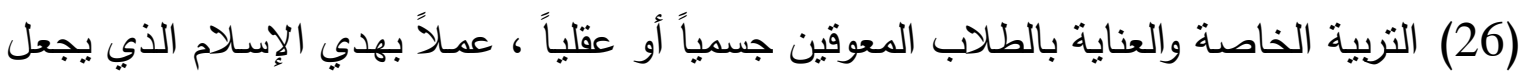
التعليم حقاً مشاعاً بين جميع أبناء الأمة . 
(27) الاهتمام باكتثاف الموهوبين ورعايتهم ، وإتاحة الإمكانيات والفرص المختلفة لنمو مواهبهم في

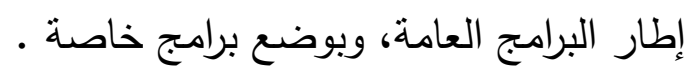

(28) تدريب الطاقة البشرية اللازمة ، وتتويع التعليم مع الاهنمام الخاص بله بالتعليم المهني.

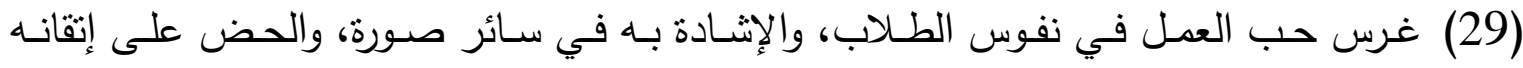

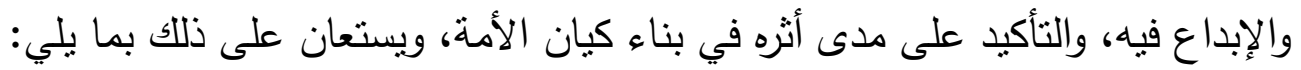

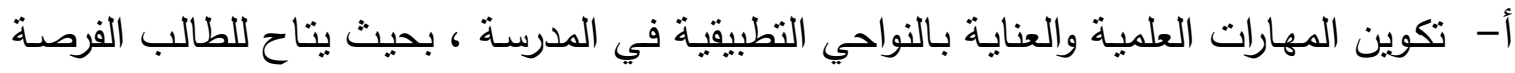

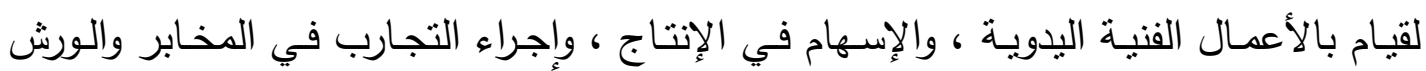

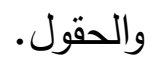

ب- دراسـة الأسس العلمية التي تقوم عليها الأعمال المختلفة ، حتى يرتفع المستوى الآلي للإنتاج إلى مستوى النهوض والابتكار •

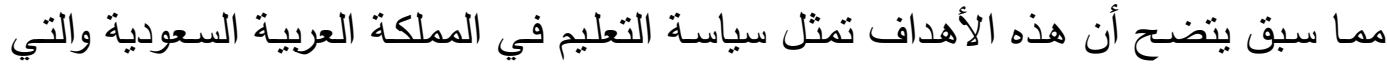
بُنبيت على الثريعة الإسلامية ، فجاءت متفقة مع القرآن الكريم ومع هدي المصطفى لفئ ع، وهي أيضاً تمثل سياسة الدولة في التعليم وهو عبارة عن الخط الذي رسمته لأبنائها الطلاب في كافة فئة المراحل

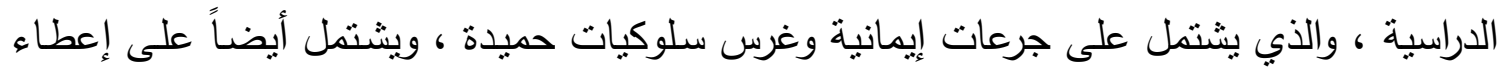

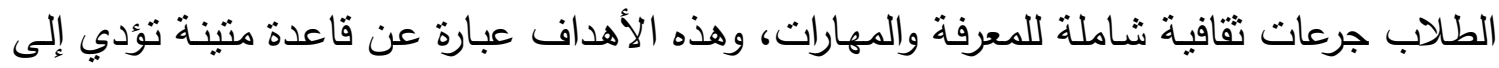

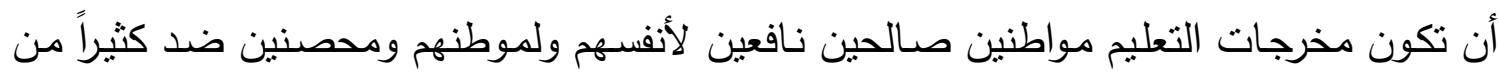
أمراض العصر الفكرية. ويمكن القول إن هذه الأهداف أهداف قويـة مستمدة من سياسة التعليم في المملكة العربية

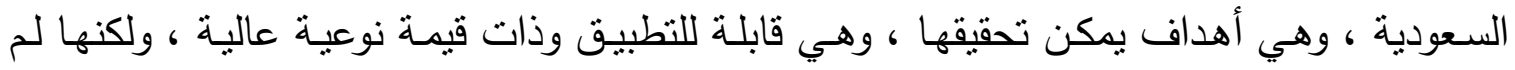

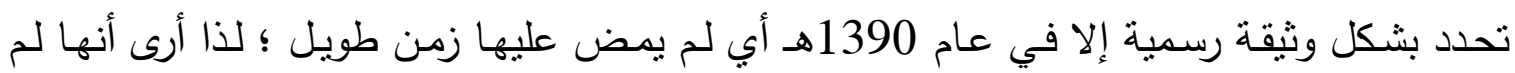

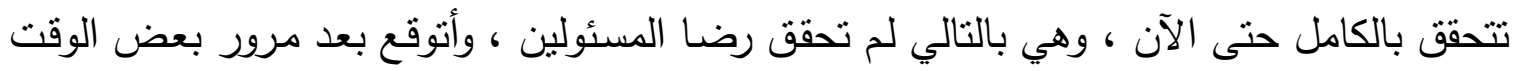

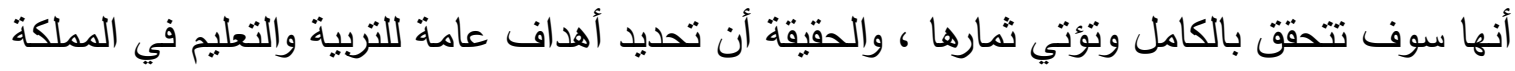
العربية السعودية تساعد على تطبيق إدارة الجودة الثاملة في إدارات التربية والتعليم.

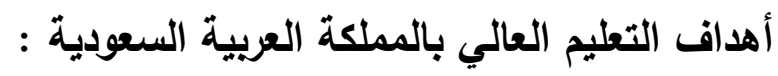
حددت وثثقة سياسة التعليم في المملكة أهداف التعليم العالي وفق ما يلي (2): -تتمية عقيدة الولاء لله سبحانه وتعالي ، وتزويد الطالب بالنقافة الإسلامية.

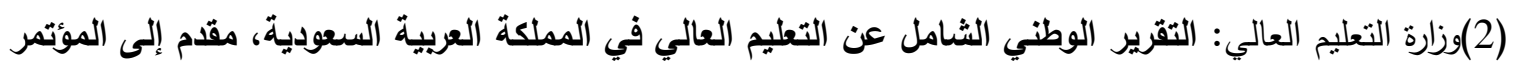
الإسلامي الأول لوزراء التعليم العالي والبحث العلمي ، الرياض، الفترة من 15-18 أكتوبر ، 2000 ، ص 4. 
- إعداد مواطنين أكفاء مؤهلين علمياً وفكرياً تأهيلاً عالياً في ضوء العقيدة ومبادئ الإسلام . -الإرتقاء بجميع مجالات الفكر والإنتاج العلمي من آداب وعلوم ، ومتابعة التقام العلمي الملائم

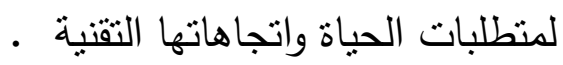
- ترجمة العلوم وفنون المعرفة النافعة إلى لغة القرآن الكريم •

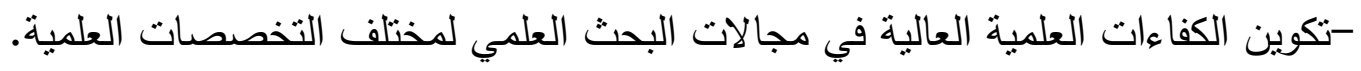

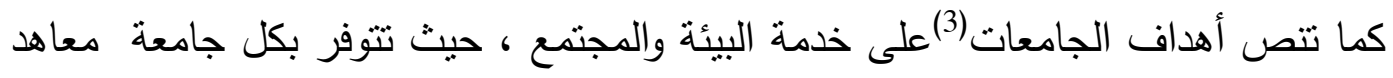

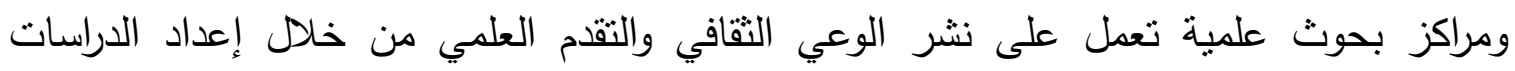

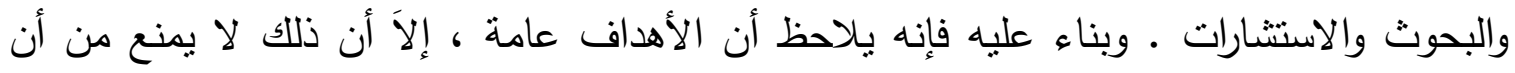

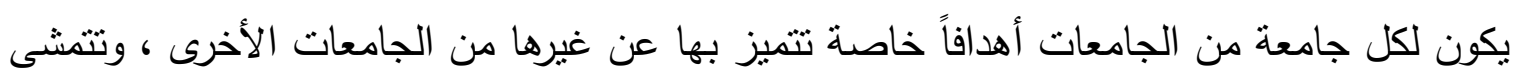

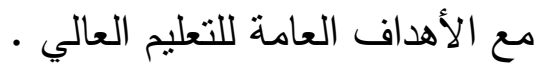

ونظرا لحداثة الجامعات في المناطق الأخرى خلال الخمس سنوات الأخيرة للعام الهجري يتم تتاول الجامعات السبع الأساسية وهي : جامعة الملك سعود ، والجامعة الإسلامية ، وجامعة الملك فهر فئل

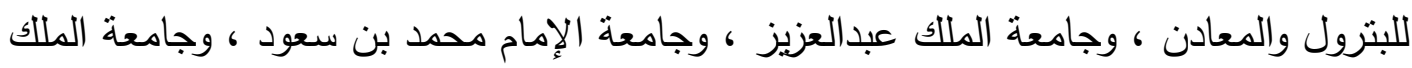

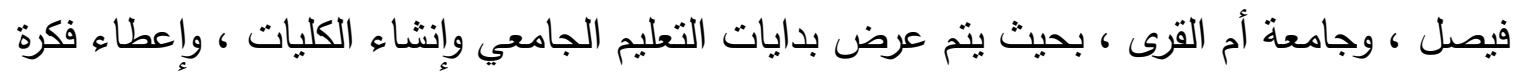
موجزة عن كل جامعة

• • السلطات المسئولة عن صنع القرار واتخاذ القرار التعليمي وتنفيذه.

تتتوع السلطات المخولة أو المسئولة عن صنع القرار واتخاذ القرار التعليمي وتتفيذه فيما يلي: 1 1

ويمثل رأس الهرم العام في الدولة وهو بذللك يمثل السلطة العليا والمرجع الأعلى في كافة

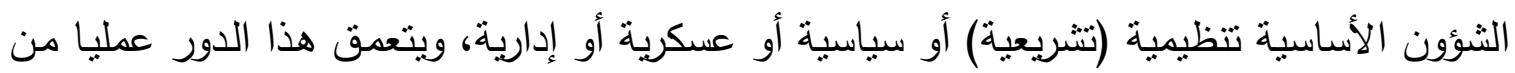

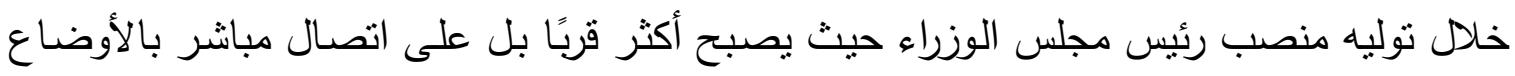
والمشاكل المختلفة، ويكون له القول الفصل في معظم القرارات والسياسات التي يصدرها المجلس. فقد نص نظام مجلس الوزراء الصادر برقم أ/13 في 1414/3/3هـ على ملى ما يأني:

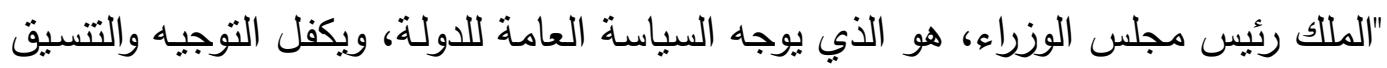

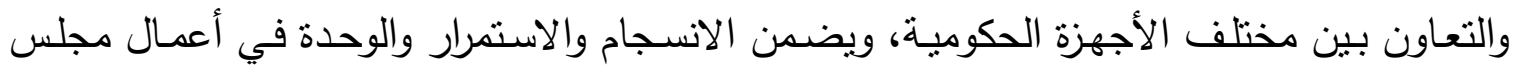

(3)سليمان جبر : الجامعة وخدمة المجتمع ، دراسة لدور كلية التربية ، جامعة الملك سعود في خدمة المجتمع ، التربية المعاصرة ، 1993 ، ص 116 ـ لجائرة 
الوزراء، ولـه الإثـراف على مجلس الوزراء والـوزارات والأجهزة الحكوميـة، وهو الذي يراقب تتفيذ الأنظمة واللوائح والقرارات". (1)

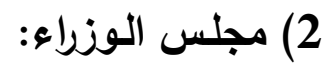

يعتبر مجلس الوزراء المرجع الأساسي المنوط بـه صنع القرارات واتخاذها، من خلاه لجانه المتعددة وما يرفع إليه من القطاعات المختصة.

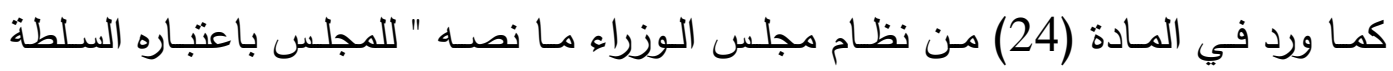
التتفيذية المباشرة الهيمنة التامة على شؤون التتفيذ والإدارة ويدخل في اختصاصاته الأمور الآتية: مراقبة تتفيذ الأنظمة واللوائح والقرارات. إحداث وترتيب المصالح العامة...الخ.

من هنا فإن لمجلس الوزراء بحكم سلطته العليا نقض بعض القرارات التي تتخذها الوزارات حتى ولو

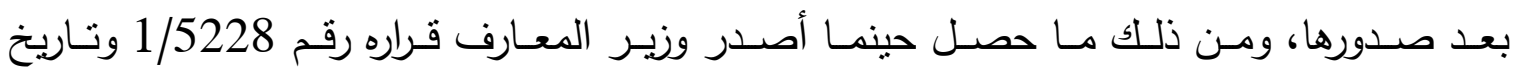
1422/11/23هـ الموافـق 2001م، بإدخـال مـادة اللغــة الإنجليزيـة للصـفوف العليـا مـن المرحلـة الابتدائية (2)، وبدأت الوزارة بالتتفيذ الفعلي واستقدمت المعلمين من خارج المملكة، بل وصل الحد إلى لى تأليف المقررات الدراسية وتمت طباعتها التجريبية، ومع ذلك أصدر مجلس الوزراء قرارا ينقض القرار

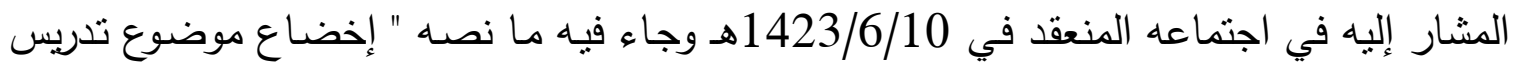
اللغة الإنجليزية في المرحلة العليا من المرحلة الابتدائية لمزيد من الدراسة المتأنية والمتعدقة من قبل فيل ماهد اللجنة العليا لسياسة التعليم". ومن موقع صـلاحية مجلس الوزراء الرقابية، فإن من اختصاصـاته إنشـاء لجان تتحرى عن سير أعمال الوزارات والأجهزة الحكومية الأخرى، أو عن قضية معينة وترفع هذه اللجان نتائج تحرياتها

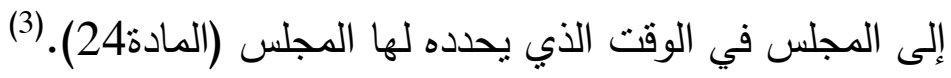
كما أن المجلس يتخذ جميع القرارات الخاصـة بالأنظمـة واللوائح المنظمـة للعمل في وزارة

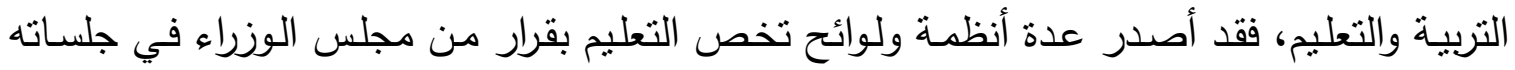
الاعتيادية مثل نظام تعليم الكبار الصادر بالمرسوم الملكي رقم 23/م وتاريخ 1392/6/9هـ ونظهام المدارس الأهلية الصـادر بقرار مجلس الوزراء رقم 1006 وتاريخ 1395/8/13هـ، ولائحسة تقويم الطالب بقرار مجلس الوزراء رقم 836/م وتاريخ 1419/8/6هـ، ولائحـة المدارس الأجنبيـة بقرار

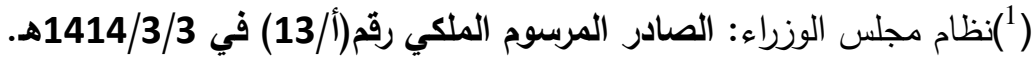

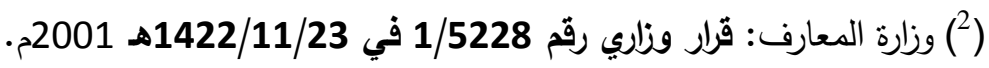

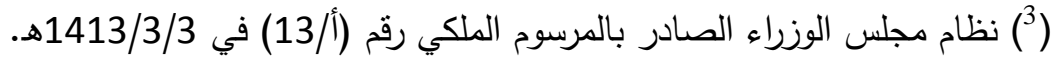


مجلس الوزراء رقم 26 في 1418/2/4هـ ولائحة البحوث والدراسات التربوية والتعليمية في مراحل التعليم العـام بقـرار مجلس الـوزراء رقم 63 وتـاريخ 1417/5/11هـ، وغيرهـا كثبـر مـن اللـوائح

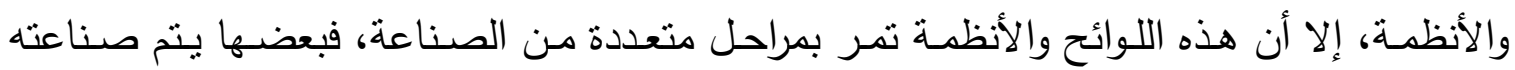
الأولية في الوزارة، ثم يدرس في مجلس الثورى الذى يحيله بعد دراسته إلى مجلس الوزراء لإصدار

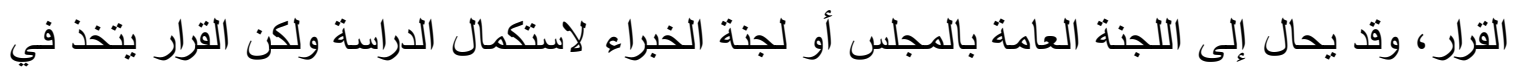
نهاية المطاف في مجلس الوزراء.

ويصدر المجلس سنويا- تقريبا- قرارًا بتحديد موعد بدء الدراسة، وبدء الاختبارات الفصلية،

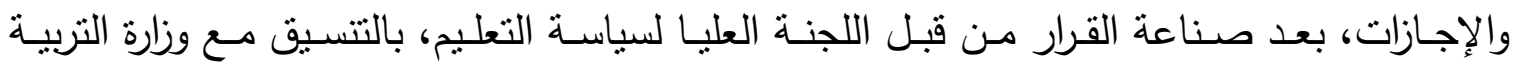
والتعليم.

3) مجلس الثورى: تم تشكيل هذا المجلس بشكل رسميَّا برئاسة ما كان يسمى النائب العام في الحكومة في ذلك

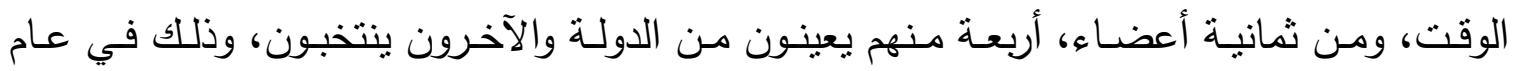

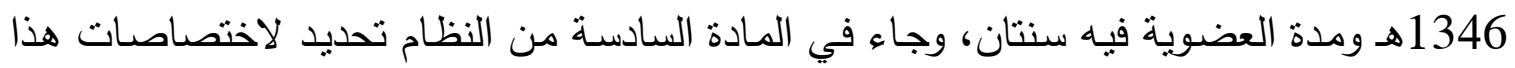
المجلس منها صنع و إصدار القرارات واستخدام الأجانب. " وبهذا تكون اختصاصـات مجلس الثورى كما ورد في المادة (15) من نظام مجلس الثورى الثهان إبداء الرأي في السياسـات العامـة للدولـة التي تحسال إليهـ مـ رئيس مجلس الوزراء ولـه على وجـه

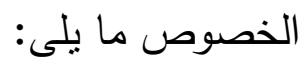
• مناقثنة الخطة العامة للتتمية الاقتصادية والاجتماعية وإبداء الرأي نحوها. • دراسة الأنظمة واللوائح والمعاهدات والاتفاقيات الدولية والامنيازات، واقتراح ما يراه بشأنها.

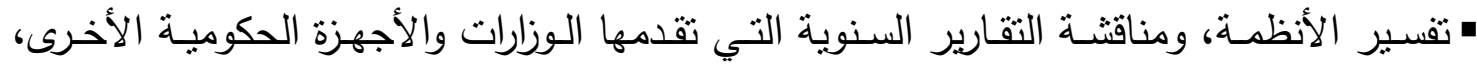

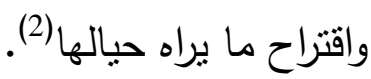

(1) المملكة العربية السعودية :رئاسة مجلس الوزراء ،مضبطة مجلس الوزراء بشأن نص القرار الذب يظهر مسار

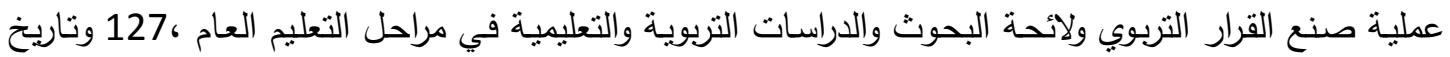


وتقوم وزارة التربية والتعليم سنويا بإعداد تقرير عام عن إنجازاتها وأعمالها كغيرها من قطاعـات الدولـة يعـرض وينـاقش في مجلس الثـورى في جلســة يحضـرها وزيـر التربيـة والتعليم ومعاونيه، ويتم المصادقة على التقرير أو إعادته لتعديل أو توضيح ما يراه المجلس.

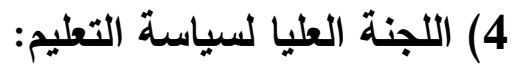
ويقصد بالسياسة التعليمية، تلك الخطوط العامة التي تقوم عليها عملية التربية والتعليم في المملكة العربية السعودية، والتي تعتبر جزءا من السياسة العامة للدولة التي عليها تسير، وقد صدرت وثثقة السياسـة التعليميـة في ثلاثمائة وست وثثلاثين مـادة، تشمل الأسس العامـة التي يقوم عليها التعليم، وغاياته وأهدافه العامة، وأهداف مراحل التعليم المختلفة، والخطط والمناهج والوسائل التربية، والتنظيم الإداري، وتمويل التعليم والجهات المسئولة عنه وصدرت هذه الوثيقة بقرار مجلس الوزراء

$$
\text { رأهم اختصاصاتها ما يلى: } 779 \text { في 1389/9/17هـ. }
$$

يعهد إلى هذه اللجنة أمر وضع سياسة شاملة للتعليم في المملكة بصفة عامة بعد دراستها وإعداد مشروع متكامل لذلك. يعرض على اللجنة اجتماعاتها كلما وجدت موضوعات للبحث. يعرض على اللجنة سائر الثؤون التعليمية بنظام التعليم والخطط الدراسية والمناهج وشؤونان

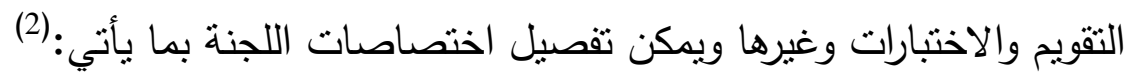
رسم السياسات التعليمية العامة للدولة بمختلف جهاتها ومؤسساتها. هإرار الخطط التعليمية وأنظمتها العامة. إقرار مشروعات الخطط التربوية الطويلة والمتوسطة والصغيرة في ضوء احتباجات خطط التتمية الاقتصادية والاجتماعية بهدف توفير الخدمات التعليمية الأساسية.

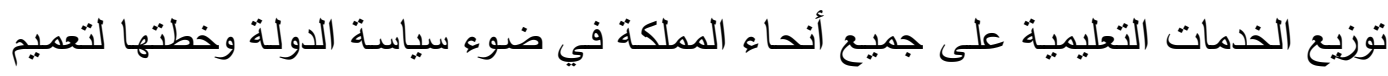
التعليم على جميع المواطنين. التتسيق بين مراحل التعليم المختلفة والقطاعات التعليمية المتتوعة للحصول على أكبر عائد من التعليم لأبناء المملكة.

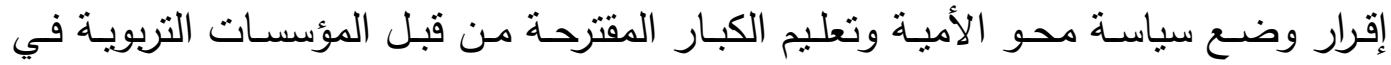
المملكة.

(1) سليمان الحقيل: سياسية التعليم في المملكة العربية السعودية، أسسها وأهدافها (الرياض، مطابع الفرزدق،

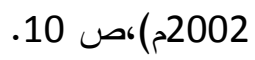
(2) سليمان الحقيل: سياسية التعليم في الملكة العربية السعودية، أسسها وأهدافها المرجع سابق، ص12. 


$$
\text { • اتخاذ القرارات التي توجه مسيرة التعليم في المملكة. }
$$

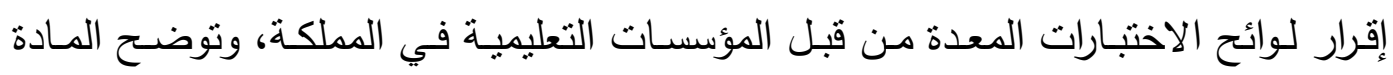

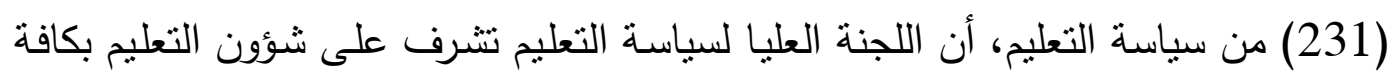
أنواعه ومراحله وسائر وسائل التثقيف والتوجيه في المملكة العربية السعودية وتعتمد نظم

وأوجه اختصاصه ومسئولياته وطرق عمله. (1)

وبناء على قرار مجلس الوزراء رقم 231 في 1385/4/8هـ أمكن إسناد مهام وكالة الوزارة

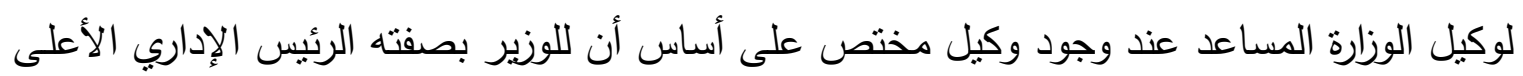

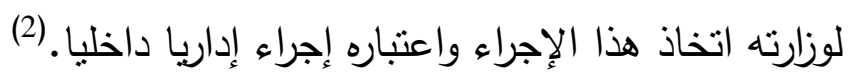

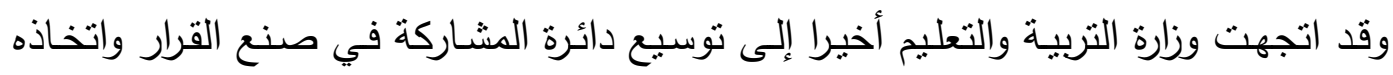

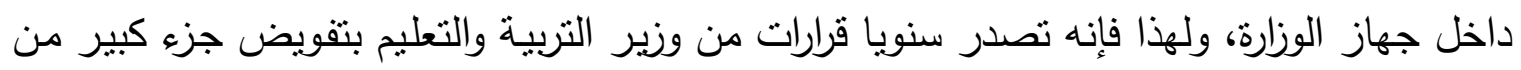
صلاحياته وسلطاته، إلى مسئولي الوزارة .

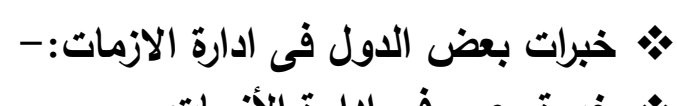

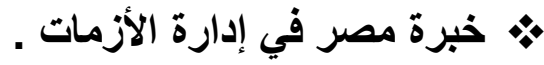

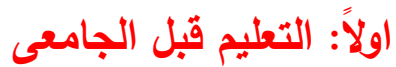

السلم التعليمي في مصر؛ بشتمل السلم التعليمي فى مصر على (12 )اثتتي عشر عاماً دراسياً

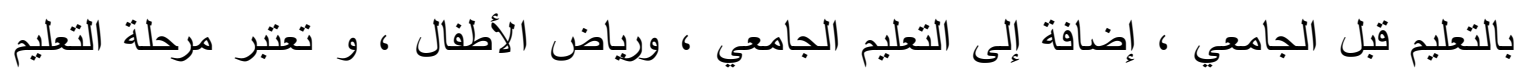

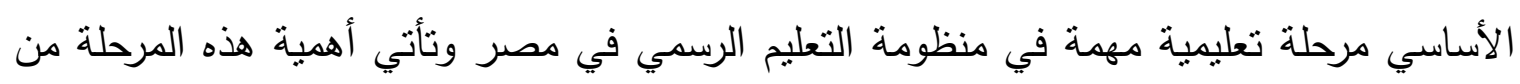

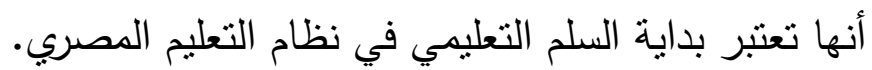

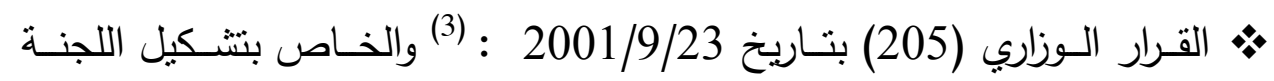
الرئيسة لإدارة الأزمات والأحداث الطارئة، حيث نص على لتارئ تشكل اللجنة الرئيسة لإدارة الأزمات والأحداث الطارئة بوزارة التربية والتعليم والجهات التابعة لها:

(1) وزارة المعارف: وثيقة سياسة النعليم في المملكة العربية السعودية،( الرياض، دار البيان، 1995)، ص45.

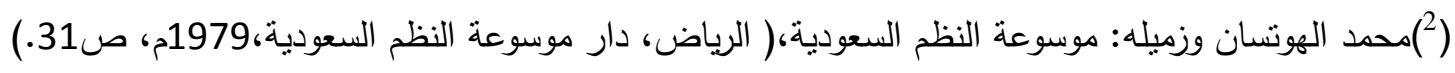

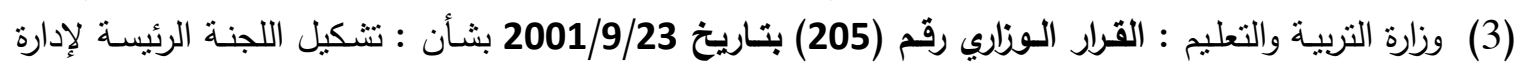
الأزمات والأحداث الطارئة (الوزارة/المديرية). 
الجمعية المصرية للقر اءة و المعرفة عضو الجمعية الدولية للمعرفة

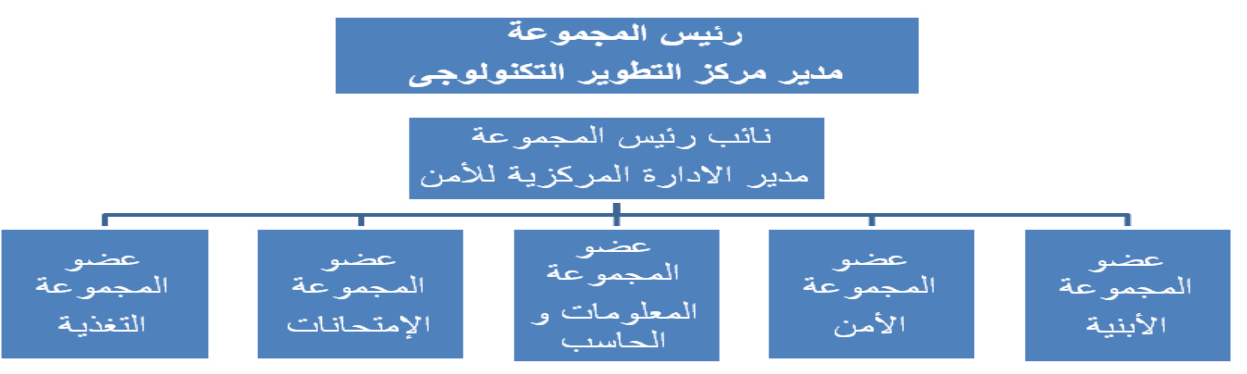

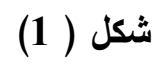

الهيكل التنظيمي للجنة الرئيسية لإدارة الأزمات بوزارة التربية والتعليم.

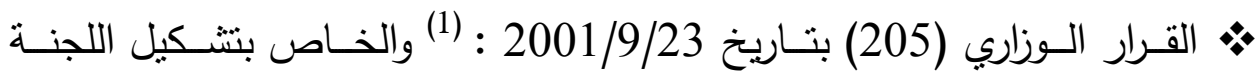

الرئيسة لإدارة الأزمات والأحداث الطارئة علي مستوي ديوان لئران عام مديرية التربية

والتعليم.

والثكل التالي يوضح الهيكل التنظيمي لمجموعة إدارة الأزمات والأحداث الطارئة بديوان عام

مديرية التربية والتعليم كما يلي :

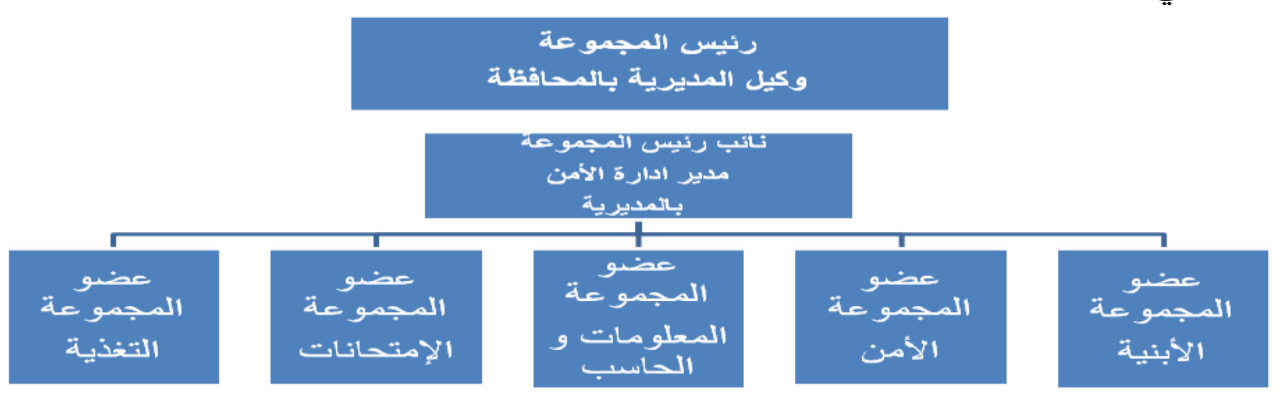

شكل ( 2 )

الهيكل التنظيمي لمجموعة إدارة الأزمات والأحداث الطارئة بديوان عام مديريات التربية والتعليم بالمحافظات

• خ أزمة الدروس الخصوصية :

تم تطبيق نظام المجموعات الدراسية للتقوية كبديل للاروس الخصوصية :

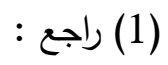

- وزارة التربية والتعليم : القرار الوزاري (205) بتاريخ 2001/9/23، بثأن: تثكيل لجنة رئيسة لإدارة الأزمات

$$
\text { والأحداث الطارئة (الوزارة / الديرية) ، (المادة الرابعة). }
$$

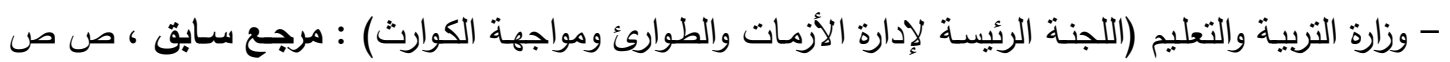
$.10-8$ 
حيث أخذت وزارة التعليم تروج لمجموعات التقوية بالمدارس وأصدرت القرارات المنظمة لها ،

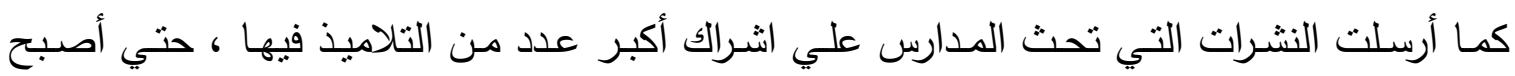
طابور الصباح في المدارس منبراً وبوقاً للاعاية لهذه المجموعات سواء كان ذلك بالترغيب أو التهديد غير المباشر • وأصبح مديرو المدارس يتباهون في عملهم أمام لجان المتابعة بإجمالي أعداد التلاميذ المشتركين في هذه المجموعات. (1) •• صدر القرار الوزاري رقم (592) بتاريخ 1998/11/17 بشأن حظر الدروس الخصوصية والذي ينص على كل هيئات الإشـراف والتدريس في جميع مدارس مراحل التعليم قبل الجامعي - بما في ذللك مدارس التعليم الخاص أو العاملين بالمديريات والإدارات التعليمية

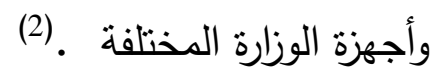

* القرار الوزاري رقم (624) بتاريخ 1998/12/10 الخاص بـإغلاق مراكز التقويـة الخارجيـة

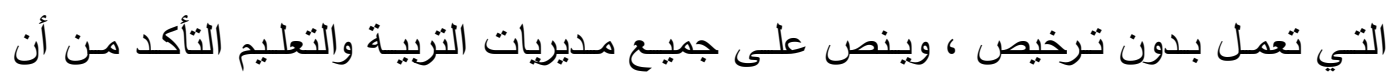

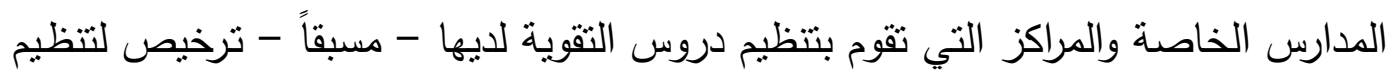

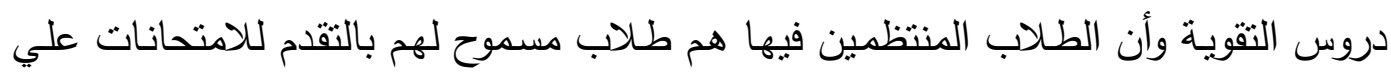
نظام المنازل فقط.

أزمات التعليم المتعلقة بالمناهج الاراسية ونظم الامتحانات .

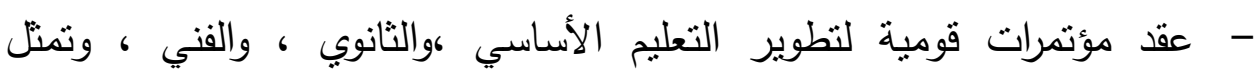

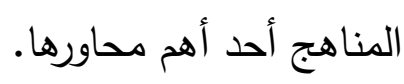
-

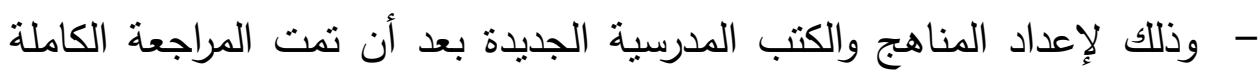

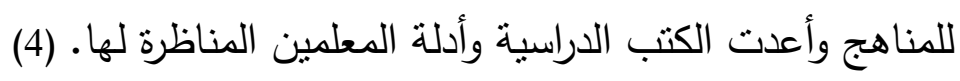
- - التعامل مع أزمة "العنف في المدارس.

(1) ناجي شنودة نخلة : "مجموعات النقوية الدراسية" ، مجموعات التقويـة كبديل للاروس الخصوصية ، دراسـة

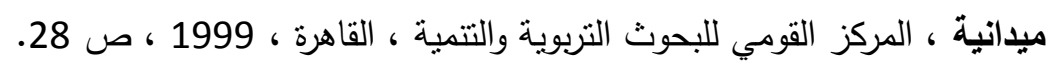

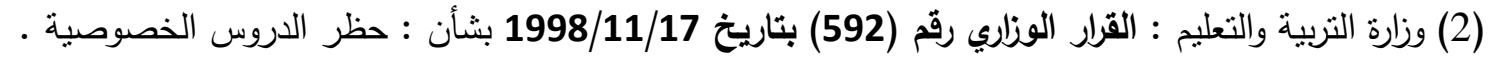

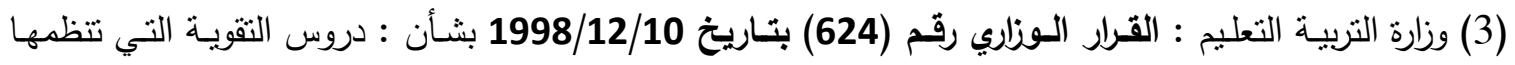

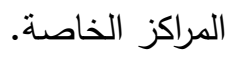
(4) وزارة التربية والتعليم : مبارك والتعليم ، المشروع القومي لتطوير التعليم ، قطاع الكتب ، 2002 . 
صدور القرار الوزاري رقم (591) بتاريخ 1998/11/17 "لمنع العنف في المدارس" : يؤكد

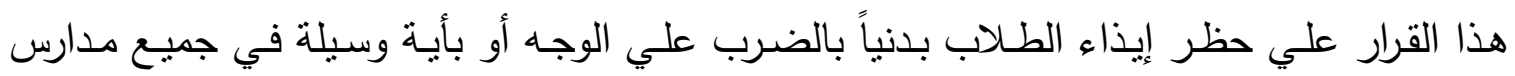
مراحل التعليم قبل الجامعي بما فيها مدارس التعليم الخاص ، ويقتصر توجيه الطلاب ومنابعة أدائهج

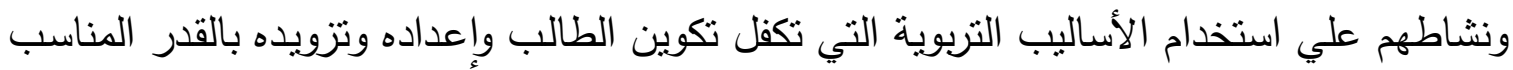
من القيم ، ويعاقب بالفصل كل طالب يثبت اعتداؤه علي أحد من المعلمين أو هيئات الإثراف

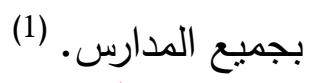

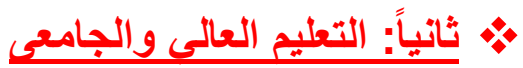

وحدة محمد رشاد الحملاوى لبحوث الأزمات بكلية التجارة - جامعة عين شمس لئمس

تعريف بالوحدة:

تأسست الوحدة في عام 1995م، وهى ذات طابع خاص لا تهدف إلى الربح ومقرها الرئيسي كلية التجارة جامعة عين شمس، وهى الوحدة الأولى من نوعها في مصر والعالم العربي. في مجال

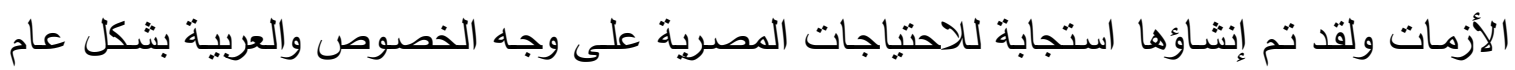

التي لمسها المسئولون بالوحدة.

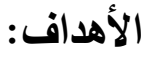

\section{تهذف الوحدة إلى: (1)}

1- إثراء البحث فى مجال الدراسات والأبحاث العلمية المتعلقة بإدارة الأزمات والوقاية منها.

$$
\text { 2- تحسين خطط إدارة الأزمات والكوارث. }
$$

3- وترشيد قرارات الأجهزة المعنية في الحكومة والقطاع الخاص، والمنظمات التي لا تهدف

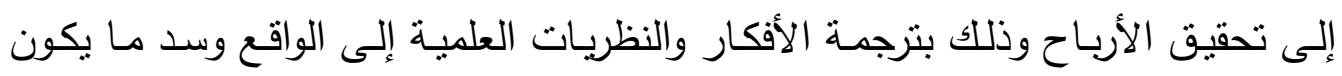

$$
\text { بينهما من فجوات. }
$$

4- تقوم الوحدة بتتمية الرصيد المعرفي في مجال إدارة الأزمات والكوارث وذلك من خلد برامج التدريب والتعليم وتبادل الخبرات بين المشتغلين في مختلف القطاعات وذللك على الى الى

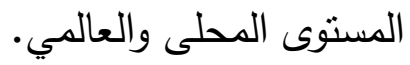

(1) وزارة التربية والتعليم : القزار الوزاري رقم (591) بتاريخ 1998/11/17 بشأن:منع العنف في المدارس.

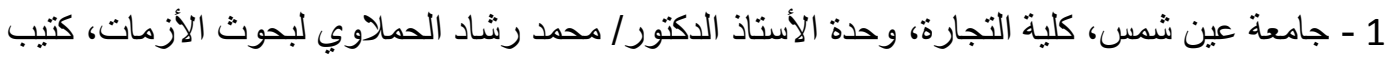




\section{الجمعية المصرية للقراءة والمعرفة عضو الجمعية الدولية للمعرفة}

5- تتمية العلاقات بين الوحدة وغيرها من الوحدات والمركز العاملة فى نفس المجال سوائ داخلياً أو خارجياً والحفاظ على تلأك العلاقات. 6- الارتقاء بمهارات وضع الخطط وإستراتيجيات إدارة الأزمات.

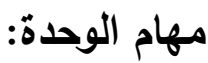

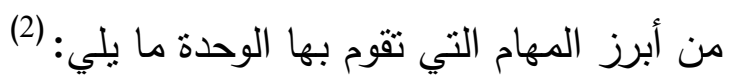
1- تصميم وتتفيذ البرامج التدريبية المتتوعة فى مجال إدارة الأزمات. 2- تصميم وتتفيذ برنامج الثهادات المهنية لإدارة الأزمات. 3- تتظيم وعقد ندوات ومؤتمرات فى أحد الموضوعات المتعلقة بمجال إدارة الأزمات. 4- تصميم خطط لإدارة الأزمات والكوارث.

5- إصدار تقارير حول الأزمات والكوارث فى مصر وكيف يمكن مواجتها؟ 6- تقديم استشارات واستفسارات للجهات الداخلية (داخل الجامعة) والخارجية (خارج الجامعة).

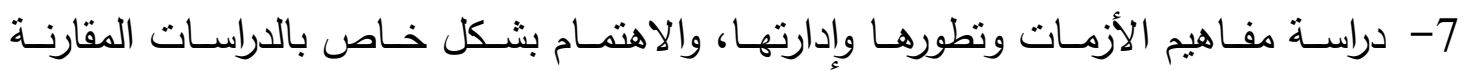
لـأزمات.

8- وضع تصورات لردود الأفعال فى كل الأزمات المكن مواجهنها. 9- الدراسة الدقيقة لبعض العوامل المؤثرة فى إدارة الأزمات.

10-دراسـة الأزمـات الموجـودة فى القطر المصـرى، واستتباط أسباب الوقايـة وأسـاليب التعامل فئل

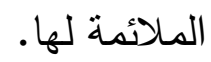

11-تقديم المساعدة والمعونة للباحثين والمتخصصين فى مجال إدارة الأزمات.

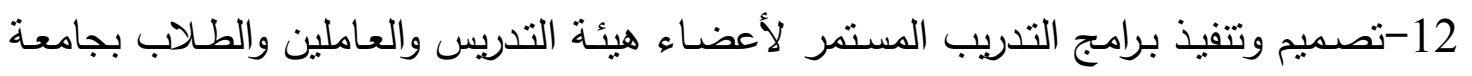
عين شمس. 13-تصميم سيناريوهات لإدارة الأزمات المحتمل وقوعها.

•للوحدة مجلس إدارة برئاسة عميد كلية التجارة، جامعة عين شمس، وعضوية بعض الخبراء الباحثين بالكلية، حيث يقوم هذا المجلس بوضع سياسة عمل المركز والإتراف على بلى تتفيذها. 
•للوحدة مدير يعينه مجلس الإدارة ويعاونه مجموعة من الباحثين من داخل وخارج الكلية،

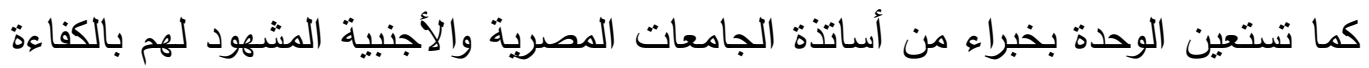
فى مجال إدارة الأزمات والكوارث، بالإضافة إلى العديد من الخبراء ذوى الخبرة العلمية المميزة مما يضاعف من فاعلية برامج عمل الوحدة.

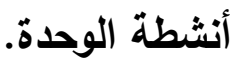
1 - التدريب:

التدريب من الأنشطة الهامة التى تحظى باهتمام كبير من وحدة بحوث الأزمات وذللك لتلبية

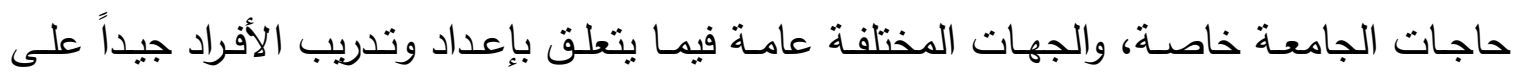
أساليب التعامل مع الأزمات ووسائل الوقاية منها

وتنقسم البرامج التتريبية للوحدة إلى التى (1) البرامج المركزية منل أنل

• مورة أساسية فى إدارة الأزمات والكوارث.

هورة متقدمة فى إدارة الأزمات والكوارث.

هور نظم المعلومات ودعم القرارات فى إدارة الأزمات والكوارث.

إدارة المفاوضات فى ظروف الأزمات.

$$
\text { • ثقييم مدى الاستعداد لمواجهة الأزمات والكوارث. }
$$

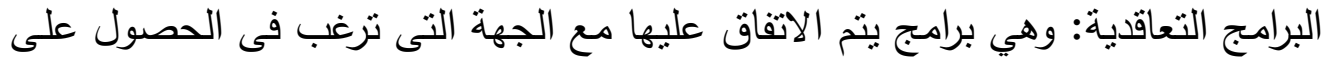

تللك البرامج فى المكان والزمان الذي تحدده وطبقا للمحتوى التدريبي الذي ترغبه.

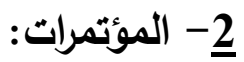

تنظم الوحدة مؤتمراً سنوياً في مجال إدارة الأزمات والكوارث الصناعية، التجارية ،

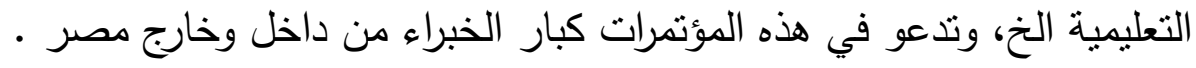

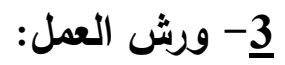

للوحدة اهتمام كبير في إعداد وتتظيم ورش عمل تتاول موضوعات محددة ويعلن عن هذه

الورش وأماكن انعقادها، ومن أبرز ورش العمل التى عقدتها الوحدة: (1)

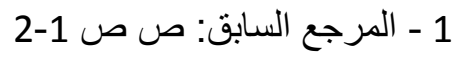

1 - جامعة عين شمس - كلية التجارة، وحدة أ.د/ الحملاوى لبحوث الأزمات، خطة البرامج و الورش التنريبية،

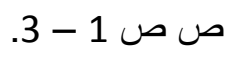

'2005 


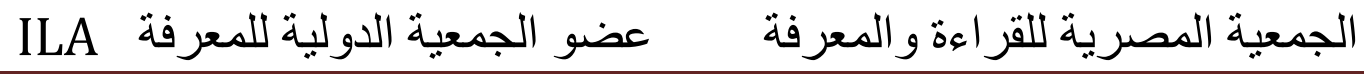

$$
\begin{aligned}
& \text { • كيف تتجح فى مواجهة أزمات الأمان الوظيفي والتعامل مع الصراعات؟ } \\
& \text { كيف نواجه ضنوط العمل والمواقف الصعبة؟ } \\
& \text { كيف تفكر بطريقة مبتكره فى مواجهة الأزمات؟ } \\
& \text { كيف تدير أزمة السيولة؟ ليطرئ }
\end{aligned}
$$

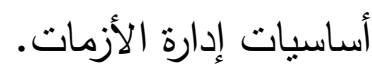

$$
\begin{aligned}
& \text { إدارة الأزمات وضغوط العمل. } \\
& \text { الأساليب الفعالة لإدارة الأزمات والكوارث. }
\end{aligned}
$$

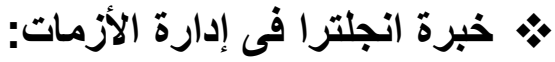

السلم التعليمي في إنجلترا :يتكون السلم التعليمي في إنجلترا من ثلاث مراحل هي : النئرة التعليم الإلزامسي في إنجلترا من سن خمس سنوات إلى سن ستة عشر عامـا ، وتقع مسئولية تتفيذ التعليم الإلزامي على الوالدين الذين تقع على عاتقهم مسئولية إلحاق أبنائهم بتعليم

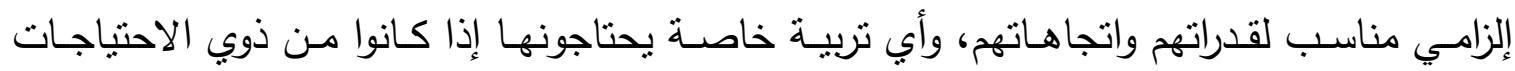

مرحلة ما قبل المدرسة : حيث تقوم بعض السلطات المحلية بتوفير هذا النوع من التعليم

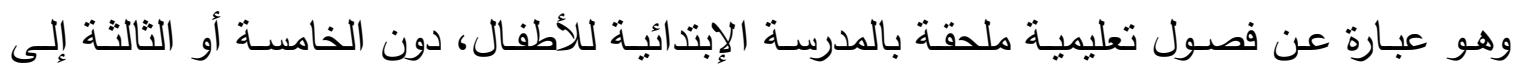

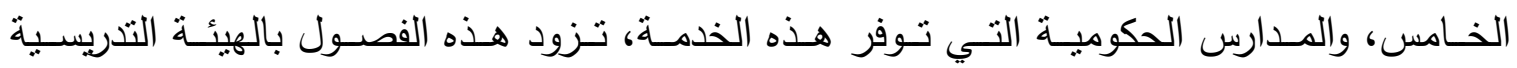

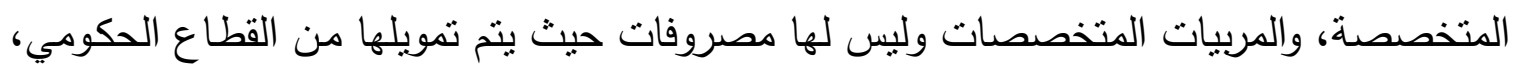
كما يتم توفير هذه الخدمة أيضاً من قبل مؤسسات المجتمع الخاصة(1).

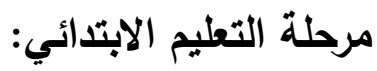

التعليم الابتدائي "هو تعليم نظـامي يتتاسب مـع متطلبات الطـلاب الذين لـم يصلوا لسن العانشرة وستة شهور ."وتتشمل مرحلة ما قبل المدرسة حيث تقدم بعض السلطات التعليمية المحلية تعليما لتلاميذ هذه المرحلة في صورة فصول تعليمية ملحقة بالمرحلة الابتدائية نستقبل أطفالا دون

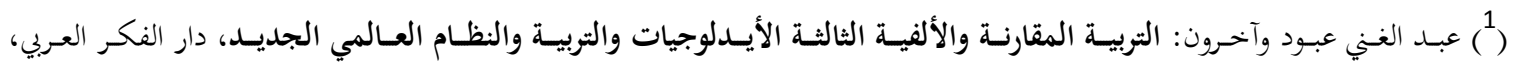

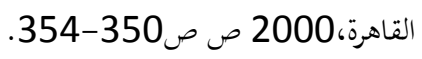


الجمعية المصرية للقر اعة و المعرفة عضو الجمعية الدولية للمعرفة المية

الخامسة كمرحلة تهيئة لهم ، قبل دخول المرحلة الابتدائية ولا تفرض مصروفات مدرسية للالتحاق

$$
\text { لأبناء المدارس الحكومية(1). }
$$

مرحلة المدرسـة الثانويـة : وتمتد من الحادية عشر إلى السادسة عشر، ويمكن للبعض الاستمرار

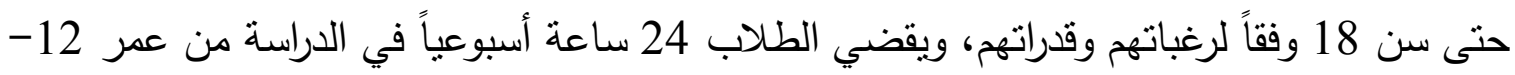
16 عاماً، وتبلغ كثافة الفصل 30 طالباً ويتم تقديم مناهج منوازنة للطلاب في جميع المراحل (2).

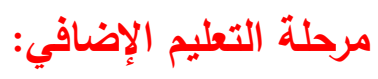

هو تعليم نظامي لكل الوقت ولبعض الوقت ملائم لمتطلبات الأفراد الذين تعدوا سن التعليم الإلزامي ويشمل التعليم المهني والاجتماعي والرياضي والتدريب ، ويعتبر قانون 1996 أن التعليم لهين

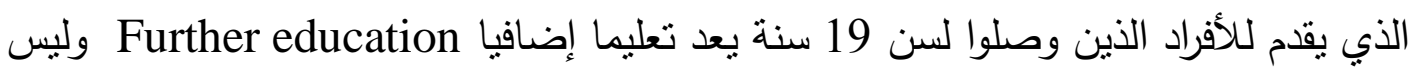
تعليما ثانويا (3)

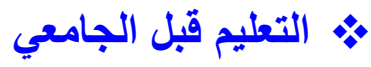

التعامل مع الأزمات في اتجلترا :

تتعامل المدارس في إنجلترا مع أزمة تعاطي المخدرات من خلال وضع نظام رقابي صارم

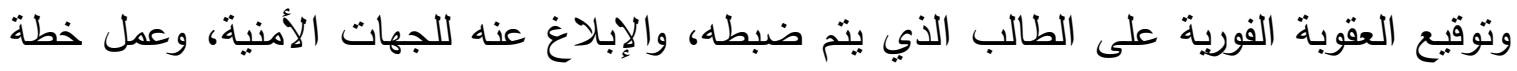

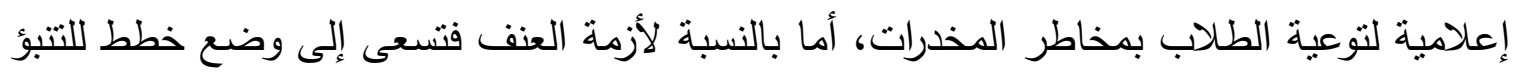
بالعنف والسلوكيات المرنبطة به، وتقعيل عملية التوجيه والإرشاد النفسي في المدارس، وتتكيل فريق للأمن المدرسي للتنخل عند الضرورة في حالات العنف والمشاغبة(4).

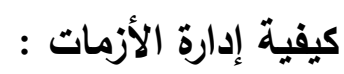
فريق إدارة الأزمات المدرسية في بريطانيا : وتنسى فريق إدارة الأزمات الددرسية في بريطانيا

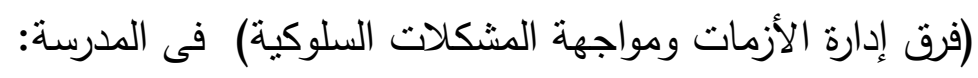

(1)عبد الغنى عبود و آخرون: التربيـة المقارنـة والألفيـة الثالثـة أيدلوجيا التربيـة والنظـام العالمي

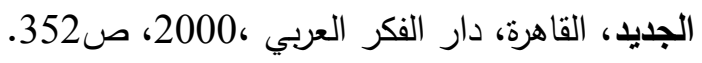

$\left(^{2}\right)$ Tina Isaacs : Profiles of Education Assessment System Worldwide Educational System in England, 2010, Op. Cit., P.316.

(3) Education System in England State and Private Sector :http:/// www.intense.co.uk/doc-pic/system/england.htm date 28/4/2012.

( $\left.{ }^{4}\right)$ Baginsky, W. : School Counseling in England, Wales, and Northern Irelands; A Review, NSPCC Information Briefing, January 
وتتكل هذه الفرق لمواجهة السلوكيات الغير المرغوب فيها من قبل طلاب التعليم الثانوي في بريطانيا، وتعمل هذه الفرق على الحفاظ على قواعد ومبادئ السلوك العامة، وعلى المدرسة بكل ما تحتويه من مبادئ وأثاث وأدوات وموارد مالية ومادية، وتتكون فرق مواجهة المشكلات السلوكية من

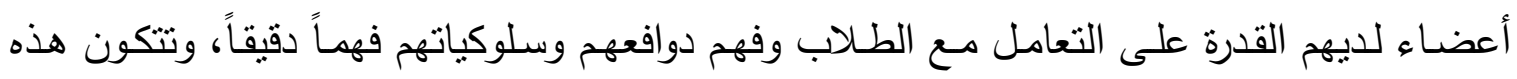

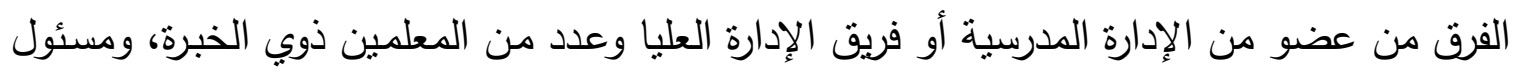

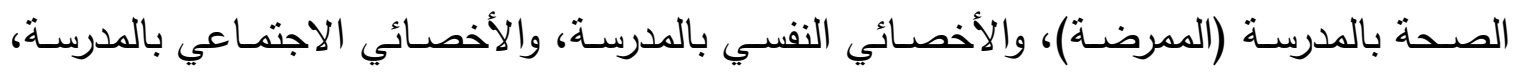

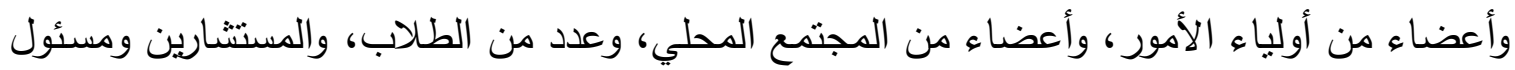

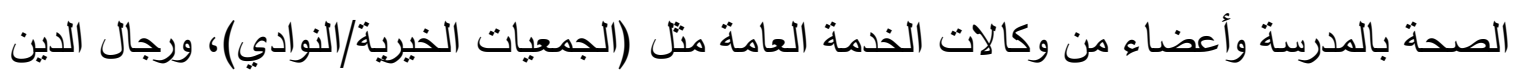

$$
\text { والمجتمع الطبي المحلي والآباء وقسم الثرطة. (1) }
$$

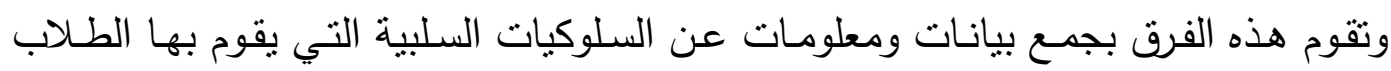
للتعرف على أسبابها وجذورها الحقيقية وذلك لوضع برامج عـاج مناسبة لها ويتم ذللك من خـال

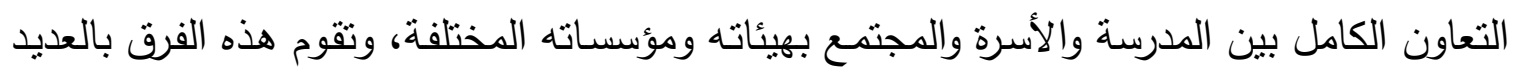

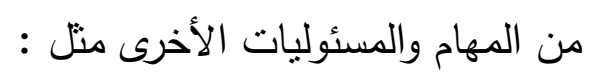

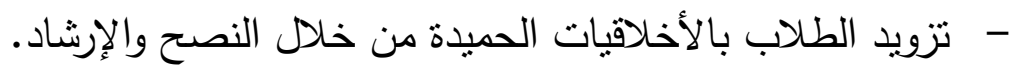

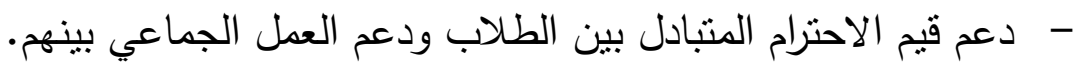
- الفهم والملاحظة العميقة والدقيقة لسلوكيات الطلاب. - - تحليل النماذج السلوكية السلبية تحليلاً دقيقاً. - تزويد المعلمين بالإستراتيجيات والأساليب الحديثة لإدارة الفصل. - - التعاون مع المنظمات المجتمعية منل مراكز الثباب (النوادي) ومنظمات الصحة. - - المساهمة في وضع السياسات المدرسية بخصوص سلوكيات الطلاب. - - إعداد وتصميم وتتفيذ برامج عملية للارتقاء بسلوكيات الطلاب.

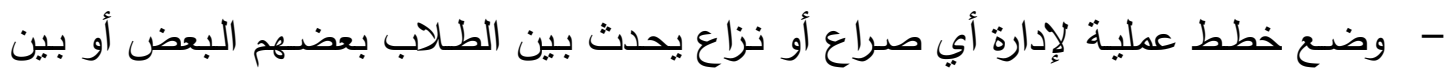
الطلاب والمعلمين أو بين الطلاب وإدارة المدرسة. أمـا عن فـرق إدارة الأزمـات فهي مسئولة عـن مواجهـة الأزمـات والحسالات الطارئـة التـي تتعرض لها المدارس بمراحل التعليم المختلفة في بريطانيا مثل حوادث العنف داخل المدارس وحوادث الاث

${ }^{(1)}$ Manchester Public School, Education Improvement Plan, PP.9-10 http;//eric. uoregon.edu/5-9-2014 


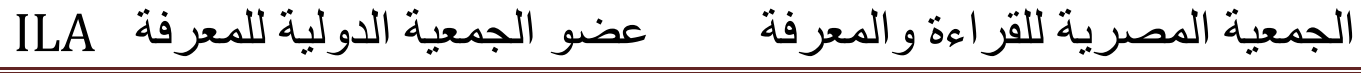

انتحـار الطـلاب والمـوت المفـاجئ لأحـد الطـلاب أو المعلمين أو الإدارة والمخدرات وتتاولها داخل المدارس والثجار بين الطلاب.

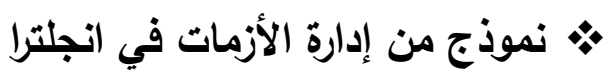

توجد العديد من السيناريوهات المستمرة التي تضعها المدارس والإدارات التعليمية المختلفة في حالة حدوث أزمات أو كوارث تعليمية أو من شأنها التأثير على العملية التعليمية منها ما يلى • معالجة أزمة الحرائق - - يتم أخذ الأدوات والمستلزمات الطبية الموجودة بحقيبة الحرائق بسرعة إلى المنطقة

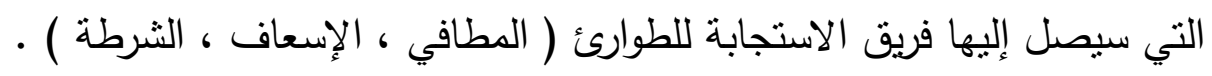

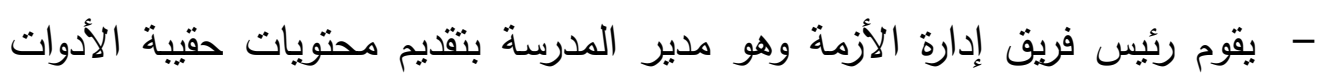

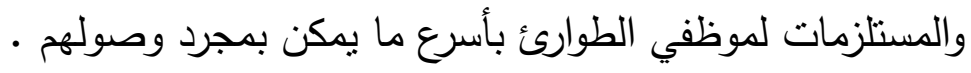
-

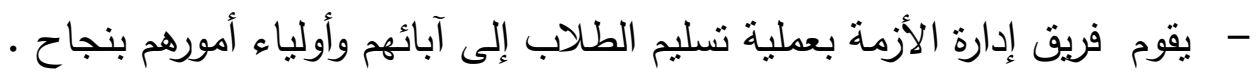

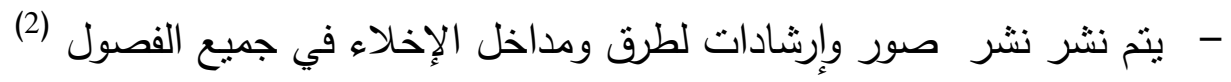

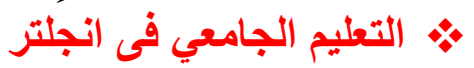

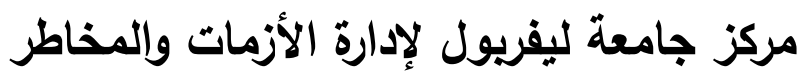

يعد المركز مؤسسة علمية بحثية في المقام الأول في إدارة الأزمات والمخاطر ، كما يعد من

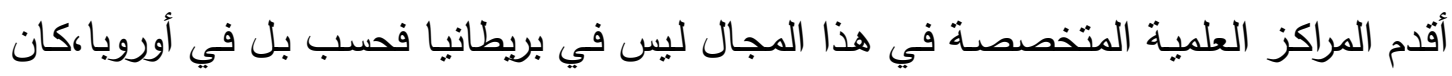

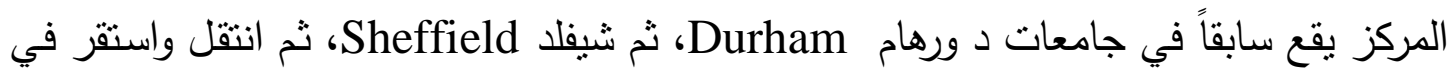

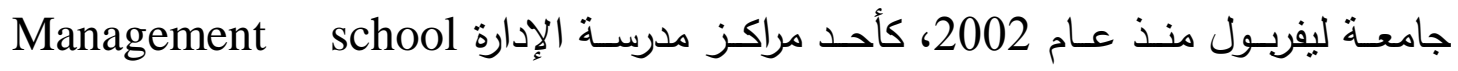
بالجامعة.يقدم المركز برامج تعليمية وبحثية متطورة، وتدور أنشطته حول خلق ونشر الئهر الخبرة

${ }^{(1)}$ Crisis Prevention and Response Is Your School Prepared? 2003, PP 12-13.. http;//eric.uoregon.edu/ issiies/safety/bulletiiiJitnil),4-7-2014 (2) see:

- The School Shooter: A Threat Assessment Perspective, Federal Bureau of Investigation, http://www.monash.edu.au/crisis.management.

- Warner, David and Palfryman, David: Managing crisis: managing universities and colleges, England, open university press, 2003.

- Laurent $f$. carrel "Epidemic in Switzerland Description of a strategic leadership exercise by The Swiss Government" Journal of contingencies \& crisis management, vol.13,No.4, December 2005, 166. 
المتخصصـة في مجـال الأزمـات والمخـاطر ، وتتــيع وتـدعيم الجهود في مواجهـة الأزمـات

والمخاطر •(1)

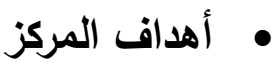

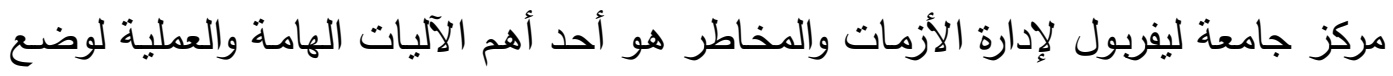

سياسة إدارة الأزمات موضع التتفيذ العملي، وذلك بتهيئة السبل إلى تعظيم استخدام أساليب البحث العلمي والتكنولوجي من خلال إرساء قواعد الممارسة الفعلية. وبناء على ذلك تتحدد أهداف المركز

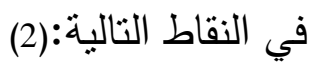

1- إدارة الأزمات والمخاطر المتعلقة بالجامعة ونشاطاتها.

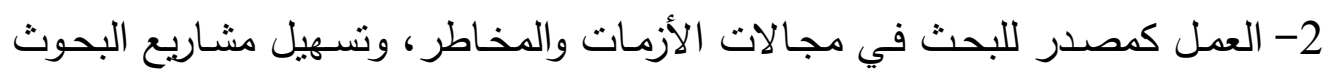

بين الأقسام في الجامعة وخارجها.

3- بحث وتعليم وإدارة الأزمات والمخاطر وإعداد الخطط لذامهاء للك.

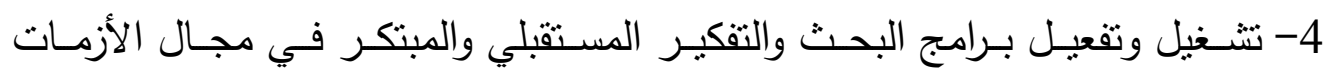

$$
\text { والمخاطر - }
$$

5- منتدى اتصـال بين الجامعـة والمؤسسـات والمنظمـات العالميـة في مجـال الأزمـات

والمخاطر وذلك بإجراء حلقات نقاشية، وورش عمل، وبرامج تدريب.

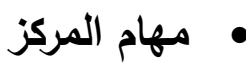

تتلخص المهام الرئيسية لمركز إدارة الأزمات والمخاطر فيما يلي:

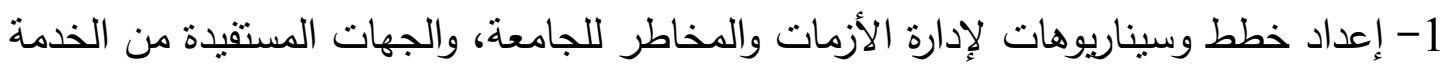

$$
\text { خارجها. (1) }
$$

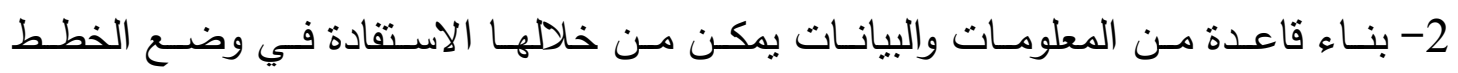

$$
\text { والسيناريوهات، والوقاية من وقوع الكثير من الأزمات والمخاطر . }
$$

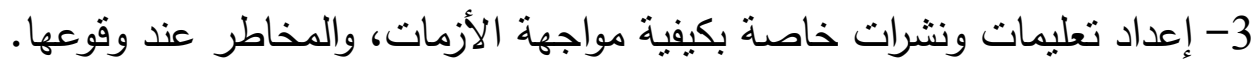

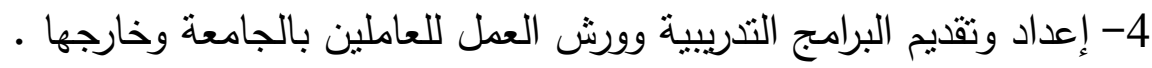

1- university of Liverpool: center for Risk and crisis management, UK, 2007, http://liv.ac.uk/ulsec/crisis.htm.p.1

2- ibid: p.2.

3 -Laurent f. carrel " Epidemic in Switzerland Description of a strategic leadership exercise by The Swiss Government" Journal of contingencies \& crisis management, vol.13,No.4, December 2005, p 170. 
الجمعية المصرية للقر اعة و المعرفة عضو الجمعية الدولية للمعرفة

5- تفعيل وتوطيد العلاقة مع مراكز إدارة الأزمات والمخاطر داخل الجامعات وخارجها.

6- الاشتراك في المؤتمرات والندوات وحلقات البحث الخاصة بورة بالأزمات والمخاطر .

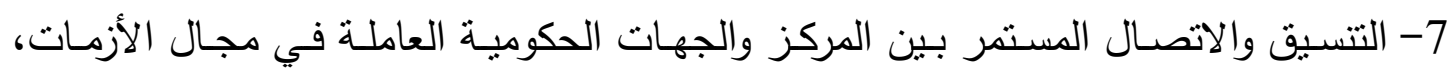

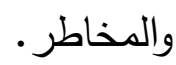

8- القيام بمشاريع بحثية داخل الجامعة وخارج الجامعة حول [أسباب الأزمات والمخاطر ، طرق

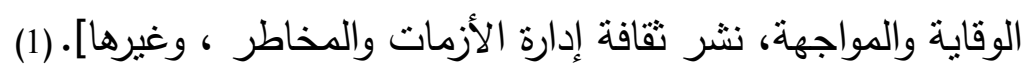

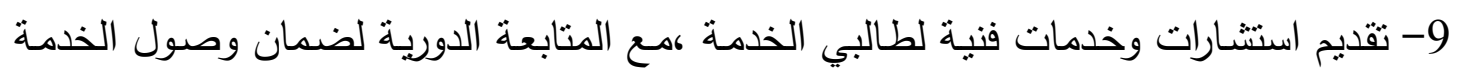

إلى المستقيد في الوقت المحدد ودون أي عقبات. (2)

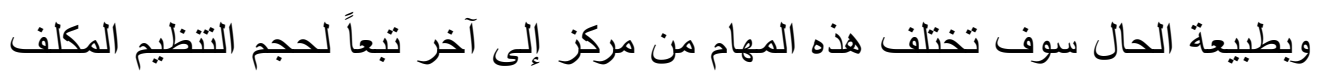

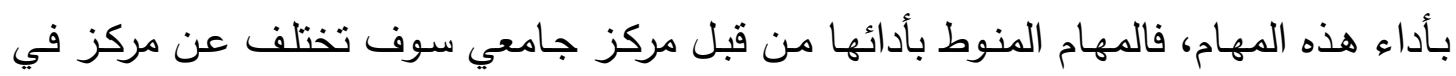

المستوى المحلي عنه على المستوى القومي.

•

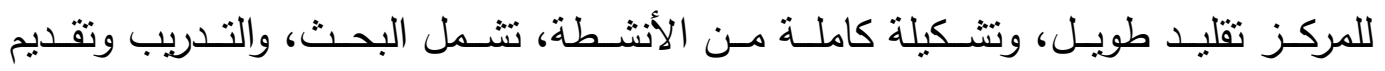

الاستشارات والنصائح لتطوير وتحسين إدارة الأزمات والمخاطر ، ومن ابرز هذه الأنشطة :

1 -1 نشاط البحوث

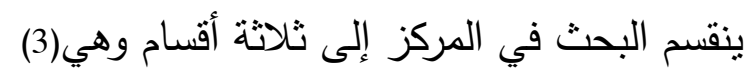

أ- بحث أساسي basic research وهو معني بالتطوير النظري لإدارة الأزمات والمخاطر . ب- بحث استراتيجي strategic research وهو مختص بتقييم المبادرات التي نساند إدارة

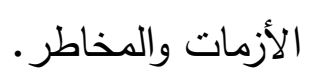

ت- بحث تطبيقي وهو يستهدف تدعيم تتفيذ إدارة الأزمة في المؤسسات المختلفة.

1 ـ جمال محمد صيام:" دور الوحدات فى تتمية البحث العلمي والدراسات البيئية دراسة حالية: مركز الدراسات

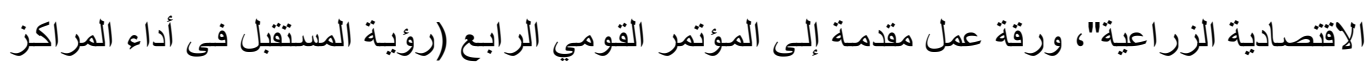

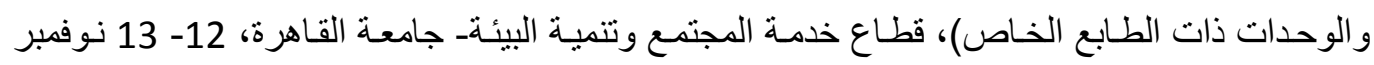
2005 ص ص 99- 101

2 - Millersville University: center for Disaster research \& Education, U.S.A, 2007 http://muwebmillersville.edu/ cdre/about.php.p.5

3- university of Liverpool: center for Risk and crisis management ,op. cit., p. 6. 
يقوم المركز بتقديم المشورة العلمية الفنية إلى المستقيدين عن طريق حلول علمية تطبيقية كاملة، يقوم بها فريق متميز من كبار المسنتارين والخبراء في المركز ، ويتميز هذا النشاط بالتالي:

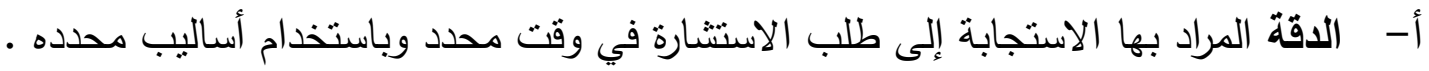
ب- السرعة والمراد بها سرعة الاستجابة لطلب المشورة بعد دراسة جوانب الأزمة ، وعدم تعطيل الرد عليها .

ت- - المنهجيـة والمراد بها استخدام الأسلوب العلمي في دراسـة الأزمـة أو طلب المشـورة حيث يعتمد المركز على تطبيق إجراءات علمية محددة .

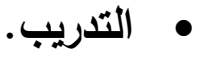

أ- يعد التدريب من أبرز الأنشطة التي تحظى باهتمام كبير من المركز ؛ وذلك تلبية لاحتباجات

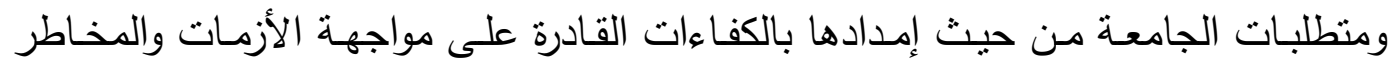
والوقاية منها، وكذللك احتياجات القطاعات الأخرى من المجتهع البريطاني،ويعطي المركز

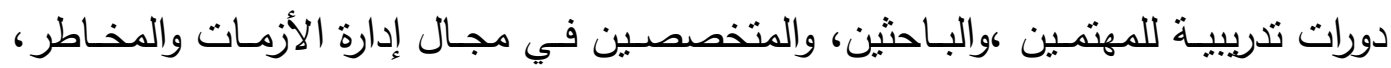
وتحدد هذه الدورات ويعلن عنها في المركز • (1)،

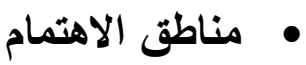
للمركز اهتمامات عدة تدور حول 1- إدارة الأزمات والمخاطر ، واستخدام وتقسير وتحليل البيانات والمعلومات عن الأزمات والمخاطر خاصة عند صنع القرار . 2- تقييم أداء فرق إدارة الأزمات والمخاطر تحت وطأة وظروف الأزمات والمخاطر . 3- التأثيرات الثقافية (تقافة المؤسسة) على مواجهة وإدارة الأزمة. 4- تفعيل وتحليل الاتصالات وقت الأزمات والمخاطر .

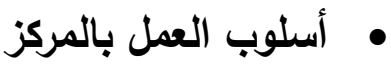
المركز وحدة بحثية في المقام الأول في مجال إدارة الأزمات والكوارث؛ لذا فإنها تعتمد على بلى شئين لنجاح هذه الإدارة وهما :

${ }^{1}$ - Bristol University: Crisis Management ,op. cit., p.6 
الجمعية المصرية للقر اءة و المعرفة عضو الجمعية الدولية للمعرفة المية

1- المعلومات والبيانات : حيث يسعى المركز إلى تكوين قاعدة معلومات كبيرة حول الأزمات

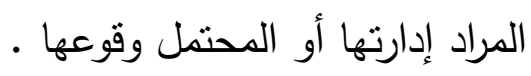

2- الخبراء والباحثون : وهم العنصر البشري المنوط به استخدام واستعمال هذه المعلومات

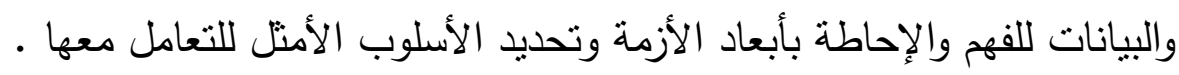

وتأسيسا على ما سبق يمكن تحديد معالم أسلوب العمل في المركز من خلال الخطوات

التالية :

الخطوة الأولى: تكوين قاعدة معلومات حول الأزمة المراد التعامل معها ـ

الخطوة الثانية: البدء بتحليل هذه المعلومات والبيانات .

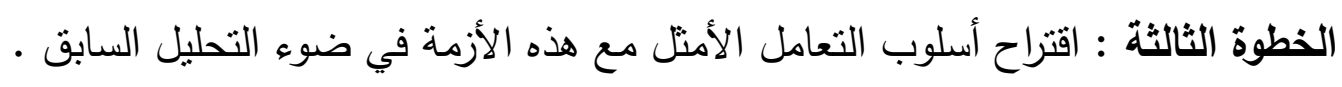

الخطوة الرابعة : متابعة تتفيذ الأسلوب المقترح •

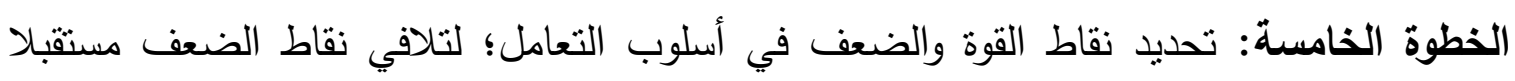
وتعظيم نقاط القوة.

• التصور المقترح لتطوير إدارة الأزمات التعليمية وصنع القرار بوزارة التعليم في ضوء خبرات بعض الدول.

فلسفة التصور المقترح :

يمكن تحديد مؤشرات وموجهات فلسفة إدارة الأزمات التعليمية وصنع القرار بالمملكة العربية

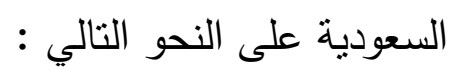

أ- إنها فلسفة تقوم على مبادئ الدين الإسلامي الموجه لحياة المجتمع في المملكة العربية السعودية والداعي إلى التطور والبحث والتتاور والاستفادة من خبرات الآخرين بما يخدم

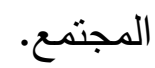

ب-إنها فلسفة تمنح النظام التعليمي الحرية بعيداً عن المركزية في تطوير التعليم في المملكة العربية السعودية بصفة عامة ووزارة التربية والتعليم بصفة خاصة ورسم الخطوط العريضة والأهداف لفئل العامة والخطط الإستراتيجية.

ج- إنها فلسفة تعتمد على تغيرات العصر الحالي والتطورات العلمية والتكنولوجيا وما بحيط بنا من ثورات معرفية وتتكل واقعاً جديداً يتحتم عليه الاهتمام بالأزمات التعليمية وبوحدة إدارة الأزمات لمواكبة ومسايرة ومواجهة هذه التحديات.

د- إنها فلسفة تؤمن بوضع الاستراتيجيات المطورة لمواجهة الأزمات بصفة عامة وماتهة والأزمات 
تطوير. إدارة الأزمات التعليمية وصنع القرار بوزارة التعليم بالمملكة العربية السعودية مرهون بقدرة

القيادات العليا على تبني ثقافة المواجهة ووضع استراتيجيات التعامل مع الأزمات التعليمية وتتمية القدرات المهنية بصورة تمكنهم من إدارة التغيير وإحداث التطوير وتحديد الأهداف وخطوات التنفيذ، التهات ويمكن تحديد أهداف التصور المقترح في النقاط التالية : وضع خطط وسيناريوهات لمواجهة الأزمات التعليمية. الاستفادة من الخبرات الدولية والاتجاهات الحديثة في مجال إدارة الأزمات التعليمية بما يتتاسب مع ظروف وثقافة المجتمع في المملكة العربية السعودية. توفير الإمكانات المادية والبشرية الكافية لفريق إدارة الأزمات التعليمية بوزارة التعليه.

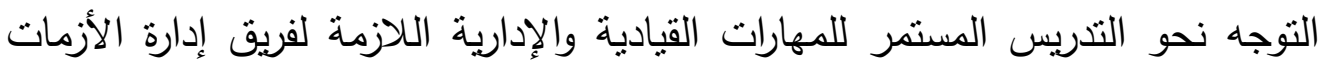

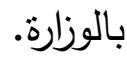

تقوية العمل بروح الفريق الواحد بريق إدارة الأزمات بالوزارة .

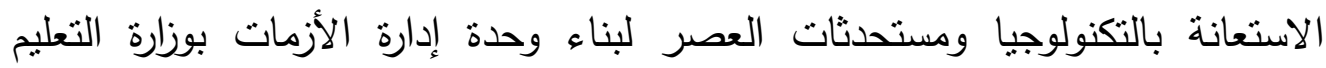
بالمملكة العربية السعودية. تشـيع صسور اتخـاذ القرارات بوزارة التعليم بالمملكة في ضـوء نظـام إدارة المعلومـات باستخدام الوسائل التكنولوجية الحديثة.

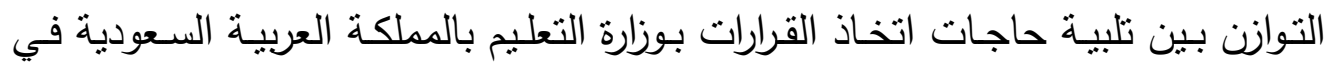
ضوء نظام إدارة الأزمات التعليمية المجتمع السعودي.

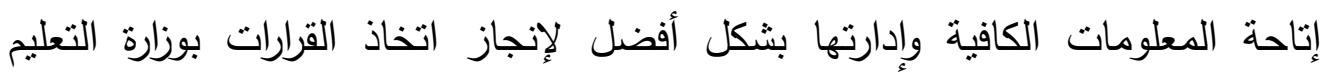
بالمملكة العربية السعودية في ضوء ادارة الازمات .

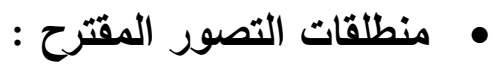

تستهدف الدراسة الحالية وضع تصور مقترح لتطوير إدارة الأزمات وصنع القرار بوزارة التعليم بالمملكة العربية السعودية بناءً على عدة منطلقات يمكن تصنيفها إلى منطلقات نظرية

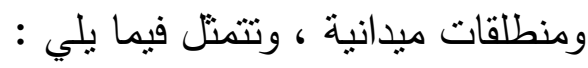
- إن تطوير إدارة الأزمات وصنع القرار بوزارة التعليم أصبح مطلبا أساسياً وحتمياً في ظل الظروف

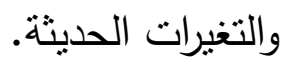




\section{الجمعية المصرية للقراءة والمعرفة عضو الجمعية الدولية للمعرفة}

- الافتقار إلى فلسفة واضحة لمواجهة إدارة الأزمات بصفة عامة ومواجهة الأزمات التعليمية بصفة

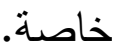

- افتقار المملكة العربية السعودية لاستراتيجيات المواجهة والتعامل مع الأزمات التعليمية. - يتعرض مجال التعليم للعديد من الأزمات في المجتمع السعودي ويتطلب ذلك صنع قرارات وحلولا لهن سريعة ومفيدة للتغلب عليها.

- وجود الدعم من جانب وزارة التعليم في المملكة يمكنها من مواكبة التقدم العلمي والتقني في مجال التعليم العام.

$$
\text { - }
$$

- وجود الدعم من جانب وزارة التعليم في المملكة يمكنها من مواجهة التقام العلمي والثقني في مجال

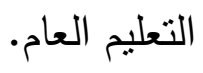

- افتقار مديري المدارس لمهارات إدارة الأزمات التعليمية بالمدارس بالمملكة العربية السعودية. - تقيد مديري المدارس بأنظمة ولوائح تعيق التصرف لديهم وقت الأزمة.

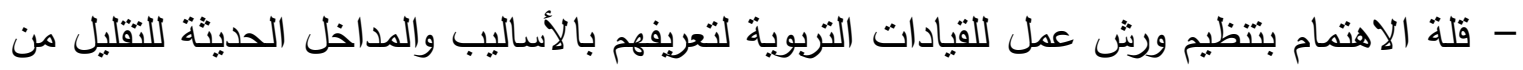
الأخطار المحتملة من الأزمات.

- أهمية تدريب وتتمية القيادات التربوية على فن التعامل مع الأزمات التعليمية.

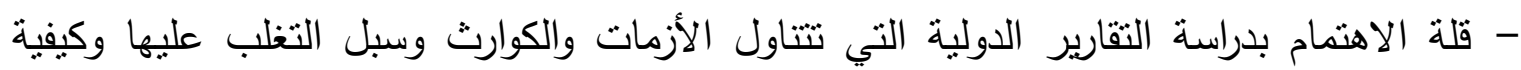
الاستفادة منها مستقبلاً.

- ضعف مشاركة الشركات والمؤسسات الأهلية في تمويل وحدة إدارة الأزمات التعليمية. - أهمية اتخاذ الإجراءات الوقائية لمنع حدوث الأزمة.

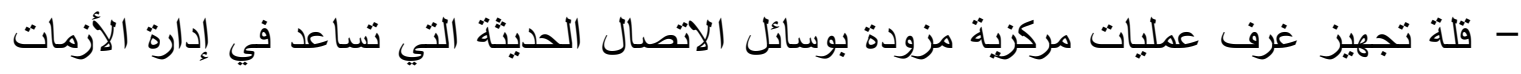
في الوزارة والإدارات التعليمية والمدارس. - ضعف الاهتمام بتتفيذ أحد السيناريوهات أو البدائل التي سبق إعدادها والتدريب عليها لمواجهة الأزمة.

- - مشاركة نماذج من كافة العاملين بوزارة التعليم بالمملكة العربية السعودية في صنع واتخاذ القرارات الخاصة بالعطلية التعليمية. 
الجمعية المصرية للقر اءة و المعرفة عضو الجمعية الدولية للمعرفة المية

- علاج المشكلات أو المعوقات التي تواجه صنع القرار التعليمي بوزارة التعليم بالمملكة العربية

السعودية.

عناصر التصور المقترح :

يقوم التصور المقترح على عدة محاور لإدارة الأزمات التعليمية وصنع القرار بوزارة التعليم

بالمملكة العربية السعودية يمكن إيضاحها على النحو التالي :

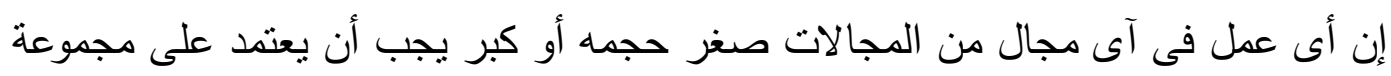

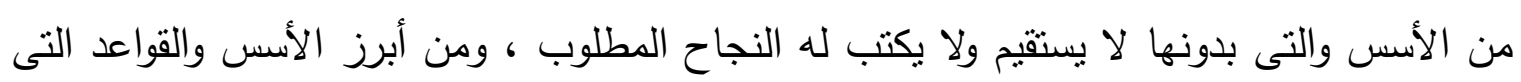

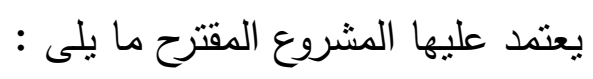

1- أن تطبيق إدارة الأزمات كأحد الاتجاهات الإدارية الحديثة فى إدارة التعليم أمر ضرورى

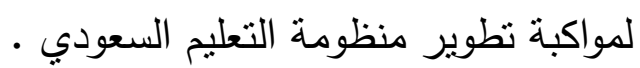

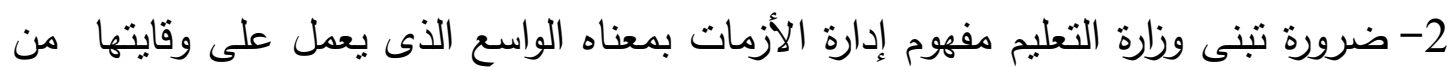

أخطار الأزمات ، ويضع فى اعتباره كل المؤثرات والمتغيرات التى تتفاعل الجامعة معها.

3- الاستفادة من تجارب بعض الدول المتقدة والتى نجحت فى تطبيق مدخل إدارة الأزمات

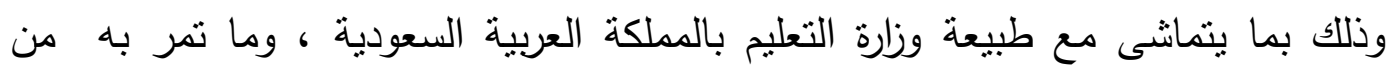

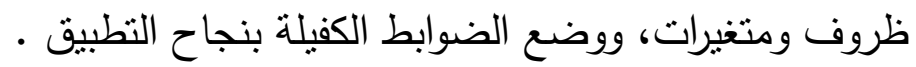

4- البعد عن الفردية فى العمل والاتجاه نحو الجماعية و التثاركية من خلال فرق إدارة

الأزمات (فهو مدخل يعتمد التعاون مصدراً لنجاحه ) .

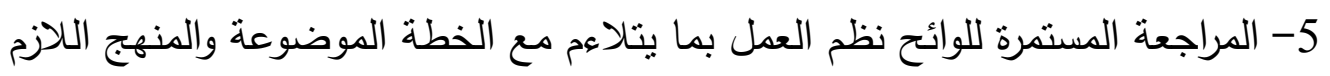

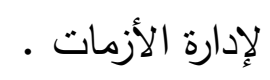

6- تحديد أدوار كل من الوزارة والمناطق التعليمية في المراحل المختلفة لاتخاذ القرار التعليمي

بوزارة التعليم بالمملكة العربية السعودية لمنع التداخل في الأدوار بينهما.

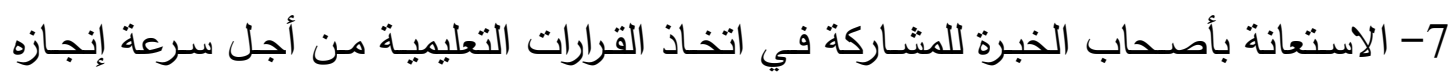

ووضعه في المكان المناسب.

8- محاولة القضاء على المركزية والاعتماد على جانب كبير من اللامركزية في اتخاذ القرار

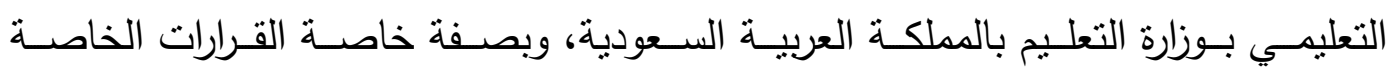

بالمديريات أو الإدارات التعليمية. 


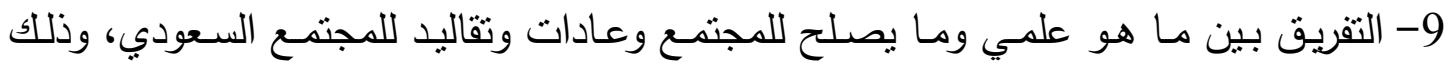
بمشاركة كافة أطياف المستويات الاجتماعية للمجتمع السعودي.

10- الاعتماد على أحدث نظم دعم القرار بواسطة شبكة المعلومات بين الوزارات المختلفة من أجل تحقيق الصالح العام للملكة العربية السعودية. 11- التتوع في مصـادر المعلومـات المستخدمة في اتخـاذ القرار التعليمي بالمملكة العربيـة

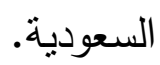

12- الاعتماد على إدارة المعلومات الإلكترونية في العصر الثبكي.

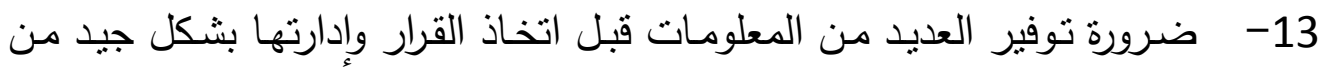
أجل اتخاذ القرار المناسب والفعال في المجالات التعليمية المختلفة. \$ إجراءات وآليات تنفيذ التصور المقترح :

توفير قاعدة بيانات ومعلومات دقيقة وكاملة يتم تحديثها باستمرار وفقاً لأهداف فريق إدارة الأزمات التعليمية بوزارة التعليم. الاستفادة من نتائج البحوث العلمية ومدى تطبيقها على أرض الواقع في مجال إدارة الأزمات بالتعليم في المملكة العربية السعودية. ضرورة أن يتم عمل التأهيل والتدريب الكافيين من الناحية البدنية والنفسية لمديري فرق إدارة الأزمات التعليمية بالوزارة لمواجهة الأعباء التي سوف تطرحها الأزمة بعد حدوثها.

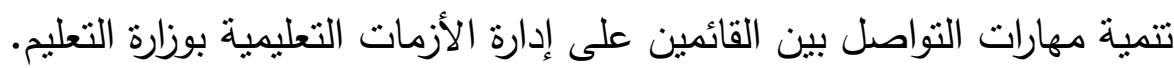
العمل على إتباع أحد الأساليب والطرق في مواجهة الأزمات. العمل على الاستفادة من الخبرات العالمية في إنشاء وحدة إدارة الأزمات التعليمية بوزارة التعليم بالمملكة. العمل بروح الفريق بين القائمين على إدارة الأزمات التعليمية بوزارة التعليم بالمملكة.

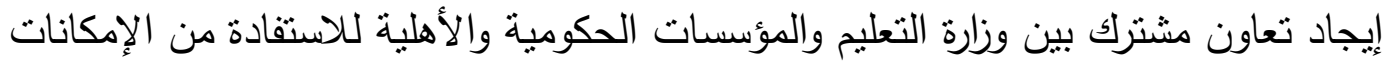
المادية والبشرية المتاحة لإنثاء وحدة إدارة الأزمات التعليمية بها.

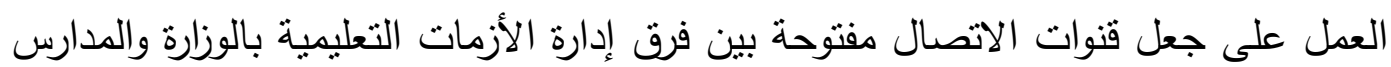
التابعة لها. العمل على توفير نظام جيد للاتصالات المتكاملة والسريعة عالية الكفاءة لتحقيق أكبر قدر من الربط بين المستويات المختلفة بوحدة إدارة الأزمات التعليمية بالوزارة. 


\section{الجمعية المصرية للقر اءة و المعرفة عضو الجمعية الدولية للمعرفة}

• التأكد من وجود خطط كافية لمواجهة الأزمات في المستقبل بوحدة إدارة الأزمات التعليمية

بالوزارة.

• العمل على توفير الموارد المالية بوحدة إدارة الأزمات بالوزارة للقيام بمهامها على أكمل وجه. المصادر والمراجع

\section{اولاً : المراجع العربية}

1. إبراهيم أنيس. المعجم الوسيط، مجمع اللغة العربية( القاهرة: دار المعارف، د.ت) . ل

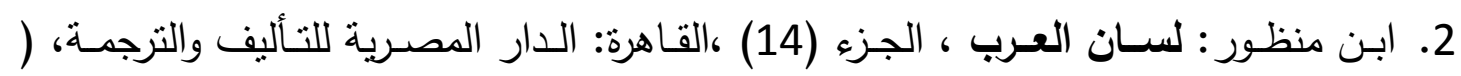

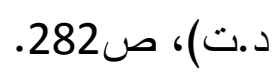

3. أحمد إبراهيم أحمد : إدارة الأزمات التعليمية في الددارس: الأسباب والعلاج، مرجع سابق،

$$
\text { ص ص 200-201- }
$$

4. أحمد إبراهيم أحدد: إدارة الأزمـات التعليميـة في المـارس الأسباب والعـلاج،القاهرة: دار

$$
\text { الفكر العربي، } 2002 .
$$

5. احمد حسين اللقانى، على أحمد الجمل: معجم المصطلحات التربوية المعرفة فى المناهج

$$
\text { وطرق التدريس ، القاهرة:عالم الكتب ، ط3 ، } 3 \text { ،2003. }
$$

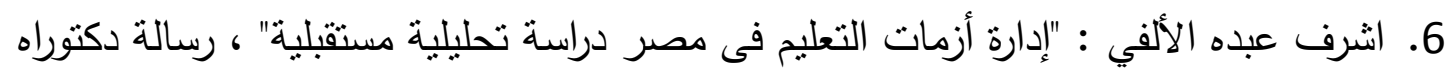

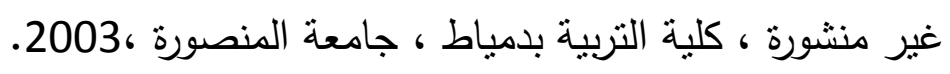

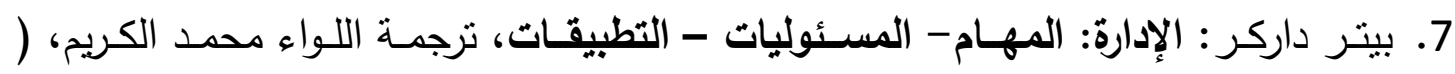

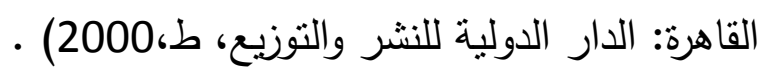

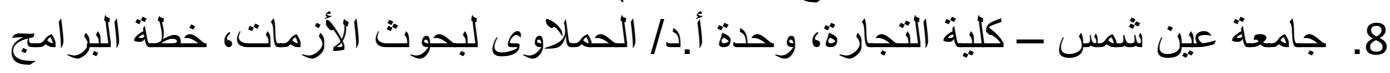

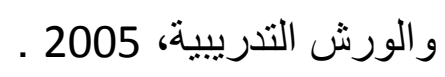

9. جامعة عين شمس، كلية التجارة، وحدة الأستاذ الدكتور / محمد رشاد الحملاوي لبحوث

$$
\text { الأزمات، كتيب الوحدة، } 2005 \text {. } 2004 \text {. }
$$

جمـال محمد صـيام:" دور الوحدات فـى تنميـة البحـث العلمي و الدراسـات البيئيـة

در اسـة حاليـة: مركز الدراسـات الاقتصـادية الزر اعيـة"، ورقـة عمل مقدمـة إلى المؤتمر

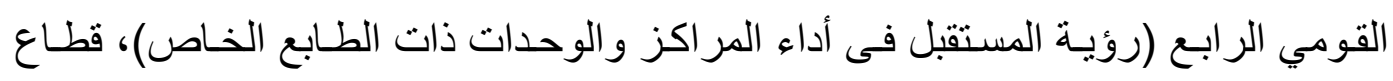
خدمة المجتمع وتنمية البيئة- جامعة القاهرة، 12- 13 نوفمبر 2005 ـ 2 
الجمعية المصرية للقر اءة و المعرفة عضو الجمعية الدولية للمعرفة المية

حافظ فرج أحمد ومحمد صبري حـافظ: إدارة المؤسسـات التتريويـة، القاهرة:عـالم

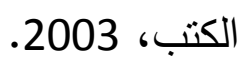

حسن محمد حسان ومحمد حسين العجمي: الإدارة التربويـة ،الأردن: عمـان، دار

المسيرة للنشر والتوزيع ، ط 2 ،2010.

حمدان أحمد الغامدي : نزر الدين عبد الجواد تطور نظام التطليم بالمملكة العربية

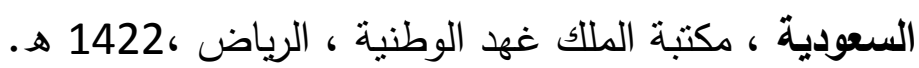

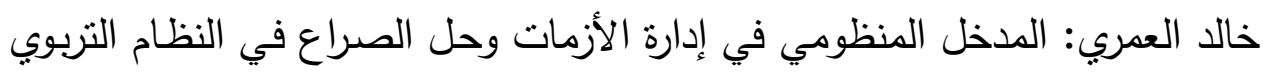

المؤتمر العبي الخامس حول "المدخل المنظومي في التريس والتعليم"، أبريل 2005 ـ

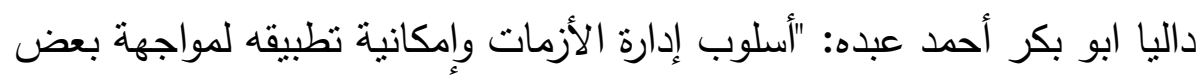

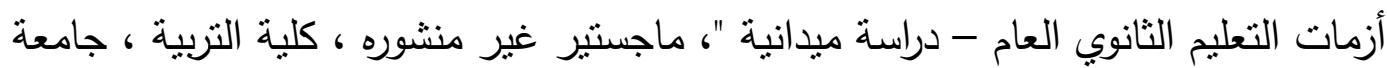

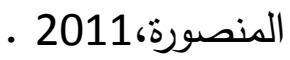

رجب عبدا لحميد : إسـتراتيجية التعامـل مسع الأزمسات وإلكوارث:دراسـة نظريـة تطبيقية،مصر :القاهرة،دار أبو المجد للطباعة والنشر ،2008 :

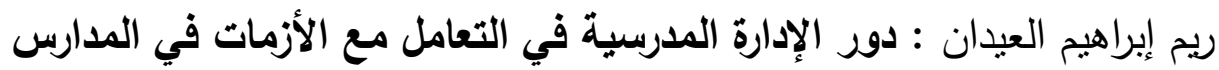

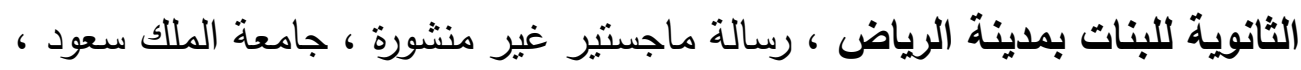

• 2009

ريم ثابـت القحطـاني : تصـور مقتـرح لــدور فـرق العــل للتعامـل مـع الازمــات

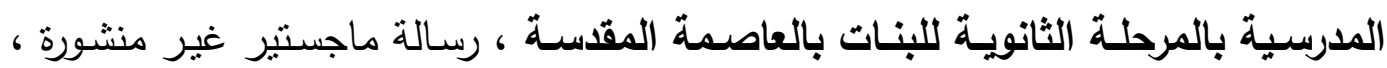

كلية التربية ، جامعة ام القرى ، 2006م .

زيد عصويد الدلمانى: "إدارة الأزمات المدرسية فى مدارس التعليم هليم العام بدولة وزارة

التعليم بالمملكة العربية السعودية"، رسالة ماجستير غير منشورة ،جامعة وزارة التعليم

بالمملكة العربية السعودية ، وزارة التعليم بالمملكة العربية السعودية ،2010 ـ

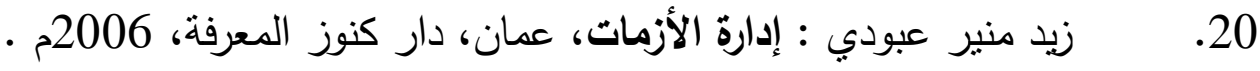

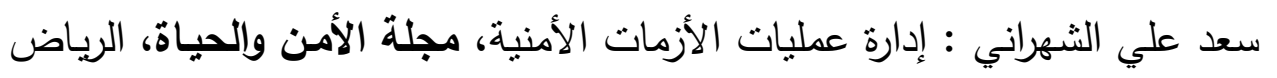

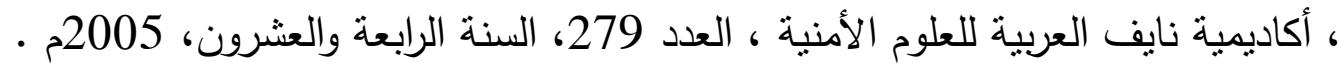

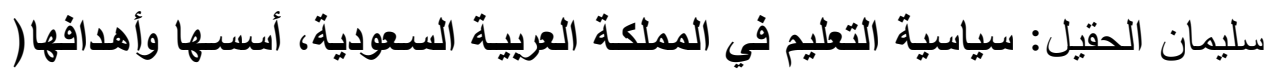


الجمعية المصرية للقر اعة و المعرفة عضو الجمعية الدولية للمعرفة المية

سليمان جبر : الجامعة وخلمة المجتمع ، دراسة لدور كلية التربية ، جامعة الملك

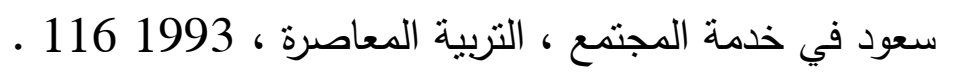

السيد عليوة: إدارة الأزمات والكوارث مخاطر العولمة والإرهاب الدولي، سلسلة دليل

صنع القرار (2). القاهرة: دار الأمين للنشر والتوزيع،2004 ـ

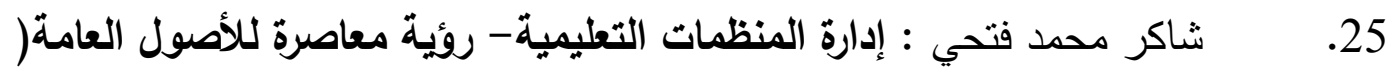

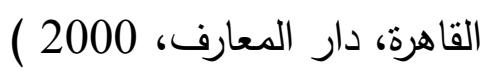

26. شـمس الدين عبد الله شـمس الدين : مدخل في نظريـة تحليل المشكلات واتخـاذ

القرارات الإدارية، مركز تطوير الإدارة والإنتاجية، (سوريا:دمشق،

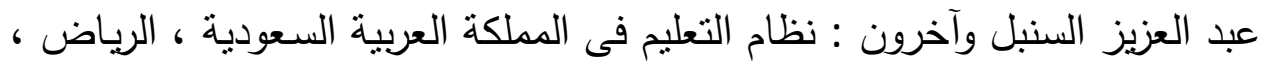

ط 6 ، دار الخريجى للطبع والتوزيع ،هـ 1417.

28. عبد الغنى عبود و آخرون: التربيـة المقارنـة والألفيـة الثالثـة أيـلولوجيا

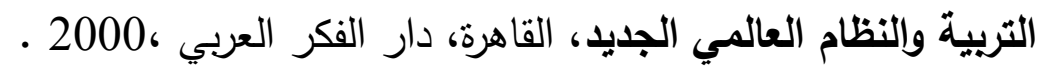

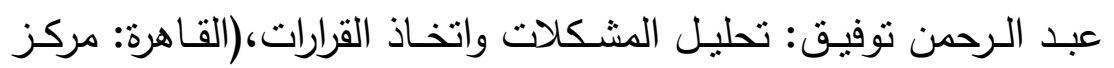

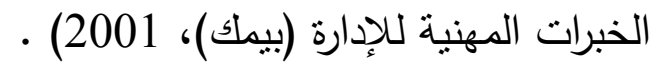

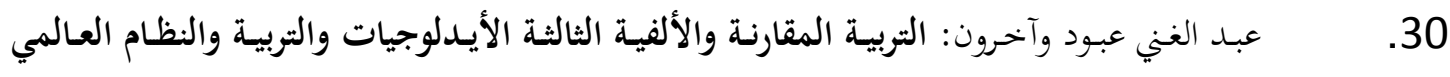

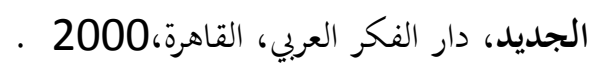

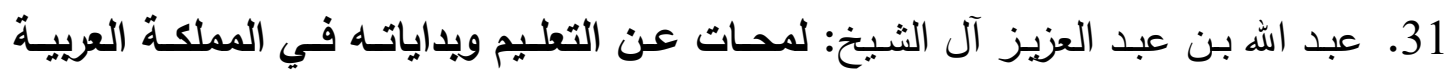

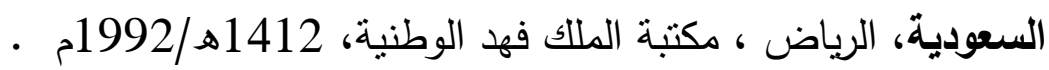

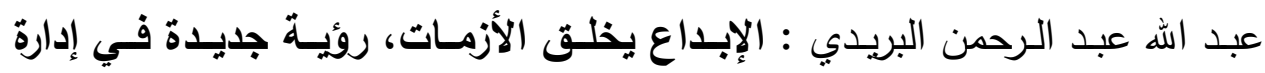

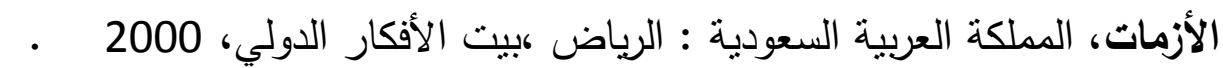

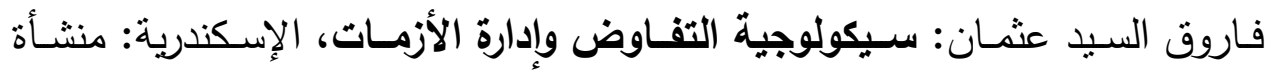

$$
\text { المعارف، 2000م. }
$$

34. فؤاد أبو حطب وآمال صلادق، مناهج البحث وطرق التحليل الإحصائي في العلوم

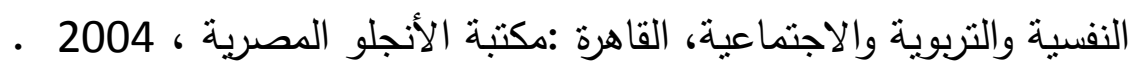

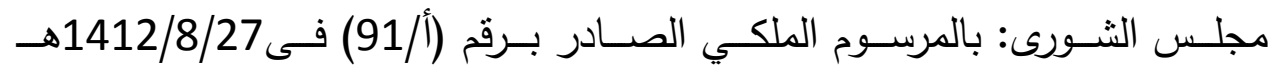

المادة(15).

مجمع اللغة العربية: المعجم الوجيز،(القاهرة : 1993: ) . 


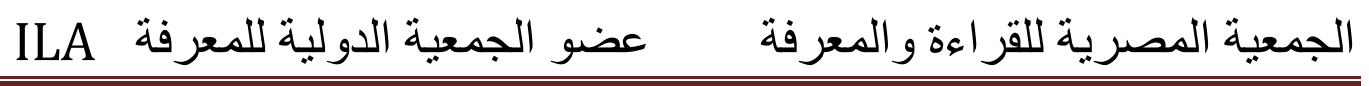

محسـن أحمــ الخضـيري: إدارة الأزمــات الإداريـة،القاهرة، شـركة الخبـرات الدوليـة

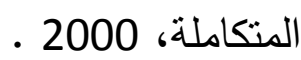

محمد إبراهيم أبو خليل"موقف مديري مدارس النعليم الأساسي من بعض الأزمات

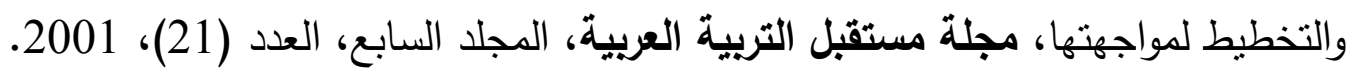

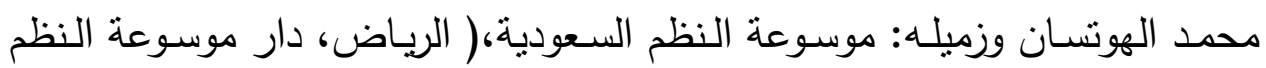

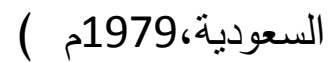

محمد بن عبد اله البرعى، محمد بن إبراهيم التو يجرى: الأسلوب القويم في صنع

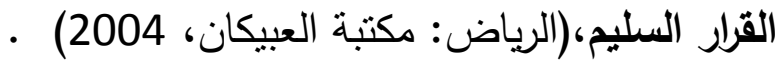

محمد عبدالغني حسن هلال : مهارات إدارة الأزمات التربوية : الأزمة الناتجة عن

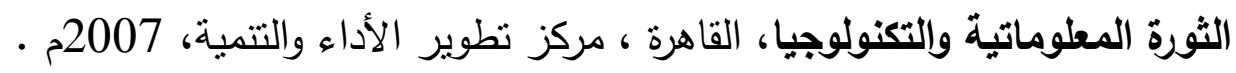

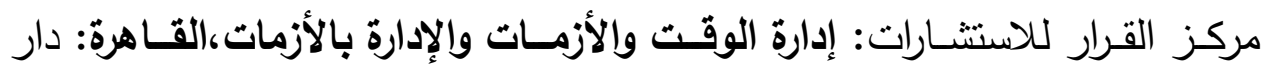

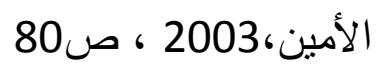

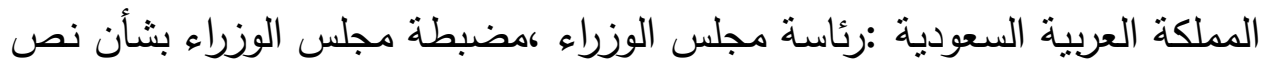

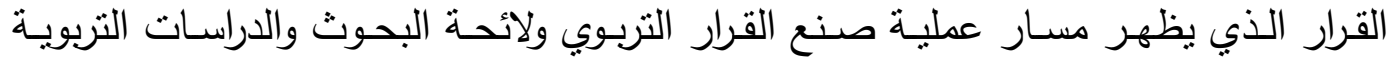

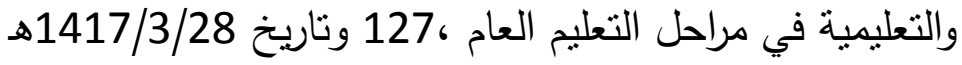

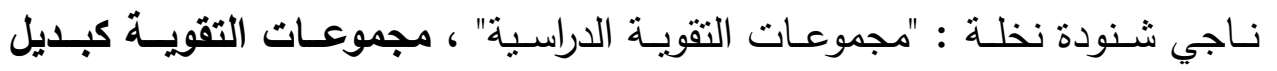

للاروس الخصوصية ، دراسة ميدانية ، المركز القومي للبحوث التربوية والتنمية ، القاهرة ،

. 1999

ناهد الموسى : إدارة الأزمات في مدارس التعليم العام بمدينة الرياض "تموذج

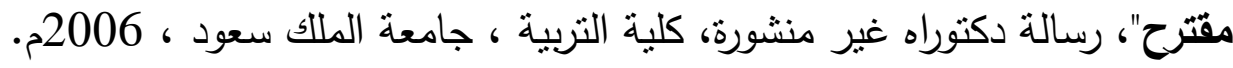

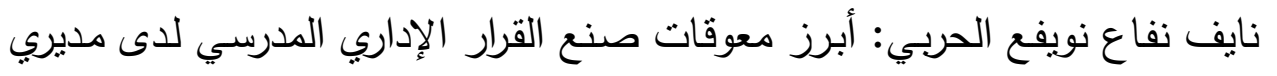

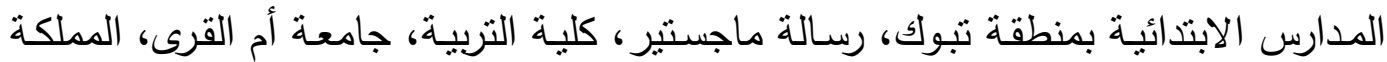

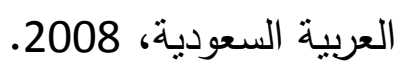

نبيل سعد خليل: "واقع عملية اتخـاذ القرارات التربوية على مستوى المدرسة:دراسة

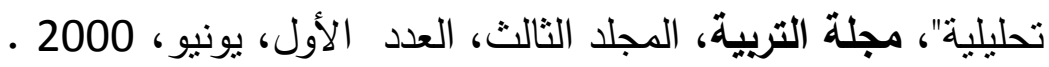

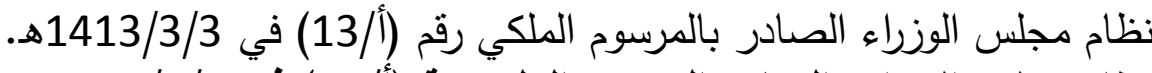

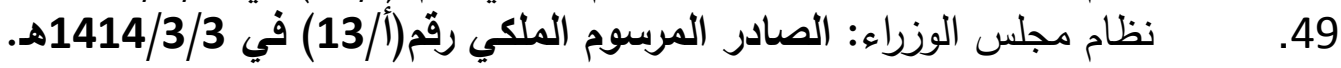

50. واستراليا " دراسة مقارنة"، رسالة ماجستير، كلية التربية، جامعة سوهاج، 2009. 
الجمعية المصرية للقر اءة و المعرفة عضو الجمعية الدولية للمعرفة المية

هليقـا دومنيـر ، اتخــاذ القـرارات الفعالــة، ترجمـة مصـطفى دراسـي،( القـاهرة:دار

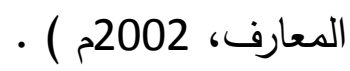

52. وزارة التربيـة التعليم : القـرار الـوزاري رقم (624) بتـاريخ 1998/12/10 بشـأن :

دروس التقوية التي تتظمها المراكز الخاصة.

وزارة التربيـة والتعليم : القرار الوزاري (205) بتاريخ 2001/9/23، بشأن: تشكيل

لجنة رئيسة لإدارة الأزمات والأحداث الطارئة (الوزارة / المديرية) ، (المادة الرابعة).

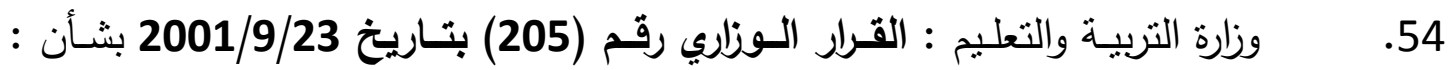

تشكيل اللجنة الرئيسة لإدارة الأزمات والأحداث الطارئة (الوزارة/المديرية).

55. وزارة التربية والتعليم : القرار الوزاري رقم (591) بتاريخ الإدئ 1998/11/17 بشأن:منع العنف في المدارس.

56. وزارة التربية والتعليم : القرار الـوزاري رقم (592) بتـاريخ 1998/11/17 بشـأن : حظر الدروس الخصوصية .

وزارة التربية والتعليم : مبارك والتعليم ، الششروع القومي لتطوير التعليم ، قطـاع الكتب ، 2002 - 20 - 20

58. وزارة التعليم العالي: التقرير الوطني الثامل عن التعليم العالي في المملكة العربية

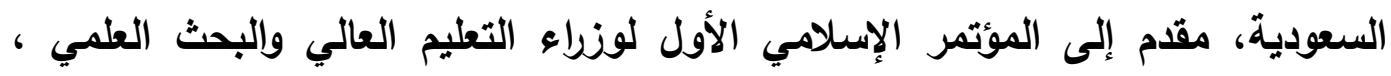

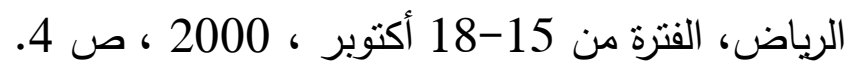
59. وزارة المعارف: سياسة التعليم في المملكة العربية السعودية،1390هـ ـ ـ

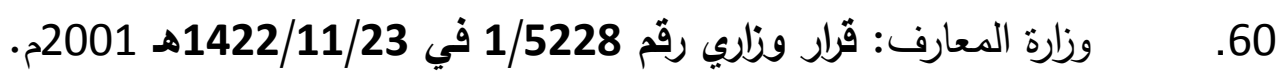

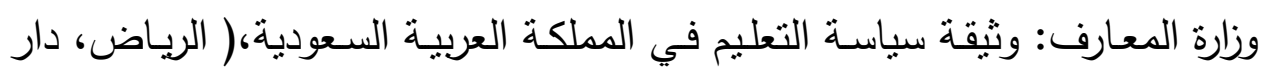
.61

\section{ثانياً:المراجع الأجنبية}

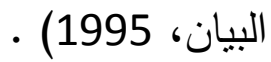

1. Abraham, Sagie. And Meni Koslowsky: Participation and Empowerment in Organizations'; Modeling Effectiveness and Applications, London: Sage Publication, Ins , 2004.

2. Baginsky, W. : School Counseling in England, Wales, and Northern Irelands; A Review, NSPCC Information Briefing, January

3. Bharat Sharma, Sylvain Boet, Dylan Bould, and others : Kirkpatrick evaluation of . 
4. Coleman, M.: A Study of Crisis response plans in suburban secondary Schools in New Jersey " .PH.D. , university of widener, U.S A, 2002.

5. Cooke Steve and Nigel Sleck: Making Management Decisions, New York: Prentic Hall, 2006.

6. Davis K: "Human Behavior at Work", Organizational Behavior, New York, McGraw- Hill, 2001.

7. Flowers N.: The Impact of Teaming: Five Research -Based Outcomes of Teaming, Middle School Journal, 2000, London, Vol.31, No.2.

8. Gainey, Barbara:Creating Crisis-ready school districts. P.H.D Undistributed,University of South Carolina, U S.A,2004.

9. Graveline, M: Teacher self - efficacy a managing of a school crisis ". Ph.D. dissertation, university Harford, London. 2003.

10.Hartley, R.and Almuhaidib S.M.Y.,"User Oriented Techniques to Support Interaction and Decision Making with Large Educational Databases", Computers and Education, V.48, N.2, feb2007.

11.interprofessional simulation-based education for preoperative crisis resource management, Journal of the American College of Surgeons, Vol. 213, Issue 3, Supplement, 2011.

12. Kenneth C. Laudon \& Jane P. Laudon. Management Information Systems. New Jersey: Prentice Hall International Inc, 2006

13.Kinaki A.\& Kreitner A: Organizational Behavior Key Concepts Skills Best Practices, McGraw Hill, New York, 2003.

14. Laurent $\mathrm{f}$. carrel "Epidemic in Switzerland Description of a strategic leadership exercise by The Swiss Government" Journal of contingencies \& crisis management, vol.13,No.4, December 2005.

15. Laurent $f$. carrel "Epidemic in Switzerland Description of a strategic leadership exercise by The Swiss Government" Journal of contingencies \& crisis management, vol.13,No.4, December 2005.

16.Mann L.: "Flinders Decision - Making Ouestionnaire I and II", Unpublished Ouestionnaires, School of Social Sciences, Flinders University of South Australia, 2008.

17. Mc Burney P.\& Parsons S.: Ensemble Theory Arguing Across and Within Scenarios, A paper Presented at the An Conference at the University of Strathclyde Graduate School of Business in Glasgow, Uk 


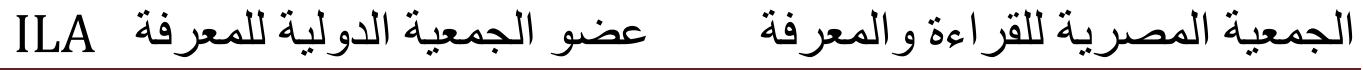

Probing the Future Developing Organizational Foresight in the Knowledge Economy, 2002.

18.Minton, C. : The Status of Crisis Preparation in Counselor Education: A National Study and Content Analysis. Journal Of Professional Counseling: Practice, Theory \& Research, 38(2), 2010.

19. Owens R.: Organizational Behavior, Adaptive Leadership and School Reform, 8th Ed, Prentice Hell, Boston, 2004.

20.Richard W. Sears, et al : Consultation Skills for Mental Health Professionals John Wiley \& Sons, INC, Canada, 2006, P.246.

21.Robert C. Appleby: Modern Business Administration, (Singapore: NP, 2000). PP.111

22.Robert C. Appleby: Modern Business Administration, Op. cit, PP.112

23.Schoemaker, A F.:The Relationship between Decision-Making Style and Negative Affect in College Students. Master of Science, Drexel University. 2010.

24.Schoemaker, A. F. :.The Relationship between Decision-Making Style and Negative Affect in College Students. Master of Science, Drexel University, 2010.

25.Soltanifar, M. : The Role of Educational Systems in International Crises: A Reappraisal of Middle East Countries. European Journal Of Social Science, 13(2), 2010, .

26.Steve, W. Williams, Making Better Business Decision ; Understanding and Improving Critical Thinking and Problem Solving Skills, NewDelhi: Sage Publications, Inc. , 2002 .

27.Twomey, P.: Analysis of crisis management planning in Illinois public schools. Ed.D. dissertation, Western Illinois University, United States, Illinois. Retrieved December 7, 2009.

28. Warner, David and Palfryman, David: Managing crisis: managing universities and colleges, England, open university press, 2003.

29.Webster New Twentieth Century: Dictionary of the English Language, new York, Collins world publishing .co inc . 
ILA الجمعية المصرية للقراءة والمعرفة عضو الجمعية الدولية للمعرفة

\section{ثُاثاً:المراجع الاككترونية}

1. Manchester Public School, Education Improvement Plan

$$
\text { http;//eric. uoregon.edu/ }
$$

2. Crisis Prevention and Response Is Your School Prepared? 2003,

3. http;//eric.uoregon.edu/ issiies/safety/bulletiiiJitnil),

4. Education System in England State and Private Sector :http:/// www.intense.co.uk/doc-pic/system/england.htm date 28/4/2012.

5. The School Shooter: A Threat Assessment Perspective, Federal Bureau of Investigation, http://www.monash.edu.au/crisis.management.

6. university of Liverpool: center for Risk and crisis management, UK, 2007, http://liv.ac.uk/ulsec/crisis.htm.p.1

7. Millersville University: center for Disaster research \& Education, U.S.A, 2007 http://muwebmillersville.edu/ cdre/about.php. 